\title{
High frequencies of HIV-1 recombination and the evolutionary potential of a hybrid retrovirus
}

Terence D. Rhodes

West Virginia University

Follow this and additional works at: https://researchrepository.wvu.edu/etd

\section{Recommended Citation}

Rhodes, Terence D., "High frequencies of HIV-1 recombination and the evolutionary potential of a hybrid retrovirus" (2006). Graduate Theses, Dissertations, and Problem Reports. 2402.

https://researchrepository.wvu.edu/etd/2402

This Dissertation is protected by copyright and/or related rights. It has been brought to you by the The Research Repository @ WVU with permission from the rights-holder(s). You are free to use this Dissertation in any way that is permitted by the copyright and related rights legislation that applies to your use. For other uses you must obtain permission from the rights-holder(s) directly, unless additional rights are indicated by a Creative Commons license in the record and/ or on the work itself. This Dissertation has been accepted for inclusion in WVU Graduate Theses, Dissertations, and Problem Reports collection by an authorized administrator of The Research Repository @ WVU.

For more information, please contact researchrepository@mail.wvu.edu. 


\title{
High Frequencies of HIV-1 Recombination and the Evolutionary Potential of a Hybrid Retrovirus
}

\author{
Terence D. Rhodes \\ Dissertation submitted to the \\ School of Medicine \\ at West Virginia University \\ in partial fulfillment of the requirements for the degree of \\ Doctor of Philosophy \\ in \\ Microbiology, Immunology, Cell Biology \\ Wei-Shau Hu, Ph.D., Chair \\ Nyles Charon, Ph.D. \\ Daniel C. Flynn, Ph.D. \\ Michael R. Miller, Ph.D. \\ Vinay K. Pathak, Ph.D. \\ Department of Microbiology, Immunology, Cell Biology \\ Morgantown, West Virginia \\ 2006
}

Keywords: HIV, Retrovirus, Recombination, Evolution 


\begin{abstract}
High Frequencies of HIV-1 Recombination and the Evolutionary Potential of a Hybrid Retrovirus
\end{abstract}

Terence D. Rhodes

Retroviruses have a great capacity to evolve in order to over come selection pressures in the environment. Such evolutional power comes from the high mutation rate and the high viral titers that can ensue during an infection. Mutation generates variation in the viral genome. In addition, previous reports found that retroviruses recombine at a relatively high rate. These sources of variation can then be exploited by the population to ensure the presence of advantageous mutations, which become amplified during virus propagation. Because the adaptability is based on the evolutionary potential of the virus, it is essential to study the mechanisms employed in this process. Recombination can accelerate the generation of multidrug-resistant HIV-1 and therefore presents challenges to effective antiviral therapy. We determined that HIV-1 recombination rates with markers 1.0, 1.3, and $1.9 \mathrm{~kb}$ apart were $42.4,50.4$, and $47.4 \%$ in one round of viral replication. Because the predicted recombination rate of two unlinked markers is $50 \%$, we conclude that markers $1 \mathrm{~kb}$ apart segregated in a manner similar to two unlinked markers in one round of retroviral replication. These recombination rates are exceedingly high even among retroviruses. To explore how efficiently HIV-1 can assort markers separated by short distances, we developed a flow-cytometry-based system to study recombination. Using this system, we determined that the recombination rates of markers separated by $588,300,288$, and 103 bp in one round of viral replication are 56, 38, 31, and $12 \%$, respectively, of the theoretical maximum measurable recombination rate. Statistical analyses revealed that at these intervals, recombination rates and marker distances have a near-linear relationship that is part of an overall quadratic fit. Additionally, we examined the effects of target cells and viral accessory proteins on recombination rate. The results indicated that infection of primary T-cells and the presence or absence of accessory proteins had no effect on recombination. These results illustrate the power of recombination in generating viral population variation and predict the rapid assortment of mutations in the HIV-1 genome in infected individuals. 


\section{Table of Contents}

Chapter 1 Introduction and Review of Literature............................

Overview of dissertation...................................... 10

Figure 1: Mature HIV-1 virion................................... 12

Figure 2: Genomic organization of HIV-1 provirus.................13

Figure 3: Replication cycle of a retrovirus........................14

Figure 4: Reverse transcription..............................15

Figure 5: Retroviral recombination models......................16

References.............................................. 17

Chapter 2 The evolutionary potential of a hybrid retrovirus......................23

Figures and Legends........................................ 33

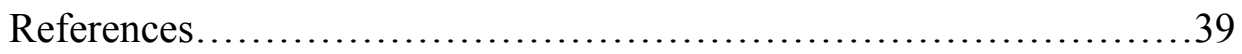

Chapter 3 High rates of human immunodeficiency virus type 1 recombination: near-random segregation of markers 1 kilobase apart in one round of viral replication ..........................................46

Tables.......................................................66

Figures and Figure legends.................................. 70

References................................................. 76

Chapter 4 Genetic recombination of human immodeficiency virus type I in one round of viral replication: the effects of genetic distances, target cells, accessory genes, and lack of interference................85

References...............................................107

Tables............................................................114

Figures and Figure legends..................................120

Chapter 5 Discussion................................................. 130

References................................................... 137

Curriculum Vitae.................................................... 141 


\section{List of Tables and Illustrations}

Chapter 1 Introduction and Review of Literature...............................

Figure 1. Mature HIV-1 virion................................ 12

Figure 2. Genomic organization of HIV-1 provirus..................13

Figure 3. Replication cycle of a retrovirus......................... 14

Figure 4. Reverse transcription................................ 15

Figure 5. Retroviral recombination models............................16

Chapter 2 The evolutionary potential of a hybrid retrovirus.........................23

Figure 1. Vector and experimental design...........................33

Figure 2. RT activity versus time................................ 34

Table 1. SNV and MLV production and infection into $293 \mathrm{~T}$ cells........35

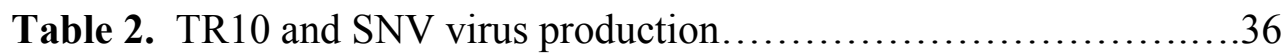

Table 3. TR10 viral propagation in $293 \mathrm{~T}$ cells............................

Figure 3. Viral propagation of three different viruses in D17/MS2

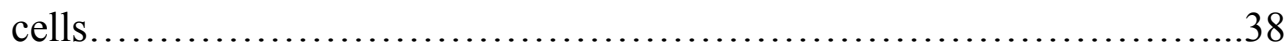

Chapter 3 High rates of human immunodeficiency virus type 1 recombination: near-random segregation of markers 1 kilobase apart in one round of viral replication

Table 1. Virus titers generated by cell clones containing

TR-HyINproviruses .66

Table 2. Virus titers generated by cell clones containing

TR-HyS2NIN and TR-HyINE2B proviruses.

Table 3. Virus titers generated by cell clones containing

TR-HyN2MIN and TR-HyINE2B proviruses.........................68

Table 4. Virus titers generated by cell clones containing

TR-HyN2NIN and TR-HyINN2N proviruses

Figure 1. Viral vectors and protocol used to measure

HIV-1 recombination rates with markers $1 \mathrm{~kb}$ apart.

Figure 2. Characterization of the proviral structures by

Southern analyses.

Figure 3. Southern analyses of the doubly resistant cell 
clones from the 1.3-kb marker distance study.

Figure 4. Southern analyses of the doubly resistant cell

clones from the 1.9-kb marker distance study. .75

Chapter 4 Genetic recombination of human immodeficiency virus type I in one round of viral replication: the effects of genetic distances, target cells, accessory genes, and lack of interference.

Table 1. Sequence comparison between wild-type and mutant

GFP.

Table 2. Recombination between two markers separated by

588 bp.

Table 3. Recombination between two markers separated by $300 \mathrm{bp}$.....

Table 4. Recombination between two markers separated by

$288 \mathrm{bp}$.

Table 5. Recombination between two markers separated by $103 \mathrm{bp}$.

Table 6. Recombination between three markers using ON-H06 and $\mathrm{ON}-\mathrm{T} 3$ viruses.

Figure 1. Viral vectors and protocol used to measure HIV-1

recombination rates.

Figure 2. Representative flow cytometry analyses of mockinfected cells, producer cells, and cells infected with control

plasmids.

Figure 3. Representative flow cytometry analyses of mockinfected and infected target cells.

Figure 4. Distribution of GFP genotypes and phenotypes in the progeny generated from double infected cells after one round of viral replication.

Figure 5. Effects of accessory proteins and target cells on HIV-1 recombination

Figure 6. Distribution of the $\mathrm{GFP}^{+}$phenotype in $\mathrm{HSA}^{+}$and 
Thy $-1^{+}$cells.....

Figure 7. Relationship between HIV-1 recombination rate

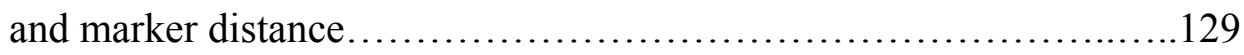




\section{CHAPTER 1}

INTRODUCTION AND REVIEW OF THE LITERATURE 
The number of articles dedicated to retrovirology has substantially increased with the discovery of human immunodeficiency virus type 1 (HIV-1), the major contributing virus to the AIDS epidemic. Because of the AIDS crisis, much effort has been placed on the study of retroviruses in order to better understand the mechanisms of replication and selective pressures these viruses encounter with the hopes that better therapy and an effective vaccine for this disease will be found. HIV-1 infection continues to be incredibly difficult to treat. The high mutation rate and the high viral loads that patients often carry contribute to the enormous genetic variation seen within patients and within the world population $(15,33,39-41)$. Because of this genetic variation, drug resistance and immune system evasion occurs quickly and complicates therapy (12). Another aspect is the ability for retroviruses to recombine $(29,48)$. Retroviral recombination provides the viral population with a mechanism to readily assort various mutations, which then can lead to the generation of variants that have increased fitness within the environment. For example, recombination can assort two different mutations from two different viruses and generate progeny carrying both of these mutations. Previous to the work presented in this thesis, it was established that HIV-1 can recombine, as shown in the literature that recombinant HIV-1 strains are often found in dually infected individuals $(6,19,32,34,51)$. In the laboratory, HIV-1 recombination has been observed to be frequent $(11,25,26,31,36,42,52)$. This apparent high rate of recombination necessitates a more extensive study into the mechanisms of HIV-1 recombination. Also, studying mechanisms of retroviral evolution would provide information to combat the difficult problem of rapid adaptation. These next few pages will outline in detail the 
HIV-1 lifecycle. In addition, current literature on retroviral recombination will be reviewed, followed by a brief description of the experiments proposed for the completion of this thesis.

Retroviruses have a unique step in their lifecycle; these viruses carry two copies of single-stranded full-length viral RNA in virions $(3,17)$. Upon infection of the host cell, viral RNA is reverse transcribed into double-stranded DNA, which then is integrated into the host genome (46). Genes, viral structure, encoded viral proteins, and major steps in viral replication are described below.

\section{Genes and structures of retroviruses}

Retroviruses can be divided into two major classes, simple and complex retroviruses. HIV-1 is classified as a complex retrovirus. This classification is based on the presence or absence of accessory proteins in addition to proteins commonly found in every type of retrovirus. First, gag encodes the structure proteins, which consist of matrix (MA), capsid (CA), and nucleocapsid (NC), These structure proteins are transcribed in cells as a polyprotein - Gag. Figure 1 is a schematic representation of a mature HIV-1 virion. MA provides structure support to the lipid membrane envelope, CA makes up the outer shell of the condensed core of the virion, and NC is associated with the genomic RNA. Second are the proteins that perform some of the essential enzymatic activities for replication. Pol polyprotein consists of two major components after protease cleavage in all retroviruses; reverse transcriptase (RT) transcribes singlestranded RNA into double-stranded DNA (47) and integrase (IN) allows the integration of double-stranded viral DNA into the host genome. Protease (PR) cleaves the polyproteins Pol and Gag into the individual components described above. PR is 
translated as part of Pol in HIV-1 but in some retroviruses it is translated as part of Gag or as a separate Gag-Pro reading frame. Envelope (Env) is a transmembrane protein embedded in the outer lipid envelope of the virion. It is responsible for the host range of the virus, and by interacting with the host cellular receptor, HIV-1 Env mediates virus entry via direct fusion with the membrane.

The genomic organization of the provirus, the integrated viral genome, of HIV-1 is illustrated in Figure 2. Each end of the proviral structure is composed of long terminal repeats (LTR). The LTRs can be further subdivided into U3, R, and U5. Immediately proximal to the LTRs are the primer binding site (PBS) at the 5' end and the polypurine tract (PPT) at the 3' end. These cis-acting elements (R, U5, PBS, and PPT) play crucial roles during reverse transcription, which is described in detail below. Downstream from the PBS are sequences important for RNA packaging, gag, pol, and env. In addition, the positions of HIV-1 accessory proteins, namely vif, vpr, vpu, tat, rev, and nef are indicated (35).

\section{Retrovirus replication cycle}

The replication cycle of a retrovirus (Fig. 3) is discussed in the following paragraphs from the contact of a virion to a target cell to the production and release of progeny virus. Since the understanding of reverse transcription is crucial for retroviral recombination described in this thesis, it will be discussed extensively.

Env interacts with the host cellular receptor, which induces a conformational change of both proteins that promotes fusion of the virus and cellular membrane. HIV-1 Env interacts with two host proteins for virus entry, namely CD4 and another co-receptor, most commonly CCR5 or CXCR4. Once fusion has occurred the core of the virion is 
released into the cytoplasm. For most of the retroviruses, reverse transcription starts after virus entry.

Reverse transcription is the process in which single-stranded RNA is copied into double-stranded DNA (47) (Fig 4). Reverse transcription start near the 5' end of viral RNA using a tRNA as a primer for DNA synthesis. This tRNA primer was packaged from the previous host into the virion $(22,45)$. RT then proceeds to transcribe DNA through the U5 and R region, which this segment of DNA is called minus-strand strong stop DNA. In addition to the DNA polymerase activity, RT has an RNase H domain that degrades RNA from a DNA/RNA hybrid. During synthesis, RNase H domain degrades RNA from the minus-strand strong stop DNA, which leaves the DNA free to anneal elsewhere. RT then makes the first of two obligatory jumps (or template switches) and jumps to the 3' end of the RNA strand; this jump is facilitated by the complimentary between the R region of the newly synthesized DNA and the 3' R of the viral RNA (10, 14, 16). Synthesis continues through U3, the protein encoding regions and PBS. RT makes a sequence specific cut at the PPT and the PPT is used as a primer for plus-strand DNA synthesis. Plus-strand DNA synthesis proceeds through the U3, R, U5, and the portion of the tRNA that is complimentary to the PBS; using this complimentarity RT again jumps (or switches templates) to the complimentary PBS region on the minusstrand DNA. DNA synthesis continues on both strands which yields a double stranded DNA product (21).

Once reverse transcription is complete, the double-stranded DNA along with IN enters the nucleus and integrates into the host genome. For some retroviruses, access to the host genome is thought to be passive and occurs during cell division. After the 
nuclear membrane disassociates the pre-integration complex comes in contact with the host genome. Other retroviruses have evolved sequences in proteins that bind to viral DNA to allow viral DNA to pass through the intact nuclear membrane into the nucleus; these proteins sequences are known as the nuclear localization signal (NLS). This NLS circumvents the need for cell division and these retroviruses, HIV-1 being among them, can infect non-dividing cells. IN recognizes specific sequences within twelve to fifteen nucleotides from either end of the viral DNA called attachment sites $(a t t)(5,37)$. These att sites, which sequences can vary greatly among retroviruses, are imperfect inverted repeats (37). The att sites are usually specific to the particular retroviral integrase. However, a CA dinucleotide is found common in all attachment sites. These nucleotides occupy position three and four proximal of the blunt end viral DNA. For most retroviruses, sequences closer to the ends of the molecule are assigned greater importance in efficient integration than others (50). IN must perform two reactions; first, it processes the 3' end of the viral DNA by clipping off two nucleotides, and second, IN catalyzes strand transfer with the cellular DNA to integrate the viral DNA into the host genome. It has been proposed that the 3 ' end processing reaction utilizes water as an intermediate and the resulting 3' hydroxyls are used for a nucleophilic attack on the host DNA in the strand transfer step (4). This attack cleaves the host DNA and allows the provirus to become integrated. Host enzymes repair gaps in the DNA sequence.

Host cellular machinery drives the transcription of viral mRNA and the expression of proteins. In the host nucleus, viral mRNA can either remain full length or become spliced. Env and other accessory proteins are expressed from spliced message. The full length viral mRNA can be packaged by viral proteins to serve as the genetic 
material for progeny virus, or the mRNA can be translated for production of Gag and Gag-Pol polyproteins.

After the syntesis of viral RNA and proteins, viral assembly and packaging of full length viral mRNA occurs. Gag specifically recognizes and encapsidates the packaging signal located on the full length viral RNA. The assembled viral proteins and RNA eventually bud from the cell membrane and are released. After release, the virion undergoes a maturation step where PR cleaves the polyproteins and forms the mature condensed core. Infection of another host completes the life cycle.

\section{Retroviral Recombination}

Retroviral recombination is the process in which sequences from two different RNA transcripts are incorporated into the reverse transcribed DNA molecule $(29,48)$. Retroviral recombination is facilitated by the packaging of two copies of its viral genome into virions. If the two co-packaged RNA were different and if RT, during reverse transription, switches from one co-packaged RNAs to the other, a recombinant DNA molecule is formed.

Two models have been proposed to explain retroviral recombination, namely the copy-choice (13) and strand displacement-assimilation models (27) (Fig. 5). The copychoice model is sometimes referred to as minus-strand recombination because it proposes that the template-switching event takes place during minus-strand DNA synthesis. As RT proceeds to transcribe along the viral RNA transcript, it is possible that RT can switch to use the other co-packaged viral RNA transcript as a template and proceed with reverse transcription. It has been proposed that homology and the dynamic processes of polymerization and degradation of RNA from the DNA/RNA hybrid play very important 
roles in copy-choice recombination. Experiments examining the required template switch of strong-stop minus-stand DNA to the 3' end of the RNA transcript showed that homology alone was sufficient to facilitate this process $(10,16)$. In addition, the examination of a phenomenon called direct-repeat deletion, where an intramolecular template switch between two similar sequences located on the RNA transcript occurs, resulting in a deletion of sequences between these two similar repeats, revealed that lack of homology between the two direct repeats drastically reduced the rate of direct-repeat deletion (1). Also, mutations of the polymerization domain and RNase H domain of RT showed that a dynamic relationship exists between the rate of polymerization and the rate of degradation which effects the rate of template switching $(24,44)$. The slower the degradation and/or the faster the polymerization result in a slower rate of template switching. The opposite is also true; higher rates of direct-repeat deletion were observed if polymerization slowed down and/or degradation was increased. It is thought that a situation fostering greater base pairing between the newly transcribed minus-strand DNA and the homologous region located on the same RNA or co-packaged RNA promotes template switching $(24,44)$.

Evidence for the strand displacement-assimilation model was first found by EM studies (27). In this model, it is assumed that each RNA transcript undergo minus-strand synthesis and both initiates plus-strand DNA synthesis. Plus-strand synthesis can occur in a discontinuous and disjointed manner with multiple initiations along the minus-strand DNA. If one strand were displaced by a leading strand directly upstream from its position, then it would be free to anneal to a portion of the other minus-strand DNA. This strand would then become incorporated into the double-stranded DNA product and 
integrated into the host genome. Because this event results in mismatched base pair or base pairs, the host enzymes must repair the mismatch. If the host enzymes repair the minus-strand, then a recombinant was generated. There is significance evidence showing that the copy-choice model is the major contributor in recombination among some simple retroviruses (2).

Another aspect of the retroviral lifecycle that effects recombination is the rate at which heterozygotic virions are formed. It has been shown that virus populations that have the ability to recombine only arise from cells that are infected with more than one virus (23). A cell containing two proviruses can produce three different types of virus, namely two different homozygotic virions and one type of heterozygotic virion. If retroviral proteins package RNA transcripts from the other provirus as efficiently as its own, than the packaging is random. Random packaging assures that the ratio of total homozygotic virions to total heterozygotic virions is $1: 1(\mathrm{AA}+2 \mathrm{AB}+\mathrm{BB})$. If the packaging of transcripts from the other provirus is not as efficient, than the formation of heterozygotic virions occurs at a decreased rate. Since recombination can only be observed from infection by heterozygotic virions, the lower the frequency of heterozygote formation, the lower the amount of recombinants will be observed.

\section{Implications of HIV-1 recombination}

There has been much learned by studying different aspects of recombination in simple retroviruses. Many of these findings have already been discussed above, but it is not known how well these observations correlate with recombination in HIV-1. Evidence of recombination that has repeatedly been found in infected individuals suggests that HIV-1 recombination is not a rare event and contributes greatly to variation in te viral 
population. The acquisition of multi-drug resistant HIV-1 mutants has been attributed to recombination. A greater understanding of this phenomenon must be explored in order to develop appropriate therapy and vaccine development.

\section{Introduction to Chapter 2, 3, and 4}

The end result of the great evolutionary potential of HIV-1 is therapy failure and immune system evasion. Evolution occurs in response to selective pressures placed on the viral population. Although both advantageous and deleterious mutants arise during the generation of viral variation, the advantageous mutants become more fit for the current environment. In chapter 2, a simple retroviral system that consisted of propagating a replication-competent chimeric virus was tested to observe evolutional changes in the viral population. This chimeric virus replicated one hundred fold less than wild type virus. Examining the changes in the viral population as the defective viral population evolves into a wild type-like population should show illustrate important aspects of this process.

Previous experiments in various laboratories have observed HIV-1 appears to have a high rate of recombination and that there were multiple crossover events occurring along the genome for those viruses that underwent recombination. However, it has been difficult from these experiments to determine a recombination rate. A recombination rate is a measure of the assortment of genetic markers at a certain distance apart in one round of replication. In chapter 3, experiments determined the recombination rate in HIV-1 at marker distances of $1.0 \mathrm{~kb}, 1.3 \mathrm{~kb}$, and $1.9 \mathrm{~kb}$. By using these distances and the same type of vectors used in the murine leukemia and spleen necrosis viral recombination 
studies, it was possible to not only determine a recombination rate of HIV-1, but also directly compare that rate to MLV and SNV.

Because HIV-1 has a high rate of recombination, Aim III experiments were designed to measure the recombination rate at distance less than $1.0 \mathrm{~kb}$. This required the development of a different system than the one that was utilized in Aim II. The Aim II system was based on drug resistance markers, where the Aim III system utilized markers that could be visualized by flow cytometry. Distances of approximately $0.6 \mathrm{~kb}, 0.3 \mathrm{~kb}$, and $0.1 \mathrm{~kb}$ were measured. Development of the flow cytometry based system also will allow future recombination experiments to be performed quickly and effectively. 


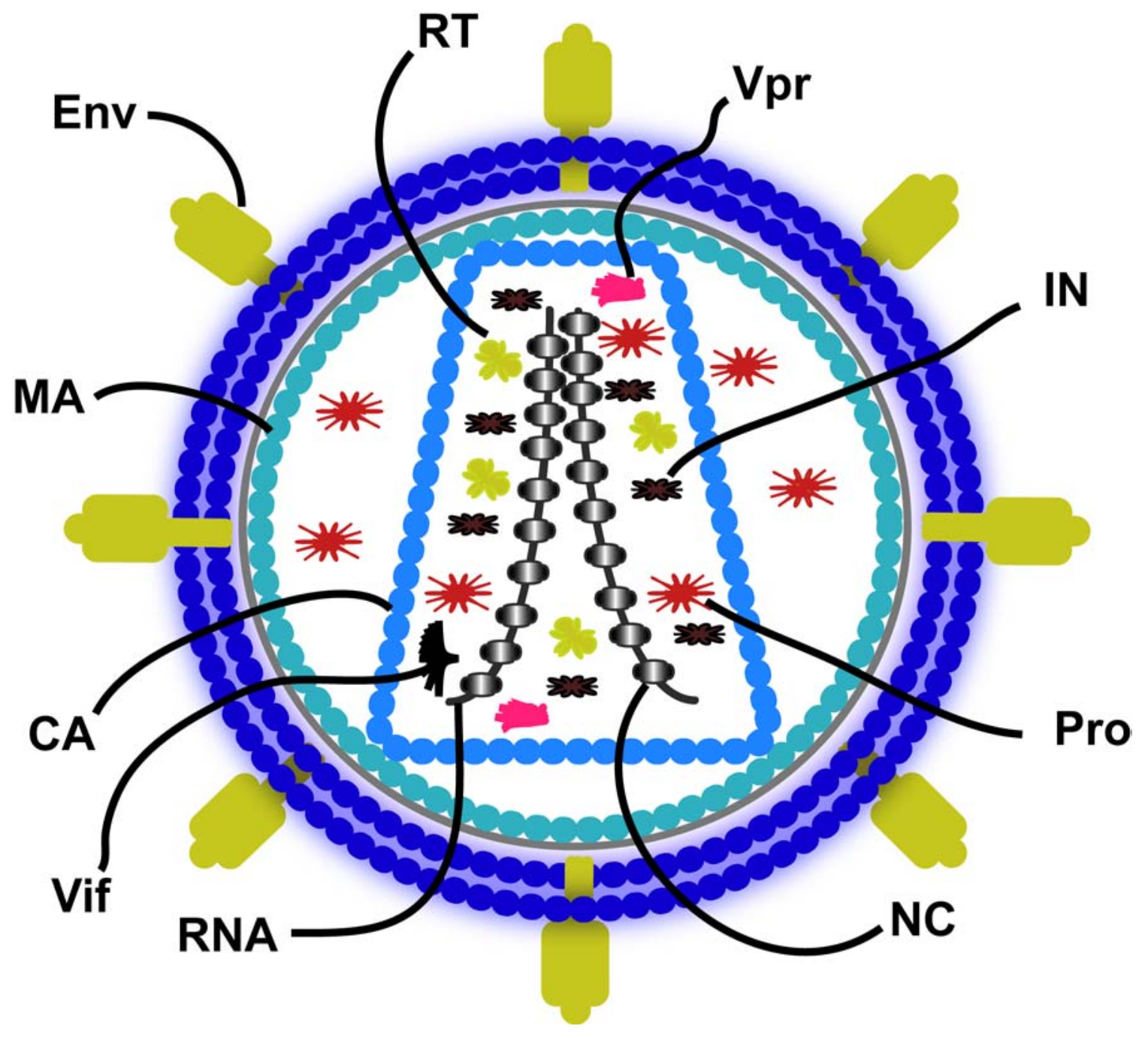

Figure 1. Mature HIV-1 virion 


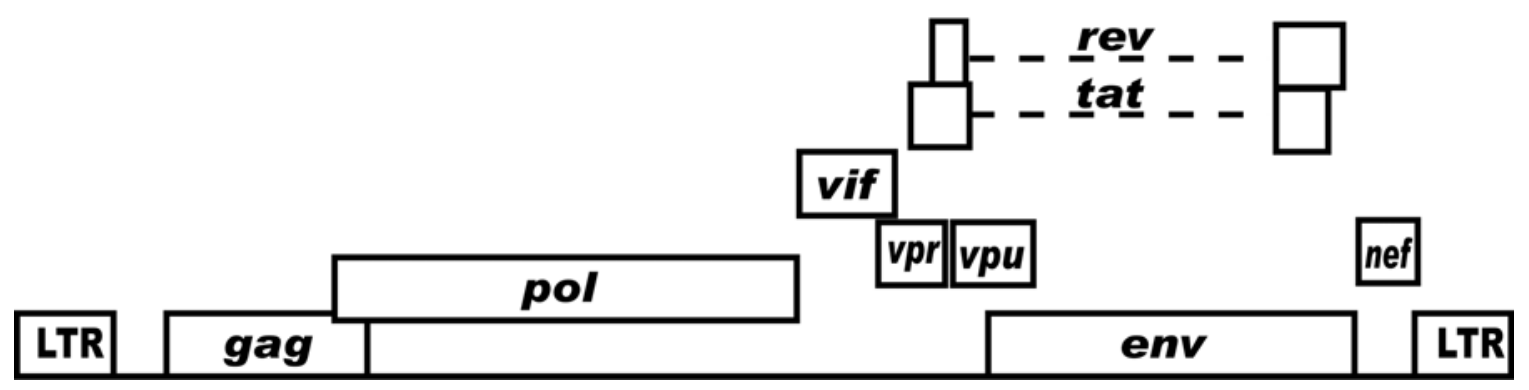

Figure 2. Genomic organization of a HIV-1 provirus. 


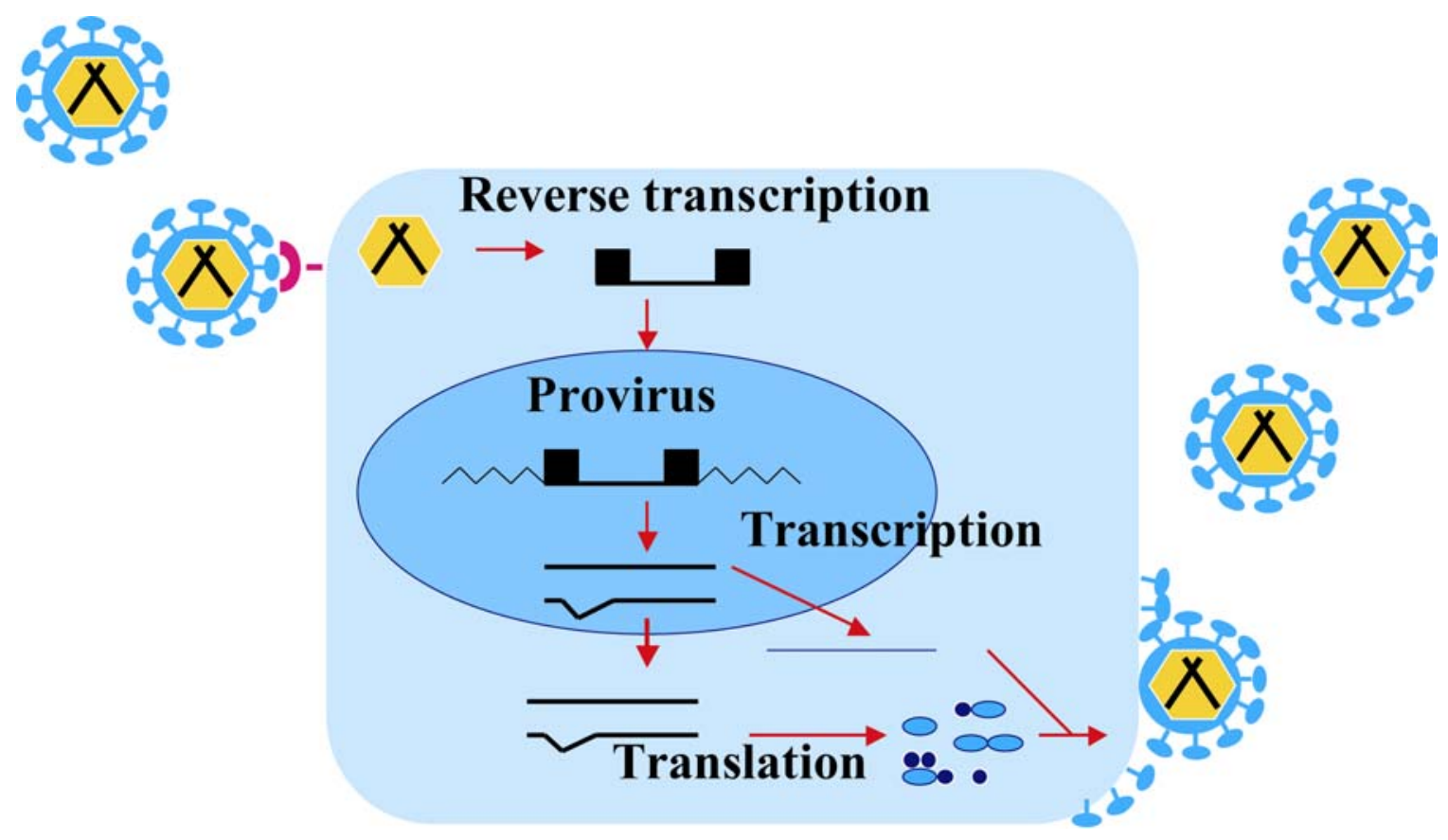

Figure 3. Replication cycle of a retrovirus. 

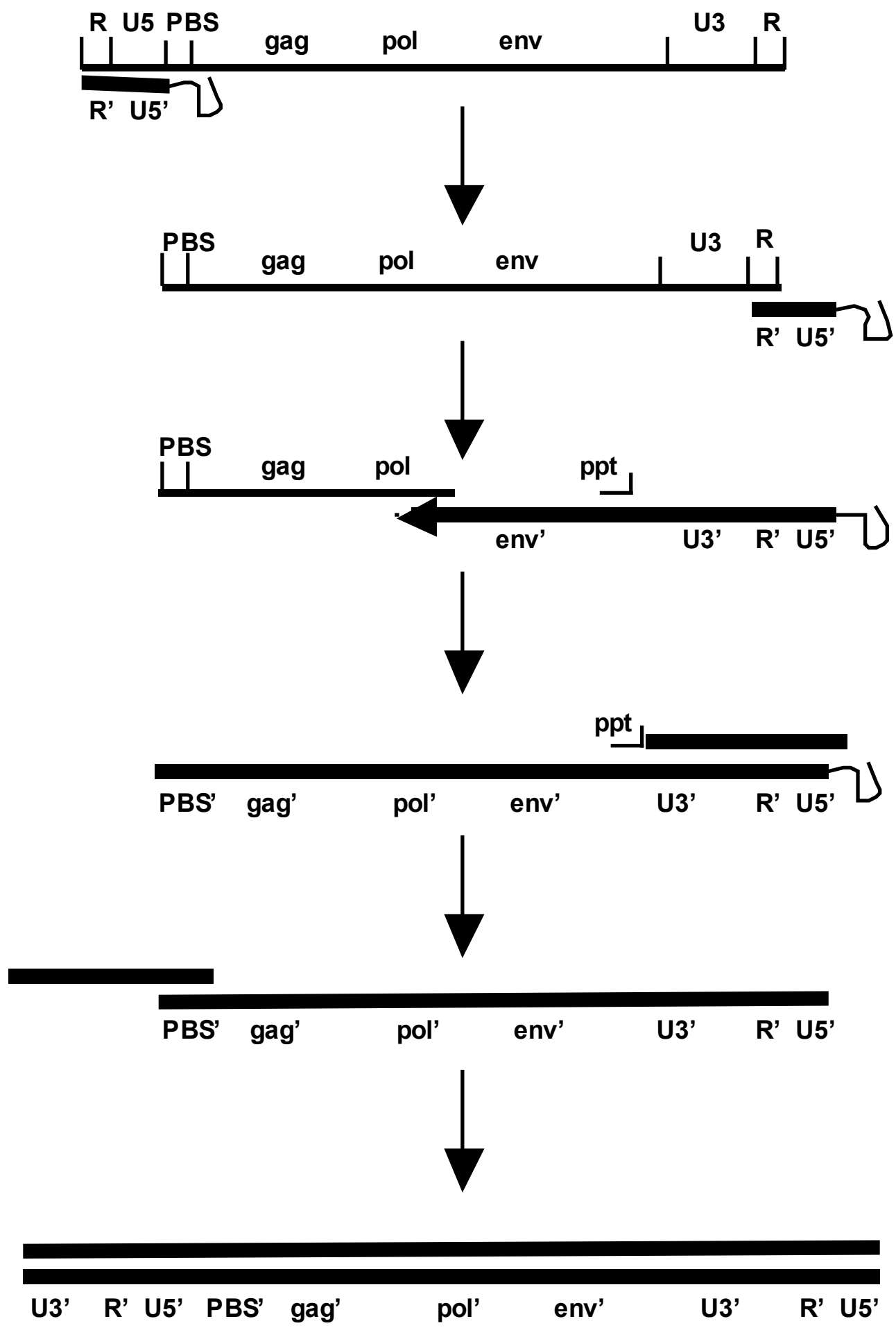

Figure 4. Reverse transcription. Thin lines represent RNA; thick lines, DNA 
A.

RNA A

RNAB B

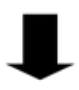

Recombinant DNA



(D)

DNA A
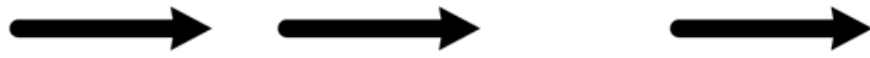

DNA B

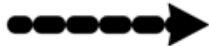

Qе
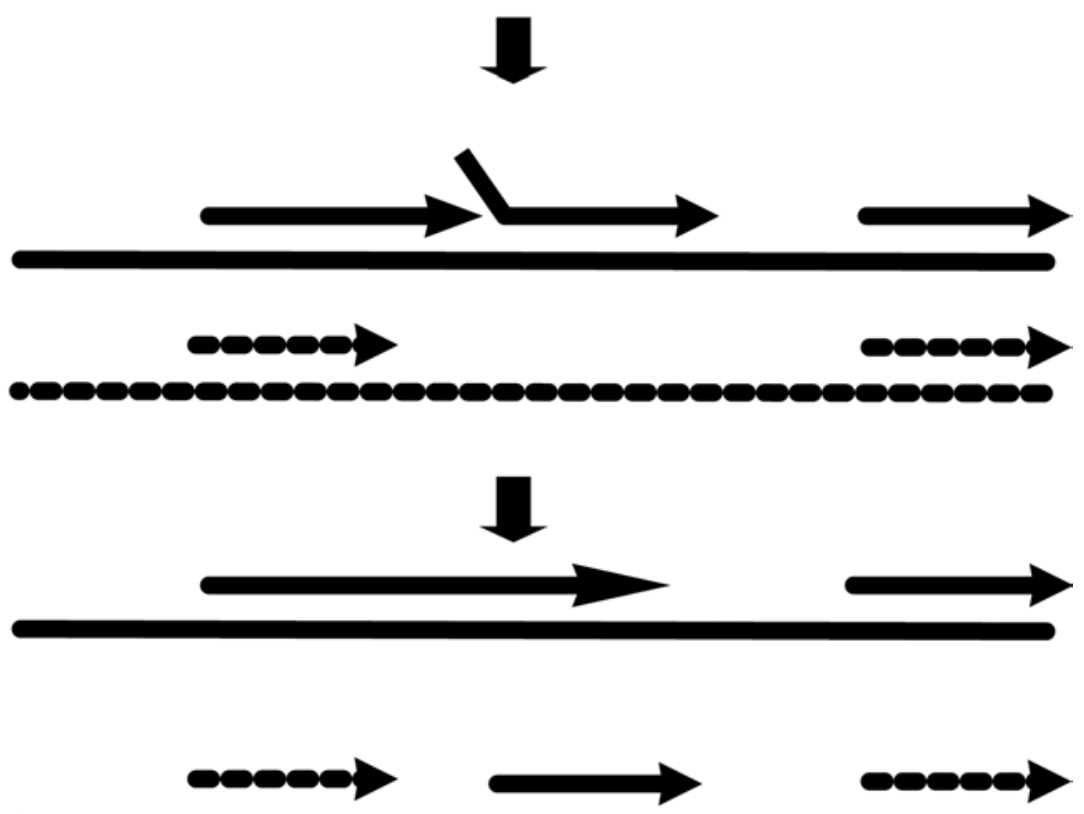

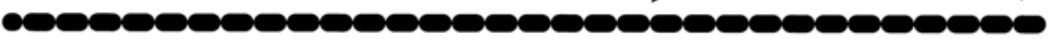

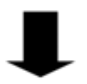

Recombinant DNA

פ"

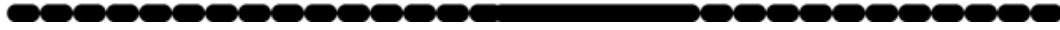

Figure 5. Two proposed models to explain the generation of proviral recombinants. 


\section{References}

1. An, W., and A. Telesnitsky. 2002. Effects of varying sequence similarity on the frequency of repeat deletion during reverse transcription of a human immunodeficiency virus type 1 vector. J Virol 76:7897-7902.

2. Anderson, J. A., E. H. Bowman, and W. S. Hu. 1998. Retroviral recombination rates do not increase linearly with marker distance and are limited by the size of the recombining subpopulation. J Virol 72:1195-1202.

3. Beemon, K., P. Duesberg, and P. Vogt. 1974. Evidence for crossing-over between avian tumor viruses based on analysis of viral RNAs. Proc Natl Acad Sci U S A 71:4254-4258.

4. Brown, P. O. 1997. Integration, p. 161-203. In J. Coffin, S. Hughes, and H. Varmus (ed.), Retroviruses. Cold Spring Harbor Laboratory Press, New York.

5. Bushman, F. D., and R. Craigie. 1990. Sequence requirements for integration of Moloney murine leukemia virus DNA in vitro. J Virol 64:5645-5648.

6. Carr, J. K., M. O. Salminen, C. Koch, D. Gotte, A. W. Artenstein, P. A. Hegerich, D. St Louis, D. S. Burke, and F. E. McCutchan. 1996. Full-length sequence and mosaic structure of a human immunodeficiency virus type 1 isolate from Thailand. J Virol 70:5935-5943.

7. Cheslock, S. R., J. A. Anderson, C. K. Hwang, V. K. Pathak, and W. S. Hu. 2000. Utilization of nonviral sequences for minus-strand DNA transfer and gene reconstitution during retroviral replication. J Virol 74:9571-9579. 
8. Clavel, F., M. D. Hoggan, R. L. Willey, K. Strebel, M. A. Martin, and R. Repaske. 1989. Genetic recombination of human immunodeficiency virus. J Virol 63:1455-1459.

9. Coffin, J. M. 1995. HIV population dynamics in vivo: implications for genetic variation, pathogenesis, and therapy. Science 267:483-489.

10. Coffin, J. M. 1979. Structure, replication, and recombination of retrovirus genomes: some unifying hypotheses. J Gen Virol 42:1-26.

11. Coffin, J. M., and W. A. Haseltine. 1977. Terminal redundancy and the origin of replication of Rous sarcoma virus RNA. Proc Natl Acad Sci U S A 74:1908-1912.

12. Daar, E. S., T. Moudgil, R. D. Meyer, and D. D. Ho. 1991. Transient high levels of viremia in patients with primary human immunodeficiency virus type 1 infection. N Engl J Med 324:961-964.

13. Dang, Q., and W. S. Hu. 2001. Effects of homology length in the repeat region on minus-strand DNA transfer and retroviral replication. J Virol 75:809-820.

14. Duesberg, P. H. 1968. Physical properties of Rous Sarcoma Virus RNA. Proc Natl Acad Sci U S A 60:1511-1518.

15. Gao, F., D. L. Robertson, S. G. Morrison, H. Hui, S. Craig, J. Decker, P. N. Fultz, M. Girard, G. M. Shaw, B. H. Hahn, and P. M. Sharp. 1996. The heterosexual human immunodeficiency virus type 1 epidemic in Thailand is caused by an intersubtype (A/E) recombinant of African origin. J Virol 70:70137029.

16. Gilboa, E., S. W. Mitra, S. Goff, and D. Baltimore. 1979. A detailed model of reverse transcription and tests of crucial aspects. Cell 18:93-100. 
17. Harada, F., R. C. Sawyer, and J. E. Dahlberg. 1975. A primer ribonucleic acid for initiation of in vitro Rous sarcarcoma virus deoxyribonucleic acid synthesis. J Biol Chem 250:3487-3497.

18. Hu, W. S., and H. M. Temin. 1990. Genetic consequences of packaging two RNA genomes in one retroviral particle: pseudodiploidy and high rate of genetic recombination. Proc Natl Acad Sci U S A 87:1556-1560.

19. Hwang, C. K., E. S. Svarovskaia, and V. K. Pathak. 2001. Dynamic copy choice: steady state between murine leukemia virus polymerase and polymerasedependent RNase $\mathrm{H}$ activity determines frequency of in vivo template switching. Proc Natl Acad Sci U S A 98:12209-12214.

20. Iglesias-Sanchez, M. J., and C. Lopez-Galindez. 2002. Analysis, quantification, and evolutionary consequences of HIV-1 in vitro recombination. Virology 304:392-402.

21. Jetzt, A. E., H. Yu, G. J. Klarmann, Y. Ron, B. D. Preston, and J. P. Dougherty. 2000. High rate of recombination throughout the human immunodeficiency virus type 1 genome. J Virol 74:1234-1240.

22. Junghans, R. P., L. R. Boone, and A. M. Skalka. 1982. Retroviral DNA H structures: displacement-assimilation model of recombination. Cell 30:53-62.

23. Kawai, S., and H. Hanafusa. 1972. Genetic recombination with avian tumor virus. Virology 49:37-44.

24. Levy, D. N., G. M. Aldrovandi, O. Kutsch, and G. M. Shaw. 2004. Dynamics of HIV-1 recombination in its natural target cells. Proc Natl Acad Sci U S A. 
25. Liu, S. L., J. E. Mittler, D. C. Nickle, T. M. Mulvania, D. Shriner, A. G. Rodrigo, B. Kosloff, X. He, L. Corey, and J. I. Mullins. 2002. Selection for human immunodeficiency virus type 1 recombinants in a patient with rapid progression to AIDS. J Virol 76:10674-10684.

26. Mansky, L. M., and H. M. Temin. 1995. Lower in vivo mutation rate of human immunodeficiency virus type 1 than that predicted from the fidelity of purified reverse transcriptase. J Virol 69:5087-5094.

27. McCutchan, F. E., P. A. Hegerich, T. P. Brennan, P. Phanuphak, P. Singharaj, A. Jugsudee, P. W. Berman, A. M. Gray, A. K. Fowler, and D. S. Burke. 1992. Genetic variants of HIV-1 in Thailand. AIDS Res Hum Retroviruses 8:1887-1895.

28. Miller, R. J., J. S. Cairns, S. Bridges, and N. Sarver. 2000. Human immunodeficiency virus and AIDS: insights from animal lentiviruses. J Virol 74:7187-7195.

29. Onafuwa, A., W. An, N. D. Robson, and A. Telesnitsky. 2003. Human Immunodeficiency Virus Type 1 Genetic Recombination Is More Frequent Than That of Moloney Murine Leukemia Virus despite Similar Template Switching Rates. J Virol 77:4577-4587.

30. Panganiban, A. T., and H. M. Temin. 1983. The terminal nucleotides of retrovirus DNA are required for integration but not virus production. Nature 306:155-160.

31. Pathak, V. K., and H. M. Temin. 1990. Broad spectrum of in vivo forward mutations, hypermutations, and mutational hotspots in a retroviral shuttle vector 
after a single replication cycle: deletions and deletions with insertions. Proc Natl Acad Sci U S A 87:6024-6028.

32. Pathak, V. K., and H. M. Temin. 1990. Broad spectrum of in vivo forward mutations, hypermutations, and mutational hotspots in a retroviral shuttle vector after a single replication cycle: substitutions, frameshifts, and hypermutations. Proc Natl Acad Sci U S A 87:6019-6023.

33. Perelson, A. S., A. U. Neumann, M. Markowitz, J. M. Leonard, and D. D. Ho. 1996. HIV-1 dynamics in vivo: virion clearance rate, infected cell life-span, and viral generation time. Science 271:1582-1586.

34. Quinones-Mateu, M. E., Y. Gao, S. C. Ball, A. J. Marozsan, A. Abraha, and E. J. Arts. 2002. In vitro intersubtype recombinants of human immunodeficiency virus type 1: comparison to recent and circulating in vivo recombinant forms. $\mathrm{J}$ Virol 76:9600-9613.

35. Svarovskaia, E. S., K. A. Delviks, C. K. Hwang, and V. K. Pathak. 2000. Structural determinants of murine leukemia virus reverse transcriptase that affect the frequency of template switching. J Virol 74:7171-7178.

36. Taylor, J. M., and R. Illmensee. 1975. Site on the RNA of an avian sarcoma virus at which primer is bound. J Virol 16:553-558.

37. Temin, H. M. 1976. The DNA provirus hypothesis. Science 192:1075-1080.

38. Temin, H. M., and S. Mizutani. 1970. RNA-dependent DNA polymerase in virions of Rous sarcoma virus. Nature 226:1211-1213.

39. Vogt, P. K. 1971. Genetically stable reassortment of markers during mixed infection with avian tumor viruses. Virology 46:947-952. 
40. Zhou, H., G. J. Rainey, S. K. Wong, and J. M. Coffin. 2001. Substrate sequence selection by retroviral integrase. J Virol 75:1359-1370.

41. Zhu, T., N. Wang, A. Carr, S. Wolinsky, and D. D. Ho. 1995. Evidence for coinfection by multiple strains of human immunodeficiency virus type 1 subtype B in an acute seroconvertor. J Virol 69:1324-1327.

42. Zhuang, J., A. E. Jetzt, G. Sun, H. Yu, G. Klarmann, Y. Ron, B. D. Preston, and J. P. Dougherty. 2002. Human immunodeficiency virus type 1 recombination: rate, fidelity, and putative hot spots. J Virol 76:11273-11282. 


\section{CHAPTER 2}

THE EVOLUTIONARY POTENTIAL OF A HYBRID RETROVIRUS 


\section{Introduction}

Retroviruses have a great capacity to evolve in order to over come selection pressures in the environment. Such evolutional power comes from the high mutation rate and the high viral titers that can ensue during an infection. Mutation generates variation in the viral genome. This variation can then be exploited by the population ensure the presence of advantageous mutations, which become amplified during virus propagation. Because the adaptability is based on the evolutionary potential of the virus, it is essential to study the mechanisms employed in this process.

Previous experiments have shown that although SNV and MLV are genetically distinct retroviruses, SNV can efficiently package and replicate MLV RNA. The reverse is not true, however. MLV proteins cannot efficiently package and replicate SNV RNA. This non-reciprocal recognition seems to extend beyond RNA packaging and also include pol gene products and other cis-acting elements. It has been shown that SNV proteins can not only package MLV RNA but can also support the replication of MLV vectors at a frequency similar to that of the SNV-based vectors. This observation indicates that SNV enzymes can reverse transcribe MLV-based RNA and integrate the DNA efficiently (8, 18). In contrast, MLV pol gene products cannot support SNV vector replication efficiently. It was found that an SNV Gag/MLV Pol chimera could package both SNVand MLV-based vectors efficiently. However, SNV vector generated titers that were approximately 100 -fold lower than those of the MLV vector (7). This result demonstrates that MLV pol gene products cannot utilize SNV cis-acting elements efficiently. The defect could be during reverse transcription when reverse transcriptase (RT) must interact with certain sequences in the viral genome and/or during integration 
when integrase (IN) needs to recognize the att sites. We hypothesize that if a virus with incompatible cis- and trans-acting elements is allowed to replicate, through mutations and selection, better-fit viruses will evolve. By examining the changes that allow the viruses to become better fit, we can gain an understanding of the elements that are important in the cis- and trans-acting factors.

\section{Material and Methods}

Nomenclature and plasmid construction. The names of all plasmids used in this study begin with $\mathrm{p}$, but the names of viruses derived from these plasmids do not. The cloning strategy for constructing pTR10 is as follows. The SNV encapsidation sequence and a small upstream portion of SNV gag were amplified by PCR from pWH460. Primers were designed to include an Asp 718 restriction site upstream and two BsmI, MluI and HindIII sites downstream. This PCR product and pJD214 were cut with the restriction enzymes Asp 718 and HindIII. Vector JD214 is an SNV-based vector that contains all the cis-acting elements for viral replication. The PCR product was ligated with pJD214 to generate pTR6. Vector pTR6 and pMP5 were both digested with the restriction enzyme BsmI. The $5.3 \mathrm{~kb}$ fragment from pMP5, which contains most of SNV gag and all of MLV pol, was ligated into the backbone of pTR6 to pTR7. An olgio containing a small portion of the 3' end of amphotropic MLV env, flanked by two ClaI sites, was inserted into ClaI-digested pTR7 to generate pTR8. Plasmid, pTR8, and pAMS were digested with $C l a \mathrm{I}$. Because $C l a \mathrm{I}$ was methylated at the downstream site, after the env portion, only a single cut was made in pTR8. Plasmid pAMS is a vector that encodes replication competent MLV, which includes amphotropic MLV env. ClaI cuts pAMS within the MLV pol and downstream of the termination codon of amphotropic 
MLV env. This $2.7 \mathrm{~kb}$ fragment was ligated into pTR8. The result, pTR10, contains all the SNV cis-acting elements, SNV gag, MLV pol, and amphotropic MLV env.

RT assay. One milliliter of virus supernatant was collected from tissue culture and added to $500 \mu \mathrm{L}$ of polyethylene glycol solution (30\% polyethylene glycol, $0.5 \mathrm{M}$ $\mathrm{NaCl}$ ). Following incubation in $4^{\circ} \mathrm{C}$ overnight, virus was spun at 13,000 RPM for $30 \mathrm{~min}$ on a Heraeus Biofuge centrifuge. Virus was resuspended in $20 \mu \mathrm{L}$ and subjected to an RT assay using standard procedures (47).

Cells, transfections and infections and flow cytometry analysis. Cultured cells were propagated in Dulbecco's modified Eagle's medium supplemented with $10 \%$ fetal calf serum for $293 \mathrm{~T}$ cells and $6 \%$ calf serum for D17 cells. Medium was also supplemented with penicillin $(50 \mathrm{U} / \mathrm{mL})$ and streptomycin $(50 \mathrm{U} / \mathrm{mL})$. Cells were maintained in a $37^{\circ} \mathrm{C}$ incubator with $5 \% \mathrm{CO}_{2}$.

DNA transfections were performed by the calcium phosphate method (43). Cells were plated at a density of $1 \times 10^{6}$ cells per 100-mm-diameter dish and transfected $24-\mathrm{hr}$ later with the appropriate mixture of DNA. The weight ratio of vectors expressing gag/pol, env, and packaging construct was 5:1:4, respectively. Transfected cells were placed in a $37^{\circ} \mathrm{C}$ incubator with $3 \% \mathrm{CO}_{2}$ overnight. Afterwards, the cell culture medium was changed and cells were placed in a $37^{\circ} \mathrm{C}$ incubator with $5 \% \mathrm{CO}_{2}$ for another $24 \mathrm{~h}$. Virus supernatants were harvested and cellular debris was removed by filtering through a $0.45-\mu \mathrm{m}$-pore-size filter. Virus was either used immediately or stored at $-80^{\circ} \mathrm{C}$ prior to use.

For infection, cells were plated at a density of $1 \times 10^{6}$ cells per 100 -mm-diameter dish or $2 \times 10^{5}$ cells per $60-\mathrm{mm}$-diameter dish $24 \mathrm{~h}$ prior to infection. Cells were infected 
by virus stocks in the presence of Polybrene at a final concentration of $50 \mu \mathrm{g} / \mathrm{mL}$.

Viruses were removed $4 \mathrm{~h}$ later and replaced with fresh media. Cells were washed with PBS containing $2 \%$ fetal calf serum. Acquisition of data was performed on a FACSCalibur (BD Biosciences).

\section{Results}

Experimental design and rationale. The experimental design is illustrated in Figure 1. Briefly, a replication competent viral vector containing incompatible cis- and trans-acting elements was transfected into cells. The cells were passed periodically and at each passage, fresh uninfected cells were added. RT assay was used to monitor the amount of virus produced from the culture cells. We expect that better-fit viruses would evolve during viral replication; this would be evident from an increased RT activity in the cell culture supernatant. After more efficient replicating viruses are detected in the cell culture system, the sequences of these viruses were amplified from the integrated provirus by PCR, and the molecular nature of these viruses was determined by sequence analysis.

Rationale for determining changes in fitness. The fitness of the viral population was monitored by RT activity. This is an in vitro assay that uses the viral RT in the virions to reverse transcribe an exogenous RNA template. Radioactive dNTPs are incorporated in the growing DNA strand during the assay. The amount of radioactivity measured is directly proportional to the amount of virions in the sample. The RT assay was used in the following manner. The supernanent was collected at various time points during the experiment and the amount of virus produced was determined by RT assay. When RT activity is plotted over time, a characteristic viral propagation profile is created 
(a hypothetical plot is shown in Fig. 2). A wild type virus is expected to spread though cultured cells quickly and produced large amount of viruses. As a result, the RT activity from the wild type virus should rise rapidly and remain high during the time course (dotted line in Fig. 2). In contrast, an unfit virus spreads through culture slowly; the RT activity should rise slowly and plateau at a lower activity than those from wild type virus. It may take much longer to see virion production (represented by the dashed line). As the viral population evolves and becomes more fit (solid line), the replication kinetics will begin to switch to an intermediate phenotype and eventually bear more similarity to that of the wild type virus than that of the unfit virus. Upon identifying a viral population with altered viral replication kinetics, virus in the supernatant was used to infect fresh 293T cells. PCR was used to amplify proviral sequences from cellular genomic DNA. These amplified products will then be sequenced. Changes within the viral sequences will then be identified.

\section{Vector and cell line used to examine viral evolution in cell culture system.}

The replication competent vector, pTR10, has all the cis-acting elements needed for SNV viral replication and SNV gag. However, SNV pol and env are replaced by MLV pol and amphotropic MLV env. The amphotropic MLV Env allows for the infection of a broad range of target cells. In addition, it has been shown previously that infectious viral particles can be generated from SNV Gag/Gag-Pol and MLV amphotropic Env. Human kidney cells, 293T, are the cells chosen for viral propagation. These cells were chosen for the following reasons: first, it is easy to achieve high efficiency transfection in 293T cells. Second, 293T cells are permissive to SNV infection, and third, human cells are known not to contain MLV-like endogenous retrovirus, which ensures the better-fit 
viruses were generated from adaptation between the cis- and trans-acting elements and not from recombination events between endogenous viruses and TR10. In previous experiments, SNV pseudotyped with amphotropic MLV Env efficiently infected 293T cells (Table 1). Also, transfecting 293T cells with SNV gag/pol constructs produced significant viral titers (Table 1). These experiments were performed by transfecting either a plasmid expressing SNV proteins or a plasmid expressing MLV proteins into 293T cells. These two plasmids were transfected with pSR2 (10), a plasmid that confers hygromycin resistance, and a plasmid encoding amphotropic MLV env. Viral supernatent harvested from transfected cells was used to infected fresh 293T cells. Based on these results, these cells should have been ideal for this experiment.

We tested whether TR10 expresses functional viral proteins essential for viral replication and support the replication of an SNV-based vector. 293T cells were transfected with either TR10 or pRD136 (a plasmid that expresses SNV wild type proteins) and a pSR2. Cells that received a plasmid encoding SNV wild type proteins also were transfected with a plasmid expressing amphotropic MLV Env. Serial dilutions of the supernatent were used to infect a dog osteosacroma cell line. Cells were put on hygromycin selection 24 hours later and 2 weeks later resistant colonies were counted to determine viral titer (Table 2). TR10 does package and replicate an SNV-based vector at SNV wild type levels, and we concluded that it could be used for the evolution experiments.

Vector pTR10 was then transiently transfected into $293 \mathrm{~T}$ cells. After 3 days, supernatant was collected and cells were mixed with fresh 293T cells at a ration of 1:1. Three time points were taken and presented in Table 3. As a control, we transfected 
pRD136, which does not produce replication competent virus, to measure RT expression generated from the initial transfection. Although there was a relative strong burst of RT activity from TR10 after transfection, TR10 did not have significant replication to produce RT activity higher than the mock infected sample.

Because we did not observe detectable RT activity for TR10 after the first passage, a different strategy was employed to test whether virus from pTR10 could propagate over time. D17 cells were stably transfected with pMS2 (10). The vector pMS2 is an MLV-based vector that contains two separate portions of green fluorescence protein (GFP) located in the LTRs. Upon infection with this construct GFP is reconstituted during reverse transcription. Virus replicating through cells stably expressing MS2 cells would give an indication of the virus's replicative capacity due to the eventual accumulation of GFP positive cells.

Three different viruses were tested in this cell line. Plasmids encoding replication competent SNV (pCG4), replication competent MLV (pAMS), and pTR10 were transfected into $293 \mathrm{~T}$ cells separately and the resulting harvested viruses were then used separately to infect D17/MS2 cells. GFP expression was monitored periodically for fiftysix days (Fig 3). Replication competent SNV and MLV infected-cells, although with different kinetics, showed a rise in the percent of GFP-expressing cells, indicating that virus replication took place. However, cells that were infected with TR10 only had background levels of GFP-expressing cells, indication that TR10 had a substantial defect in viral replication. 


\section{Discussion}

The experimental system in this report attempted to examine the evolution of a chimeric simple retrovirus and to investigate the role of sequences and/or protein residues important for virus replication. These methods have been employed in other systems with success $(9,28,49)$. A defective virus is allowed to replicate over many generations while monitoring fitness of the viral population. When better-fit virus populations are detected, strategies to examine the differences in genomic sequences are employed.

Time and virus titer are two dependent factors on evolution experiments. It is not known how many mutations in the chimeric virus that must be made in order to change its fitness level. The time it takes to make enough mutations in order to generate a betterfit virus is critical in this experiment. If large pools of infectious progeny virions were generated from one infected cell then the possibility exist that those advantageous mutations will occur and produce another round of progeny. However, the probability of the presence of advantageous mutations becomes meager when only a few progeny virions are produced per infected cell. A critical mass must be achieved for the described experiment to work, and the time it takes for TR10 to get to the critical mass is unknown.

Because SNV is an avian virus, it stands to reason that natural host cells might provide an advantage for virus replication. Performing this experiment in avian cell lines might generate the critical mass of viral titer to allow evolution to take place. In order for this experiment to proceed, these cell lines should be evaluated.

There were two conflicting previous reports on the subject of SNV production and infection in human cells $(20,30)$. Work described in Koo, et. al. discussed experiments 
in which SNV was able to infect human cell lines, but was not able to produce virus from the infected cells. They suggested a posttranslation block to productive SNV expression. However, work from Gautier, R., et. al. showed that SNV can not even infect human cells. Because a human cell line seemed idea for the evolution experiments, we made sure that the human cell line, 293T, could produce SNV virus and was permissive to SNV infection. When SNV was psuedotyped with amphotropic MLV env or GaLVenv, significant titers were produced upon infection of $293 \mathrm{~T}$ cells. These same viruses were produced from transfecting $293 \mathrm{~T}$ cells with plasmids that express SNV proteins and packaging constructs. These experiments show that $293 \mathrm{~T}$ cells do allow production and are permissive to infection. Although we obtained these results in 2000, recent published work confirms our conclusions (38). Such information would be valuable to gene therapies strategies that use retroviral constructs. 


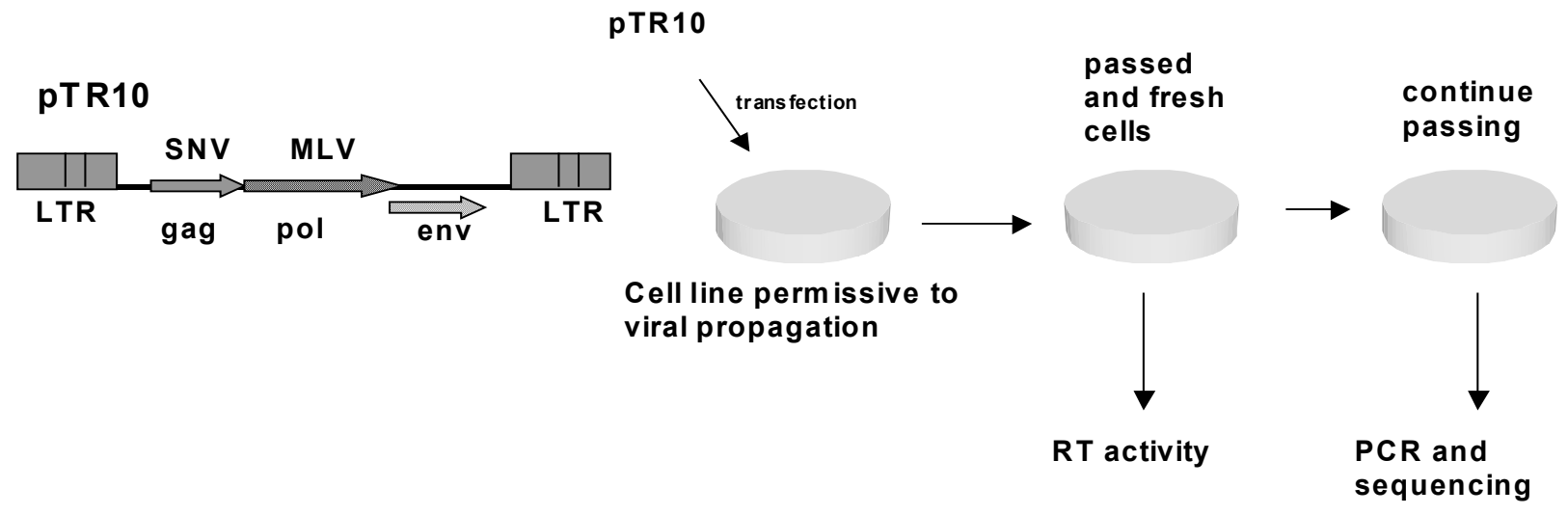

Figure 1. Vector and experimental design 


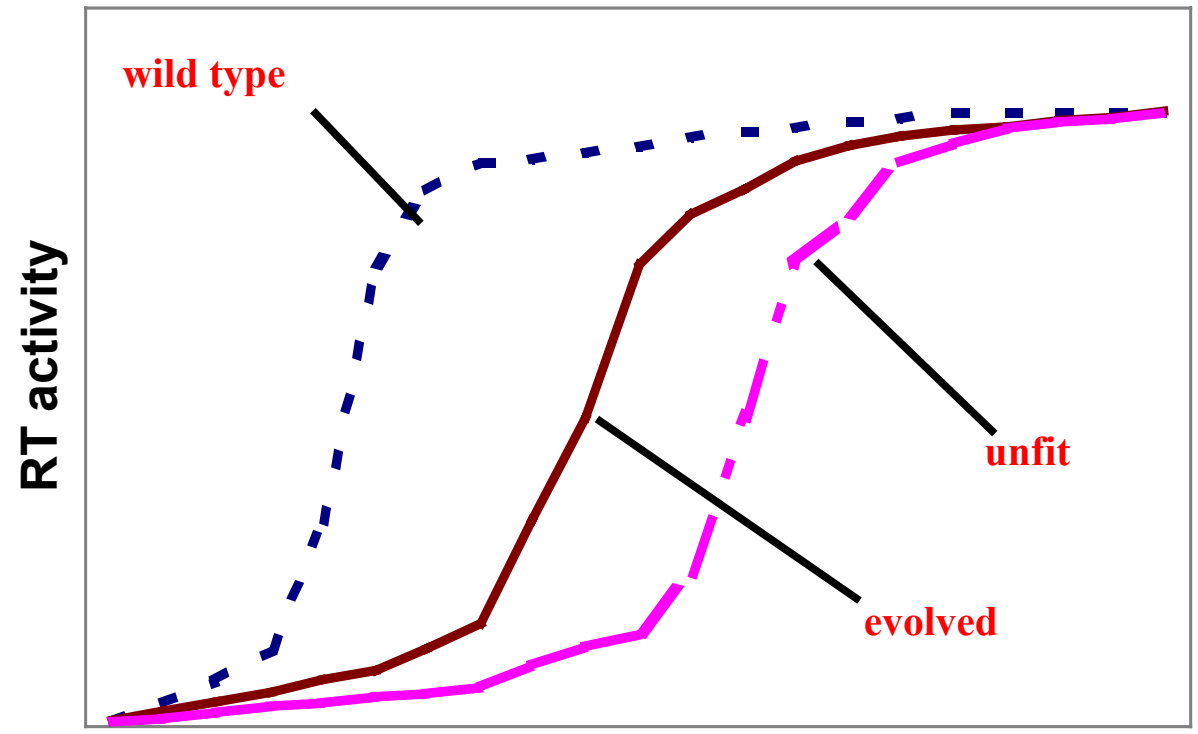

TIME

Figure 2. Hypothetical RT activity versus time graph of three different viral populations with different replication kinetics. 


\begin{tabular}{|c|c|c|}
\hline & $\begin{array}{c}\text { SNVgag/pol } \\
\text { amphoMLVenv }\end{array}$ & $\begin{array}{c}\text { MLVgag/pol } \\
\text { amphoMLVenv }\end{array}$ \\
\hline $\begin{array}{c}\text { Average } \\
\text { titer }\end{array}$ & $1.6 \times 10^{3}$ & $3.1 \times 10^{3}$ \\
\hline
\end{tabular}

Table 1. SNV and MLV virus production and infection into 293T cells. 


\begin{tabular}{|c|c|c|c|}
\hline & TR10 (SNVgag/MLVpol) & SNV wt & Mock \\
\hline $\begin{array}{c}\text { Average viral titer } \\
(\mathrm{cfm} / \mathrm{mL})\end{array}$ & $4.1 \times 10^{3}$ & $4.0 \times 10^{3}$ & 0 \\
\hline
\end{tabular}

Table 2: TR10 and SNV virus production and infection into 293T cells. 


\begin{tabular}{|c|c|c|c|}
\hline & $\begin{array}{c}\text { Day 3 } \\
(\mathrm{cpm} / \mathrm{min})\end{array}$ & $\begin{array}{c}\text { Day 6 } \\
(\mathrm{cpm} / \mathrm{min})\end{array}$ & $\begin{array}{c}\text { Day 9 } \\
(\mathrm{cpm} / \mathrm{min})\end{array}$ \\
\hline RD136 & 247,035 & 12,906 & 11,131 \\
\hline TR10 & 750,550 & 9,719 & 9,188 \\
\hline $\begin{array}{c}\text { Mock } \\
\text { infected }\end{array}$ & 11,863 & 10,198 & 10,304 \\
\hline
\end{tabular}

Table 3. TR10 viral propagation in $293 \mathrm{~T}$ cells. 


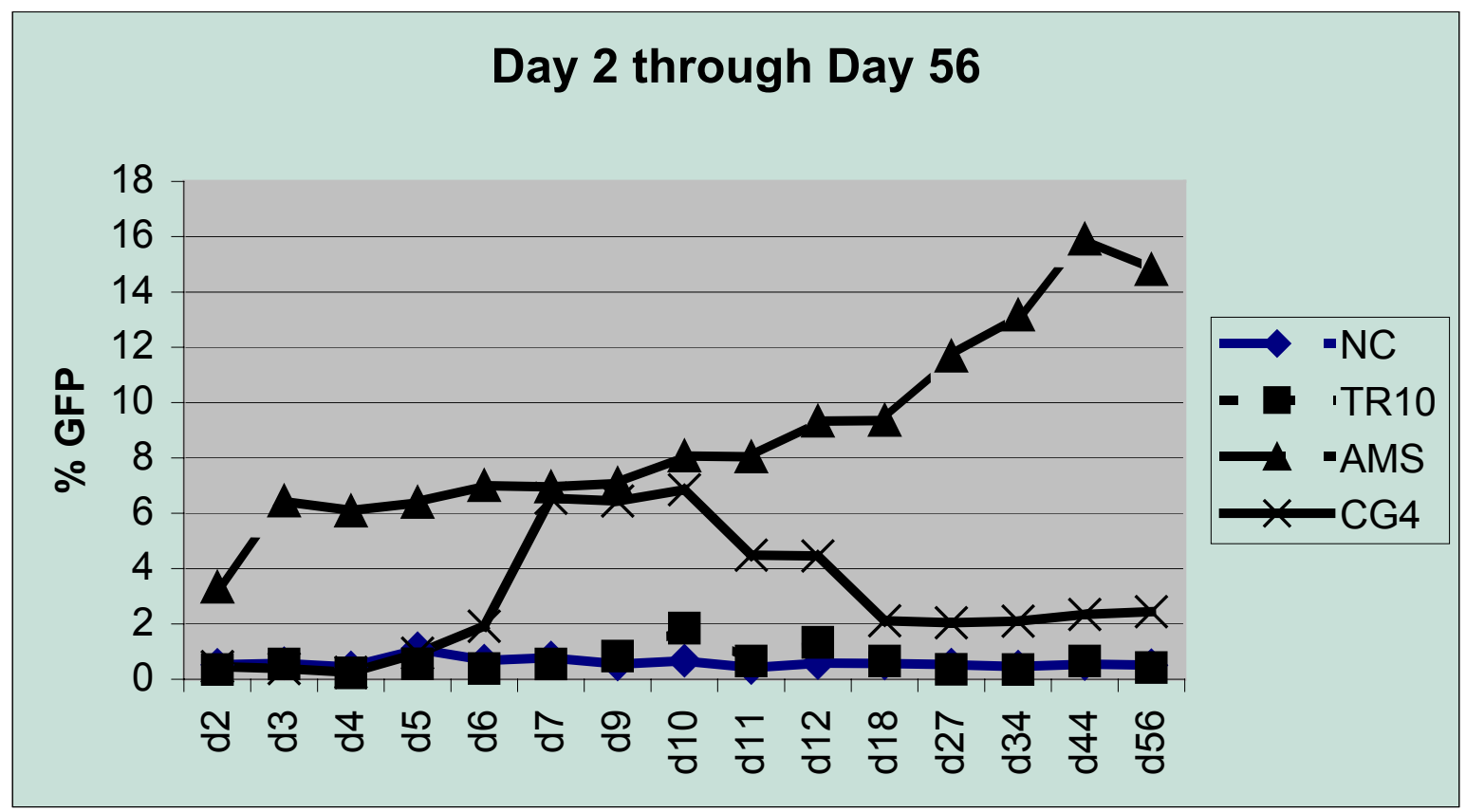

Figure 3. Viral propagation of three different viruses in D17/MS2 cells. d followed by a number on the $\mathrm{x}$-axis represents the day post infection sample was taken; $\mathrm{NC}$, negative control. 


\section{References}

1. An, W., and A. Telesnitsky. 2002. Effects of varying sequence similarity on the frequency of repeat deletion during reverse transcription of a human immunodeficiency virus type 1 vector. J Virol 76:7897-7902.

2. Anderson, J. A., E. H. Bowman, and W. S. Hu. 1998. Retroviral recombination rates do not increase linearly with marker distance and are limited by the size of the recombining subpopulation. J Virol 72:1195-1202.

3. Beemon, K., P. Duesberg, and P. Vogt. 1974. Evidence for crossing-over between avian tumor viruses based on analysis of viral RNAs. Proc Natl Acad Sci U S A 71:4254-4258.

4. Brown, P. O. 1997. Integration, p. 161-203. In H. Varmus (ed.), Retroviruses. Cold Spring Harbor Laboratory Press, New York.

5. Bushman, F. D., and R. Craigie. 1990. Sequence requirements for integration of Moloney murine leukemia virus DNA in vitro. J Virol 64:5645-5648.

6. Carr, J. K., M. O. Salminen, C. Koch, D. Gotte, A. W. Artenstein, P. A. Hegerich, D. St Louis, D. S. Burke, and F. E. McCutchan. 1996. Full-length sequence and mosaic structure of a human immunodeficiency virus type 1 isolate from Thailand. J Virol 70:5935-5943.

7. Certo, J. L., T. O. Kabdulov, M. L. Paulson, J. A. Anderson, and W. S. Hu. 1999. The nucleocapsid domain is responsible for the ability of spleen necrosis virus (SNV) Gag polyprotein to package both SNV and murine leukemia virus RNA. J Virol 73:9170-9177. 
8. Certo, J. L., B. F. Shook, P. D. Yin, J. T. Snider, and W. S. Hu. 1998. Nonreciprocal pseudotyping: murine leukemia virus proteins cannot efficiently package spleen necrosis virus-based vector RNA. J Virol 72:5408-5413.

9. Chakrabarti, L., M. Emerman, P. Tiollais, and P. Sonigo. 1989. The cytoplasmic domain of simian immunodeficiency virus transmembrane protein modulates infectivity. J Virol 63:4395-4403.

10. Cheslock, S. R., J. A. Anderson, C. K. Hwang, V. K. Pathak, and W. S. Hu. 2000. Utilization of nonviral sequences for minus-strand DNA transfer and gene reconstitution during retroviral replication. J Virol 74:9571-9579.

11. Clavel, F., M. D. Hoggan, R. L. Willey, K. Strebel, M. A. Martin, and R. Repaske. 1989. Genetic recombination of human immunodeficiency virus. J Virol 63:1455-1459.

12. Coffin, J. M. 1995. HIV population dynamics in vivo: implications for genetic variation, pathogenesis, and therapy. Science 267:483-489.

13. Coffin, J. M. 1979. Structure, replication, and recombination of retrovirus genomes: some unifying hypotheses. J Gen Virol 42:1-26.

14. Coffin, J. M., and W. A. Haseltine. 1977. Terminal redundancy and the origin of replication of Rous sarcoma virus RNA. Proc Natl Acad Sci U S A 74:1908-1912.

15. Daar, E. S., T. Moudgil, R. D. Meyer, and D. D. Ho. 1991. Transient high levels of viremia in patients with primary human immunodeficiency virus type 1 infection. N Engl J Med 324:961-964.

16. Dang, Q., and W. S. Hu. 2001. Effects of homology length in the repeat region on minus-strand DNA transfer and retroviral replication. J Virol 75:809-820. 
17. Duesberg, P. H. 1968. Physical properties of Rous Sarcoma Virus RNA. Proc Natl Acad Sci U S A 60:1511-1518.

18. Embretson, J. E., and H. M. Temin. 1987. Lack of competition results in efficient packaging of heterologous murine retroviral RNAs and reticuloendotheliosis virus encapsidation- minus RNAs by the reticuloendotheliosis virus helper cell line. J Virol 61:2675-2683.

19. Gao, F., D. L. Robertson, S. G. Morrison, H. Hui, S. Craig, J. Decker, P. N. Fultz, M. Girard, G. M. Shaw, B. H. Hahn, and P. M. Sharp. 1996. The heterosexual human immunodeficiency virus type 1 epidemic in Thailand is caused by an intersubtype (A/E) recombinant of African origin. J Virol 70:70137029.

20. Gautier, R., A. Jiang, V. Rousseau, R. Dornburg, and T. Jaffredo. 2000. Avian reticuloendotheliosis virus strain A and spleen necrosis virus do not infect human cells. J Virol 74:518-522.

21. Gilboa, E., S. W. Mitra, S. Goff, and D. Baltimore. 1979. A detailed model of reverse transcription and tests of crucial aspects. Cell 18:93-100.

22. Harada, F., R. C. Sawyer, and J. E. Dahlberg. 1975. A primer ribonucleic acid for initiation of in vitro Rous sarcarcoma virus deoxyribonucleic acid synthesis. J Biol Chem 250:3487-3497.

23. Hu, W. S., and H. M. Temin. 1990. Genetic consequences of packaging two RNA genomes in one retroviral particle: pseudodiploidy and high rate of genetic recombination. Proc Natl Acad Sci U S A 87:1556-1560. 
24. Hwang, C. K., E. S. Svarovskaia, and V. K. Pathak. 2001. Dynamic copy choice: steady state between murine leukemia virus polymerase and polymerasedependent RNase $\mathrm{H}$ activity determines frequency of in vivo template switching. Proc Natl Acad Sci U S A 98:12209-12214.

25. Iglesias-Sanchez, M. J., and C. Lopez-Galindez. 2002. Analysis, quantification, and evolutionary consequences of HIV-1 in vitro recombination. Virology 304:392-402.

26. Jetzt, A. E., H. Yu, G. J. Klarmann, Y. Ron, B. D. Preston, and J. P. Dougherty. 2000. High rate of recombination throughout the human immunodeficiency virus type 1 genome. J Virol 74:1234-1240.

27. Junghans, R. P., L. R. Boone, and A. M. Skalka. 1982. Retroviral DNA H structures: displacement-assimilation model of recombination. Cell 30:53-62.

28. Kashanchi, F., R. Shibata, E. K. Ross, J. N. Brady, and M. A. Martin. 1994. Second-site long terminal repeat (LTR) revertants of replication-defective human immunodeficiency virus: effects of revertant TATA box motifs on virus infectivity, LTR-directed expression, in vitro RNA synthesis, and binding of basal transcription factors TFIID and TFIIA. J Virol 68:3298-3307.

29. Kawai, S., and H. Hanafusa. 1972. Genetic recombination with avian tumor virus. Virology 49:37-44.

30. Koo, H. M., A. M. Brown, Y. Ron, and J. P. Dougherty. 1991. Spleen necrosis virus, an avian retrovirus, can infect primate cells. J Virol 65:4769-4776.

31. Levy, D. N., G. M. Aldrovandi, O. Kutsch, and G. M. Shaw. 2004. Dynamics of HIV-1 recombination in its natural target cells. Proc Natl Acad Sci U S A. 
32. Liu, S. L., J. E. Mittler, D. C. Nickle, T. M. Mulvania, D. Shriner, A. G. Rodrigo, B. Kosloff, X. He, L. Corey, and J. I. Mullins. 2002. Selection for human immunodeficiency virus type 1 recombinants in a patient with rapid progression to AIDS. J Virol 76:10674-10684.

33. Mansky, L. M., and H. M. Temin. 1995. Lower in vivo mutation rate of human immunodeficiency virus type 1 than that predicted from the fidelity of purified reverse transcriptase. J Virol 69:5087-5094.

34. McCutchan, F. E., P. A. Hegerich, T. P. Brennan, P. Phanuphak, P. Singharaj, A. Jugsudee, P. W. Berman, A. M. Gray, A. K. Fowler, and D. S. Burke. 1992. Genetic variants of HIV-1 in Thailand. AIDS Res Hum Retroviruses 8:1887-1895.

35. Miller, R. J., J. S. Cairns, S. Bridges, and N. Sarver. 2000. Human immunodeficiency virus and AIDS: insights from animal lentiviruses. J Virol 74:7187-7195.

36. Onafuwa, A., W. An, N. D. Robson, and A. Telesnitsky. 2003. Human Immunodeficiency Virus Type 1 Genetic Recombination Is More Frequent Than That of Moloney Murine Leukemia Virus despite Similar Template Switching Rates. J Virol 77:4577-4587.

37. Panganiban, A. T., and H. M. Temin. 1983. The terminal nucleotides of retrovirus DNA are required for integration but not virus production. Nature 306:155-160.

38. Parveen, Z., M. Mukhtar, M. Rafi, D. A. Wenger, K. M. Siddiqui, C. A. Siler, B. Dietzschold, R. J. Pomerantz, M. J. Schnell, and R. Dornburg. 2003. Cell- 
type-specific gene delivery into neuronal cells in vitro and in vivo. Virology 314:74-83.

39. Pathak, V. K., and H. M. Temin. 1990. Broad spectrum of in vivo forward mutations, hypermutations, and mutational hotspots in a retroviral shuttle vector after a single replication cycle: deletions and deletions with insertions. Proc Natl Acad Sci U S A 87:6024-6028.

40. Pathak, V. K., and H. M. Temin. 1990. Broad spectrum of in vivo forward mutations, hypermutations, and mutational hotspots in a retroviral shuttle vector after a single replication cycle: substitutions, frameshifts, and hypermutations. Proc Natl Acad Sci U S A 87:6019-6023.

41. Perelson, A. S., A. U. Neumann, M. Markowitz, J. M. Leonard, and D. D. Ho. 1996. HIV-1 dynamics in vivo: virion clearance rate, infected cell life-span, and viral generation time. Science 271:1582-1586.

42. Quinones-Mateu, M. E., Y. Gao, S. C. Ball, A. J. Marozsan, A. Abraha, and E. J. Arts. 2002. In vitro intersubtype recombinants of human immunodeficiency virus type 1: comparison to recent and circulating in vivo recombinant forms. $\mathrm{J}$ Virol 76:9600-9613.

43. Sambrook, J., E. F. Fritsch, and T. Maniatis. 1989. Molecular cloning: a laboratory manual, 2nd ed. Cold Spring Harbor Laboratory Press, Cold Spring Harbor, N.Y.

44. Svarovskaia, E. S., K. A. Delviks, C. K. Hwang, and V. K. Pathak. 2000. Structural determinants of murine leukemia virus reverse transcriptase that affect the frequency of template switching. J Virol 74:7171-7178. 
45. Taylor, J. M., and R. Illmensee. 1975. Site on the RNA of an avian sarcoma virus at which primer is bound. J Virol 16:553-558.

46. Temin, H. M. 1976. The DNA provirus hypothesis. Science 192:1075-1080.

47. Temin, H. M., and S. Mizutani. 1970. RNA-dependent DNA polymerase in virions of Rous sarcoma virus. Nature 226:1211-1213.

48. Vogt, P. K. 1971. Genetically stable reassortment of markers during mixed infection with avian tumor viruses. Virology 46:947-952.

49. Willey, R. L., D. H. Smith, L. A. Lasky, T. S. Theodore, P. L. Earl, B. Moss, D. J. Capon, and M. A. Martin. 1988. In vitro mutagenesis identifies a region within the envelope gene of the human immunodeficiency virus that is critical for infectivity. J Virol 62:139-147.

50. Zhou, H., G. J. Rainey, S. K. Wong, and J. M. Coffin. 2001. Substrate sequence selection by retroviral integrase. J Virol 75:1359-1370.

51. Zhu, T., N. Wang, A. Carr, S. Wolinsky, and D. D. Ho. 1995. Evidence for coinfection by multiple strains of human immunodeficiency virus type 1 subtype $\mathrm{B}$ in an acute seroconvertor. J Virol 69:1324-1327.

52. Zhuang, J., A. E. Jetzt, G. Sun, H. Yu, G. Klarmann, Y. Ron, B. D. Preston, and J. P. Dougherty. 2002. Human immunodeficiency virus type 1 recombination: rate, fidelity, and putative hot spots. J Virol 76:11273-11282. 


\section{CHAPTER 3}

High Rates of Human Immunodeficiency Virus Type 1 Recombination: Near-Random Segregation of Markers 1 Kilobase Apart in One Round of Viral Replication.

Terence Rhodes, ${ }^{1,2}$ Heather Wargo, ${ }^{1}$ and Wei-Shau $\mathrm{Hu}^{1}$

HIV Drug Resistance Program, National Cancer Institute at Frederick, Frederick, Maryland 21702, ${ }^{1}$ Department of Microbiology, Immunology, and Cell Biology, School of Medicine, West Virginia University, Morgantown, West Virginia $26506 .{ }^{2}$

This manuscript was published in the October 2003 issue of Journal of Virology (Vol. 77, No. 20, pp. 11193-200) 


\begin{abstract}
One of the genetic consequences of packaging two copies of full-length viral RNA into a single retroviral virion is frequent recombination during reverse transcription. Many of the currently circulating strains of human immunodeficiency virus type 1 (HIV1) are recombinants. Recombination can also accelerate the generation of multidrugresistant HIV-1 and therefore presents challenges to effective antiviral therapy. In this report, we determined that $\mathrm{HIV}-1$ recombination rates with markers $1.0,1.3$, and $1.9 \mathrm{~kb}$ apart were $42.4,50.4$, and $47.4 \%$ in one round of viral replication. Because the predicted recombination rate of two unlinked markers is $50 \%$, we conclude that markers $1 \mathrm{~kb}$ apart segregated in a manner similar to two unlinked markers in one round of retroviral replication. These recombination rates are exceedingly high even among retroviruses. Recombination rates of markers separated by $1 \mathrm{~kb}$ are $4 \%$ and $4.7 \%$ in one round of spleen necrosis virus and murine leukemia virus replication, respectively. Therefore, HIV-1 recombination can be 10 -fold higher than that of other retroviruses.

Recombination can only be observed in the proviruses derived from heterozygous virions that contain two genotypically different RNAs. The high rates of HIV-1 recombination observed in our studies also indicate that heterozygous virions are formed efficiently during HIV-1 replication and most HIV-1 virions are capable of undergoing recombination. Our results demonstrate that recombination is an effective mechanism to break the genetic linkage between neighboring sequences, thereby reassorting the HIV-1 genome and increasing the diversity in the viral population.
\end{abstract}




\section{Introduction}

Retroviruses package two copies of RNA into one virion, with each copy containing the entire genetic information needed for viral replication (16, 29). Although two copies of RNA are packaged, generally only one provirus is generated from each infectious event; therefore, retroviruses are considered pseudodiploid and not diploid (21). Retroviruses have been shown to undergo frequent recombination. One of the prerequisites for recombination is the formation of heterozygous virions, which contain two copies of RNA with different genetic information $(21,53)$. Recombination occurs during reverse transcription when portions of genetic information from both packaged RNA copies are used to generate a hybrid DNA copy $(7,52)$. Genetic recombination events cannot be identified in the progeny from homozygous virions; these virions package two identical copies of RNA and, therefore, the recombinants will have the same genotype as the parental viruses.

Previously, we determined that the recombination rates of spleen necrosis virus (SNV) and murine leukemia virus (MLV) in one round of viral replication are $4 \%$ and $4.7 \%$, respectively, with two markers $1 \mathrm{~kb}$ apart $(1,21)$. In MLV, the recombination rates increase to $5.0 \%$ and $7.4 \%$ with markers 1.3 and $1.9 \mathrm{~kb}$ apart, respectively $(1,2)$. However, when markers are separated by $7.1 \mathrm{~kb}$, the recombination rate is $8.2 \%$, which is not significantly different from the $7.4 \%$ rate observed for markers separated by $1.9 \mathrm{~kb}$ (1).

Recombination can reassort mutations in the viral genome to increase the diversity of the viral population, which can improve the probability of the survival of the viral population in a changing environment $(7,52)$. The selective advantage of having 
frequent recombination events is clearly illustrated in human immunodeficiency virus type 1 (HIV-1), which causes acquired immunodeficiency syndrome (AIDS). It was estimated that significant portions of the currently circulating strains of HIV-1 are recombinants $(9,26,45,46)$. Recombinant strains of HIV-1 have become dominant in the AIDS epidemic in certain geographical regions; for example, the $\mathrm{A} / \mathrm{E}$ recombinant causes many of the HIV-1 infection in Thailand $(18,35)$. HIV-1 recombination has also been directly observed in infected patients $(15,34,47,56)$.

Much research effort has been devoted to understanding HIV-1 recombination. Recombination has been observed during reverse transcription in vitro using purified nucleic acids and proteins $(3,12-14,38,39)$. Frequent HIV-1 recombination events have also been observed in cell culture systems $(6,22,30,42,50)$. More recently, the frequency of HIV-1 recombination was estimated by studying recombination between two similar strains of HIV-1 and mapping the crossovers by using a heteroduplextracking assay $(23,57)$. These studies revealed that within limited cycles of replication, many HIV-1 genomes contained more than one recombination event; an average of 2-3 crossovers per genome was estimated. These studies are highly informative; however, direct comparisons among the HIV-1, SNV, and MLV recombination rates are complicated by the different strategies used to calculate the recombination frequencies. In this report, we measured HIV-1 recombination rates in one round of viral replication. We found that HIV-1 recombines at an exceeding high frequency even when compared with other retroviruses such as MLV and SNV. These comparisons were made possible by using the same target sequences measured in the MLV recombination studies. 


\section{Materials and Methods}

Nomenclature and plasmid construction. The names of all plasmids used in this study begin with $\mathrm{p}$ but the names of the viruses derived from these plasmids do not; for example, pTR-HyIN refers to a plasmid and TR-HyIN refers to the virus or provirus derived from this plasmid. Plasmids were constructed using standard molecular cloning techniques (48). Plasmid pTR-HyIN was constructed from pJS30 (1) and pKDHIV(PIN), which was a generous gift from Dr. Vinay K. Pathak and a derivative of pHR'-CMVLacZ (37). Plasmids pKD-HIV(PIN) and pJS30 were digested with BamHI and BsrGI, respectively, treated with the Klenow fragment of Escherichia coli DNA polymerase I (Klenow) to fill in the 3' ends of DNA fragments, and then digested with $B c l$ I. The 1.8-kb DNA fragment derived from pJS30 containing hygromycin phosphotransferase B gene (hygro)(19) and internal ribosomal entry site (IRES) from encephalomyocarditis virus (EMCV) was ligated to the backbone from $\mathrm{pKD}-\mathrm{HIV}(\mathrm{PIN})$ to generate pTR-HyIN, which contains hygro and the neomycin phosphotransferase gene (neo) (24). To generate pTR-HyS2NIN, pTR-HyIN was digested with SacII, treated with T4 DNA polymerase to remove the protruding 3' termini, and self-ligated. This treatment generated an inactivating frameshift mutation in hygro, destroyed the SacII site and generated an NgoMIV site. To generate pTR-HyN2MIN, pTR-HyIN was partially digested with NdeI, then a linker (5'-TATGACGCGTCA-3') was inserted; these treatments generated a 10-bp addition to the sequence, which resulted in an inactivating frameshift mutation in hygro and an additional MluI site. To generate pTR-HyINE2B, a 0.9-kb MscI-to-BamHI region in pTR-HyIN was replaced by its counterpart from pJA32$1 \mathrm{~kb}(1)$; the resulting plasmid contained the same structure as pTR-HyIN except for a 4- 
bp inactivating insertion in neo that destroyed an EheI site and added a BssHII site.

Plasmid pTR-HyIN was partially digested with NcoI, treated with Klenow enzyme, and ligated to generate pTR-HyN2NIN and pTR-HyINN2N, which contained a 4-bp insertion that inactivated hygro and neo, respectively.

Cells, transfections, and infections. Cultured cells were propagated in Dulbecco's modified Eagle's medium supplemented with $10 \%$ fetal calf serum, penicillin $(50 \mathrm{U} / \mathrm{ml})$, and streptomycin $(50 \mathrm{U} / \mathrm{ml})$. Cells were maintained in a $37^{\circ} \mathrm{C}$ incubator with $5 \% \mathrm{CO}_{2}$.

DNA transfections were performed by the calcium phosphate method (48) using an MBS Mammalian Transfection Kit (Strategene). Cells were plated at a density of $4 \times$ $10^{6}$ per $100-\mathrm{mm}$-diameter dish and transfected $18 \mathrm{~h}$ later with a mixture of DNA. After incubating for $4 \mathrm{~h}$ at a $37^{\circ} \mathrm{C}$ incubator with $3 \% \mathrm{CO}_{2}$, the DNA mixture was removed, fresh medium was added to the cells, and the cells were transferred to a $37^{\circ} \mathrm{C}$ incubator with $5 \% \mathrm{CO}_{2}$. Viral supernatants were harvested $24 \mathrm{~h}$ later; cellular debris was removed by filtering the supernatants through a $0.45-\mu \mathrm{m}$ filter. Viral supernatants were either used immediately or stored at $-80^{\circ} \mathrm{C}$ prior to infection. Helper constructs pCMV $\Delta \mathrm{R} 8.2$ (36) together with pSV-A-MLV-env (31) or pHCMV-G (54) were transfected into cells to generate viruses. Plasmid $\mathrm{pCMV} \Delta \mathrm{R} 8.2$ expresses all HIV-1 viral proteins needed for infection except Env. Plasmid pSV-A-MLV-env or pHCMV-G expresses amphotropic MLV Env or vesicular stomatitis virus G protein (VSV-G), respectively. DNA mixtures used for transfection were either at a $5: 1: 4$ (pCMV $\Delta$ R8.2 : pSV-A-MLV-env : vector) or $2: 1$ (pCMV $\Delta$ R8.2 : pHCMV-G) ratio. 
For the infection procedure, target cells were plated at a density of $1 \times 10^{5}$ per $60-$ $\mathrm{mm}$-diamter dish $24 \mathrm{~h}$ prior to infection. Serial dilutions were generated from each viral stock and used for infection in the presence of Polybrene at a final concentration of 50 $\mu \mathrm{g} / \mathrm{ml}$. Viruses were removed $4 \mathrm{~h}$ later and drug selections were carried out $24 \mathrm{~h}$ postinfection. Selection with hygromycin, G418, or hygromycin plus G418 were performed at 170,609 , or 170 plus $473 \mu \mathrm{g} / \mathrm{ml}$, respectively.

Southern hybridization analyses. Genomic DNAs from infected cells were purified using the QIAamp DNA Blood Mini Kit (Qiagen) or AquaPure Genomic DNA Isolation Kit (BioRad). Southern hybridization was performed by standard procedures (48). A 1.0-kb HindIII-to-NgoMIV DNA fragment derived from pWH390 (1) containing the $3^{\prime}$ portion of the IRES, and the $5^{\prime} 0.6-\mathrm{kb}$ portion of neo was used to generate a ${ }^{32} \mathrm{P}-$ labeled probe by random priming (17) (Random Primed DNA Labeling Kit, Roche). Southern hybridization results were obtained by autoradiography or PhosphorImager analyses.

\section{RESULTS}

Strategy used to measure HIV-1 recombination rates. The following constructs and strategy were used to measure the HIV-1 recombination rates. We constructed an HIV-1-based vector (pTR-HyIN) that expresses hygro and neo, which confer resistance to hygromycin and G418, respectively. In this vector, hygro expression is directed by an internal cytomegalovirus promoter, whereas neo expression is directed by an EMCV IRES (Fig. 1). Plasmid pTR-HyIN also contains all the $c i s$-acting elements 
essential for viral genome replication; however, it does not express HIV-1-encoded viral proteins.

Two vectors were derived from pTR-HyIN, each containing an inactivating mutation in one of the drug-resistance genes. Vector pTR-HyS2NIN contains an inactivating frameshift mutation in hygro that destroys a SacII site and generates an NgoMIV site, whereas pTR-HyINE2B contains an inactivating frameshift mutation in neo that destroys an EheI site and generates a BssHII site (Fig. 1). The distance between the SacII site in hygro and the EheI site in neo is $1 \mathrm{~kb}$. Because these two vectors each contain only one functional drug-resistance gene, a provirus derived from pTR-HyS2NIN or pTR-HyINE2B can only confer resistance to one drug selection. However, if recombination occurs within the $1-\mathrm{kb}$ distance separating the mutations, it could generate a provirus containing two functional drug-resistance genes conferring resistance to double drug selection. By measuring the frequency at which recombinants with two functional genes are generated, we can calculate the recombination rate between markers $1 \mathrm{~kb}$ apart.

The protocol used to measure the HIV-1 recombination rate is illustrated in Fig. 1B. TR-HyS2NIN- or TR-HyINE2B-containing virions were generated separately by transfecting 293T cells with vector plasmid, pCMVAR8.2, and pSV-a-MLV-env. Helper construct pCMVDR8.2 expresses most HIV-1-encoded proteins except Env, whereas pSV-A-MLV-env expresses the amphotropic MLV Env, which can functionally replace HIV-1 Env to generate infectious pseudotyped HIV-1 virions. These viruses were used to infect 293 cells simultaneously, and the resulting hygromycin-plus-G418 double resistant cell clones were selected and characterized by Southern analyses. Only cell 
clones containing one copy of each provirus with intact structures were selected and used for further experiments.

To measure the recombination rate, these characterized cell clones were transfected with helper constructs pCMV $\Delta$ R8.2 and pHCMV-G, which expresses VSVG. VSV-G can be used to generate infectious pseudotyped HIV-1 virions. Twenty-four hours after transfection, viruses were harvested and serial dilutions were generated. These viral stocks were used to infect 293 target cells in triplicates; these cells were then selected with hygromycin, G418, or hygromycin plus G418. The numbers of drugresistant cell colonies were determined and viral titers were calculated. Hygromycinplus-G418-resistant cell clones were isolated and the molecular nature of the proviruses was characterized. These data were used to calculate the frequency at which recombinants with two functional drug-resistance genes were generated. This frequency was then used to calculate the recombination rate.

\section{Comparisons of TR-HyIN-derived viral titers resulting from different drug}

selections. The strategy described above relied on viral titers generated from different drug selections to calculate how frequently recombinants with two functional genes were generated. Therefore, it was important to first define the relative viral titers from different drug selections. Using a protocol similar to that described above, we generated cell clones containing a single copy of TR-HyIN provirus. Viruses were generated from these cells and used to infect 293 target cells; hygromycin, G418, or hygromycin-plusG418 viral titers were determined. A summary of viral titers generated from five different cell clones is shown in Table 1. In each of the five cell clones, viral titers generated by the three selection regimens were similar. Therefore, viral titers generated 
from single and double drug selections reflect the number of infection events and can be used to calculate recombination rates.

Measuring HIV-1 recombination rates with two markers $1 \mathrm{~kb}$ apart. Using the aforementioned protocol, we generated cell clones containing a copy of each TRHyS2NIN and pTR-HyINE2B provirus with intact structures. These characterized cell clones were transfected with helper constructs $\mathrm{pCMV} \Delta \mathrm{R} 8.2$ and $\mathrm{pHCMV}-\mathrm{G}$ to generate viruses; the resulting viral titers from five cell clones are summarized in Table 2. In general, hygromycin and G418 viral titers within each cell clone were similar, indicating that the two parental proviruses were expressed at similar levels; in addition, the hygromycin-plus-G418 viral titers were approximately $20 \%$ of the single drug-resistant viral titers. Each of the parental viruses can only confer single drug resistance; a doubly resistant cell can be generated by the presence of both parental viruses or by the presence of a recombinant virus with two functional drug-resistance genes. To characterize the molecular nature of the proviruses in the doubly resistant cells, we isolated 11 hygromycin-plus-G418-resistant target cell clones and performed Southern analyses (Fig. 2). The two parental viruses are identical in sequence except for the two inactivating mutations, which convert a SacII site in hygro to an NgoMIV site and an EheI site in neo to a BssHII site. Therefore, the nature of the proviruses can be distinguished by Southern analyses. A representative Southern analysis is shown in Fig. 2B. DNA samples were digested with NgoMIV plus EheI and hybridized with a probe generated from a DNA fragment containing the 3 ' half of IRES and most of neo. A provirus derived from one of the parental viruses should generate either a $1-\mathrm{kb}$ band plus a $0.5-\mathrm{kb}$ band (TRHyS2NIN) or a 2.3-kb band (TR-HyINE2B), whereas a recombinant provirus with two 
functional genes should generate a $1.8-\mathrm{kb}$ band plus a $0.5-\mathrm{kb}$ band. Southern analyses of DNA samples from two types of cells are shown: virus-producing cells, and doubly resistant target cells infected with virus generated from the producer cells. Lanes labeled 1.0B2, 1.0C 3 , and 1.0C4 contained DNA isolated from virus producer cell clones doubly infected with the two parental viruses. In each of these lanes, three bands were detected, corresponding to the expected $2.3,1.0$, and $0.5 \mathrm{~kb}$ fragments. In contrast, a 1.8 -kb band and a $0.5-\mathrm{kb}$ band were observed in DNA samples isolated from resistant target cell clones (lanes labeled B2B1, B2B2, B2C1, C3A1, and C4B1). All of the 11 target cell clones contained recombinant proviruses (Fig. 2 and data not shown). These results indicate that most of the hygromycin-plus-G418-resistant viral titers were generated from infection of recombinant proviruses rather than double infection of the two parent viruses. Therefore, the doubly resistant viral titers reflect the amount of recombinants containing two functional drug resistance genes.

Two types of recombinants can be generated in this system: recombinants with two functional drug resistance genes and recombinants with two inactivated genes. Because the double drug selection protocol specifically detected recombinants with the two functional drug-resistance genes, only half of the recombination events were measured. To calculate the recombination rate, the hygromycin-plus-G418 viral titers were divided by the lower of the two single drug selection titers, and then multiplied by two. The average recombination rate from the five clones is $42.4 \pm 1.8 \%$ [standard error (SE), Table 2].

Theoretical recombination rate of unlinked markers in this system. We performed the following calculation to estimate the recombination rate of two unlinked 
markers (Fig. 3). Assuming that in the virus-producing cells, RNA expression of the two proviruses is equal, and the formation of homozygous and heterozygous virions is random, then $50 \%$ of the virions should be heterozygous, $25 \%$ of the virions should be homozygous containing two copies of TR-HyS2NIN RNA, and 25\% of the virions should be homozygous containing two copies of TR-HyINE2B RNA. Homozygous virions generate progeny proviruses with the same phenotypes as their parents. In contrast, heterozygous virions can generate four different types of progeny proviruses: the TR-HyS2NIN phenotype, the TR-HyINE2B phenotype, the recombinant phenotype with two functional drug-resistance genes, and the recombinant phenotype with two inactivated genes. If the mutations in hygro and neo are unlinked, then random segregation is predicted, which infers that the four different phenotypes of progeny proviruses should be generated at the same frequencies. Therefore, of the $50 \%$ heterozygous virions, $12.5 \%$ of each phenotype of progeny is generated. Totaling all of the progeny generated by both homozygous and heterozygous virions, $50 \%$ of the proviruses should confer resistance to a single drug selection ( $25 \%$ from the homozygous virions, $12.5 \%$ from the parental phenotype generated from heterozygous virions, and $12.5 \%$ from the double drug-resistance phenotype), whereas $12.5 \%$ of the proviruses should confer resistance to double drug selection. Therefore, the recombination rate should be $50 \%[(12.5 \% / 50 \%) \times 2]$.

\section{HIV-1 recombination rate does not increase significantly when markers are}

1.3 or $1.9 \mathrm{~kb}$ part. The rate that we measured with two markers $1 \mathrm{~kb}$ apart is $42.4 \%$, which approaches the rate at which two markers reassort randomly. To investigate whether the HIV-1 recombination rate can increase further, we measured the 
recombination rates when two markers are 1.3 or $1.9 \mathrm{~kb}$ apart. These two distances were chosen because using the same target sequences we have previously measured the MLV recombination rates when markers were 1.3 or $1.9 \mathrm{~kb}$ apart $(1,2)$; additionally, the $1.9-\mathrm{kb}$ recombination rate is significantly higher than the $1.0-\mathrm{kb}$ recombination rate (1).

Three vectors were derived from pTR-HyIN; the structures of their proviruses are shown in Fig. 3A and 5A. Vector pTR-HyN2MIN contains an inactivating frameshift mutation in hygro that introduced an MluI site in an NdeI site; when paired with the previously described pTR-HyINE2B, the recombination rate with markers $1.3 \mathrm{~kb}$ apart can be determined (Fig. 3A). Vector pTR-HyN2NIN contains an inactivating mutation in hygro that changed an $N c o$ I site to an $N$ si I site, and pTR-HyINN2N contains an inactivating mutation in neo that changed an NcoI site to an NsiI site (Fig. 4A); the distance between the NcoI site of hygro and the NcoI site of neo is $1.9 \mathrm{~kb}$.

Using a protocol identical to that used to measure the recombination rate between markers $1.0 \mathrm{~kb}$ apart, we generated and characterized cell clones containing one copy each of TRHyN2MIN and TR-HyINE2B. Helper constructs were used to transfect these cell clones, viruses were harvested, target cells were infected, and viral titers were determined. Viral titers generated from five different cell clones are summarized in Table 3. Because all the inactivating mutations are accompanied by restriction enzyme site alterations, the structures of the proviruses with a parental or recombinant genotype can be distinguished by Southern analyses. To characterize the molecular nature of proviruses in the hygromycin-plus-G418 resistant cells, we isolated and analyzed DNA from doubly resistant target cell clones. As illustrated in Fig. 3A, after digestion with MluI, EheI, and XhoI and hybridization with probes generated from the aforementioned 
DNA fragment, proviruses with parental genotypes are expected to have either a 1.3-kb band plus a $0.8-\mathrm{kb}$ band, or a $2.7-\mathrm{kb}$ band, whereas recombinant proviruses with two functional genes are expected to generate a $1.8-\mathrm{kb}$ and a $0.8-\mathrm{kb}$ band. A representative Southern blot is shown in Fig. 3B; the two virus-producing cell clones (1.3A4 and 1.3C2) contained the two parental proviruses, whereas the three doubly resistant target cell clones ( $\mathrm{A} 4 \mathrm{~A} 4, \mathrm{C} 2 \mathrm{C} 3$, and $\mathrm{C} 2 \mathrm{C} 5$ ) contained recombinant proviruses with two functional genes. All of the eight doubly resistant target cell clones that were analyzed contained recombinant proviruses with two functional drug-resistance genes (Fig. 3 and data not shown). These data indicate that the hygromycin-plus-G418-resistant viral titers reflect the numbers of recombinant proviruses containing two functional drug-resistance genes. Therefore, the average recombination rate of two markers $1.3 \mathrm{~kb}$ apart is $50.4 \pm 3.7 \%$ (SE, Table 3).

Using the same protocol, we established and characterized cell clones containing a copy each of TR-HyN2NIN and TR-HyINN2N proviruses. Viral titers were measured from seven of these cell clones; these data are summarized in Table 4. Similar to data generated from cell clones containing proviruses with markers 1.0 and $1.3 \mathrm{~kb}$ apart, within each cell clone, the two single-selection titers are generally comparable whereas the double drug selection titers are approximately $20 \%-25 \%$ of the single-selection titers. Doubly resistant target cell clones were isolated, and the proviral structures were analyzed. As shown in Fig. 4A, when digested with $N c o$ I and XhoI and hybridized with probes, the two parental proviruses are expected to generate a $2.7-\mathrm{kb}$ band and a $2.3-\mathrm{kb}$ band, whereas the recombinants with two functional genes are expected to generate a 1.9$\mathrm{kb}$ band. A representative Southern blot is shown in Fig. 4B; the two virus-producing 
cell clones (1.9B3 and 1.9G2) contained the two parental viruses, and the four doubly resistant target cell clones contained the recombinant proviruses (B3A1, G2A1, G2A2, and G2B1). We examined nine double drug resistant target cell clones and all of them contained recombinant proviruses with two functional drug-resistance genes (Fig. 4 and data not shown). Therefore, the average recombination rate with markers $1.9 \mathrm{~kb}$ apart is $47.4 \pm 2.2 \%$ (SE, Table 4). Therefore, HIV-1 recombination rate does not increase significantly when the marker distance is increased from $1.0 \mathrm{~kb}$ to 1.3 or $1.9 \mathrm{~kb}$ apart. Furthermore, all three rates remain similar to the $50 \%$ predicted rate on unlinked markers.

The experimental protocols used in these experiments mainly measured events that occurred during one round of HIV-1 replication. Viruses were harvested from cells $24 \mathrm{~h}$ after transfection; in order for more than one round of viral replication to occur, viral proteins have to be expressed from the transfected helper plasmids, and virions have to be generated, infect new target cells, complete the viral replication cycle, express the proviral genome, and form new viruses within $24 \mathrm{~h}$. We estimate that only a very small percentage of the events measured in the system will be derived from more than one round of replication and these infrequent events should not affect the recombination rate that we measured. To test this, we generated two cell pools, one containing TRHyN2NIN proviruses and one containing TR-HyINN2N proviruses. Equal numbers of cells from these two pools were mixed together, and transfected with helper constructs, then viruses were harvested and used to infect target cells by the same protocol described above. Because the two cell pools each contained only one parental virus, only homozygous virions should be produced; thus, recombinant proviruses with two functional drug-resistance genes should not be generated in one round of viral replication. 
However, cells containing both parental proviruses could be generated after the first round of viral infection, and recombinant proviruses could be generated at later replication cycles. We observed that the hygromycin-plus-G418 double resistant viral titer was less than $2 \%$ of the single-selection viral titers, which is in sharp contrast with the previous experiments using coinfected cell clones. This experiment demonstrated that the majority of the events measured in this system occurred in one round of viral replication.

\section{Discussion}

High rates of HIV-1 recombination and their implications. In this report, we described a series of experiments measuring HIV-1 recombination rates. We found that the recombination rate in one round of viral replication is $42.4 \%$ with markers $1 \mathrm{~kb}$ apart, which predicts that two markers separated by $1 \mathrm{~kb}$ can reassort at a frequency similar to that of unlinked markers. This observation indicates that recombination is an incredibly powerful tool to break the linkage between neighboring sequences in the viral genome, thereby generating diversity in the viral population and increasing the evolutionary capacity of HIV-1. This heightened ability to generate diversity also presents more challenges in the development of effective anti-HIV-1 treatments and vaccines. Although many anti-HIV-1 drugs have been developed in the past decades, resistance-conferring mutations in the HIV-1 genome have been observed for every FDA-approved drug. For example, mutation L10I in protease confers resistance to indinavir and lopinavir $(8,28)$, and mutation T215Y in reverse transcriptase confers resistance to AZT $(27,32)$. These two mutations are separated by approximately $1 \mathrm{~kb}$, and should segregate randomly if 
recombination occurs between a virus with L10I and a virus with T215Y. Therefore, the high rates of recombination can accelerate the generation of multi-drug-resistant HIV-1 strains. In addition, high recombination rates are also important to the generation of novel strains of HIV-1. HIV-1 isolates are classified into group $\mathrm{M}, \mathrm{N}$, and $\mathrm{O}$ based on sequence identity; the vast majority of the isolates belong to group $\mathrm{M}$, which is further divided into different subtypes (44). Recombination can occur between closely related strains $(15,34,47,56)$, between isolates from different subtypes $(4,5,10,33,43,49,55)$, or even between different HIV-1 groups $(41,51)$. Currently, many of the circulating strains of HIV-1 are intersubtype recombinants $(9,26,45,46)$. The high rates of recombination indicate that the mixing of the viral genomes from different strains can occur much faster than previously anticipated, and novel HIV-1 variants can also be generated at an accelerated pace.

Efficient formation of heterozygous HIV-1 virions. Previously, we demonstrated that the formation of the heterozygous virions is critical to SNV and MLV recombination [(21), Anderson and $\mathrm{Hu}$, unpublished data]. Here, we also show that high rates of recombination occurred when viruses were harvested from cell clones containing both parental viruses (thus allowing the formation of heterozygous viruses) but not from coinfection of two stocks of homozygous viruses. Therefore, similar to simple retroviruses, the high frequency of HIV-1 recombination also requires heterozygous virion formation.

We calculated the hypothetical recombination rate of unlinked markers with the assumptions that RNA expressed from the two parental viruses would be equal and the formation of homozygous and heterozygous virions would be random. The calculated 
hypothetical rate (50\%) is similar to our measured rate (42.4 to $50.4 \%)$. Our titer data indicate that within each cell clone, the two parental viruses were expressed at similar levels (Tables 2-4). These results validate the assumption regarding RNA expression. The observed high recombination rates in these experiments allow us to conclude that heterozygous virions must be formed efficiently during HIV-1 replication.

\section{Comparison of SNV, MLV, and HIV-1 recombination. The HIV-1}

recombination rates described in this report are approximately 6- to 9-fold higher than the MLV recombination rates (1-kb distance: $4.7 \%$ versus $42.4 \%, 1.9-\mathrm{kb}: 7.4 \%$ versus 47.4\%). Because the same target sequences were used in the measurement of HIV-1 and MLV recombination rates, the large difference in recombination rates most likely reflects the difference between MLV and HIV-1 replication. Previously, we observed that in SNV and MLV, intramolecular template switching occurred far more frequently than intermolecular template switching $(1,11,20,21,25)$. We hypothesized that although most viruses are capable of undergoing intramolecular template switching, only a subpopulation of the virions are capable of undergoing intermolecular template switching (recombination) (20). We provided two possible explanations for the limited recombination subpopulation: nonrandom copackaging of viral RNA (inefficient heterodimer formation), or altered structures of reverse transcription complex which hampered the access of both RNA copies to be used as the template during reverse transcription (20). Currently, we do not know the mechanisms that limit the intermolecular template-switching events in MLV and SNV. However, HIV-1 does not appear to have the same constraints, because we were able to measure a $42.4-50.4 \%$ recombination rate in HIV-1, similar to the $50 \%$ hypothetical recombination rate of 
unlinked markers. Therefore we can also conclude that a major portion of HIV-1 viruses are capable of undergoing intermolecular template switching (recombination) events.

As we were completing this manuscript, a report was recently published concluding that HIV-1 recombines more frequently than MLV (40). There are several differences in the systems used and the conclusions of these two studies. In our study, viruses were harvested from producer cell clones that were characterized to contain a copy of each parental provirus, whereas in the other study viruses were generated by transiently cotransfecting two vectors and helpers. Cell clones produced viruses have several advantages. First, viral RNAs were generated from proviruses, and we measured any bias in the transport and sorting of RNA expressed from proviruses integrated at different locations of the host chromosomes. Second, the homogeneity of the characterized cell clones allows assessment of the expression levels of the two proviruses, which can be used to estimate the efficiency of heterologous virions formation. Such estimation cannot be easily obtained using viruses generated from a transfected pool because the heterogeneity of such pools creates uncertainty about the numbers of doubly transfected cells and the expression levels of the vectors in each cell. Third, DNA recombination during transfection is not a complicating factor in our system. In addition, our system allows the simultaneous scoring of the two parents and the recombinants. In both systems, recombination is scored by the simultaneous presence of the two parental phenotypes, which can be complicated by double infection of the two parental viruses. We have characterized target cell clones to ensure that our measurements reflected the recombination events. 
There are differences in our conclusions as well. We have measured HIV-1

recombination rates at three marker distances; we have observed that markers $1 \mathrm{~kb}$ apart can segregate in a manner similar to unlinked markers in one round of retroviral replication, which has strong implications for HIV-1 evolution and the development of antiviral treatments and vaccines. In addition, we concluded that heterozygous virions are formed efficiently in HIV-1, and most of the HIV-1 virions are capable of carrying out recombination events.

The results from our study add to a growing body of evidence that HIV-1 recombination is an important factor in generating diversity in the viral population. Many questions about HIV-1 recombination remain to be answered, such as the mechanisms of recombination and the factors that affect recombination. However, our current understanding indicates that the rapid redistribution of mutations in the viral genomes must be taken into account when designing new treatment regimens and developing effective vaccines.

\section{ACKNOWLEDGEMENTS}

We thank Dr. Vinay K. Pathak for intellectual input, sharing unpublished reagents, and critical reading of this manuscript, Dr. Jenny Svarovskaia for assistance with experimental protocols, Dr. Inder Verma for his gift of plasmid pCMV $\Delta$ R8.2, and Anne Arthur for expert editorial help.

This work was supported by the HIV Drug Resistance Program, National Cancer Institute. 
TABLE 1. Virus titers generated by cell clones containing TR-HyIN proviruses

\begin{tabular}{cccc}
\hline \multirow{3}{*}{ Clone } & \multicolumn{3}{c}{ Titers $\left(10^{2} \mathrm{CFU} / \mathrm{ml}\right)$} \\
\cline { 2 - 4 } & Hygromycin & G418 & Hygromycin + G418 \\
\hline HN A1 & 1.4 & 1.8 & 1.2 \\
HN C1 & 2.2 & 2.8 & 2.4 \\
HN C3 & 4.1 & 5.0 & 3.6 \\
HN E2 & 3.7 & 5.2 & 2.8 \\
HN E4 & 0.3 & 0.7 & 0.4 \\
\hline
\end{tabular}


TABLE 2. Virus titers generated by cell clones containing TR-HyS2NIN and TRHyINE2B proviruses

\begin{tabular}{|c|c|c|c|c|}
\hline \multirow{2}{*}{ Clone } & \multicolumn{3}{|c|}{ Titers $\left(10^{2} \mathrm{CFU} / \mathrm{ml}\right)$} & \multirow{2}{*}{ Recombination rate $(\%)$} \\
\hline & Hygromycin & G418 & Hygromycin + G418 & \\
\hline $1.0 \mathrm{~B} 2$ & 0.9 & 1.1 & 0.2 & 44.4 \\
\hline $1.0 \mathrm{C} 2$ & 1.4 & 1.8 & 0.3 & 42.8 \\
\hline $1.0 \mathrm{C} 3$ & 1.4 & 2.5 & 0.3 & 42.8 \\
\hline $1.0 \mathrm{C} 4$ & 11.4 & 11.2 & 2.6 & 46.4 \\
\hline $1.0 \mathrm{D} 1$ & 7.7 & 6.7 & 1.2 & 35.8 \\
\hline $\operatorname{Avg} \pm \mathrm{SE}$ & & & & $42.4 \pm 1.8$ \\
\hline
\end{tabular}


TABLE 3. Virus titers generated by cell clones containing TR-HyN2MIN and TRHyINE2B proviruses

\begin{tabular}{ccccc}
\hline \multirow{2}{*}{ Clone } & \multicolumn{3}{c}{ Titers $\left(10^{2} \mathrm{CFU} / \mathrm{ml}\right)$} & Recombination rate $(\%)$ \\
\cline { 2 - 4 } & Hygromycin & $\mathrm{G} 418$ & Hygromycin $+\mathrm{G} 418$ & \\
$1.3 \mathrm{~A} 1$ & 9.5 & 8.3 & 2.2 & 53.0 \\
$1.3 \mathrm{~A} 4$ & 13.7 & 13.6 & 3.0 & 44.1 \\
$1.3 \mathrm{C} 2$ & 9.1 & 10.3 & 2.2 & 48.4 \\
$1.3 \mathrm{E} 3$ & 4.4 & 8.5 & 1.4 & 63.6 \\
$1.3 \mathrm{~F} 4$ & 9.7 & 8.8 & 1.9 & 53.1 \\
$\mathrm{Avg} \pm \mathrm{SE}$ & & & & $50.4 \pm 3.7$ \\
\hline
\end{tabular}


TABLE 4. Virus titers generated by cell clones containing TR-HyN2NIN and TRHyINN2N proviruses

\begin{tabular}{ccccc}
\hline \multirow{2}{*}{ Clone } & \multicolumn{3}{c}{ Titers $\left(10^{2} \mathrm{CFU} / \mathrm{ml}\right)$} & \multirow{2}{*}{ Recombination rate (\%) } \\
\cline { 2 - 4 } & Hygromycin & $\mathrm{G} 418$ & Hygromycin $+\mathrm{G} 418$ & \\
\hline $1.9 \mathrm{~B} 1$ & 2.5 & 3.1 & 0.51 & 40.8 \\
$1.9 \mathrm{~B} 3$ & 3.9 & 4.1 & 1.1 & 56.4 \\
$1.9 \mathrm{~B} 4$ & 7.5 & 8.2 & 2.0 & 53.3 \\
$1.9 \mathrm{C} 2$ & 9.5 & 6.7 & 1.6 & 47.8 \\
$1.9 \mathrm{D} 1$ & 10.7 & 11.5 & 2.4 & 44.9 \\
$1.9 \mathrm{G} 2$ & 11.3 & 9.3 & 1.9 & 40.9 \\
$1.9 \mathrm{I} 2$ & 11.7 & 15.2 & 2.8 & 47.9 \\
Avg $\pm \mathrm{SE}$ & & & & $47.4 \pm 2.2$ \\
\hline
\end{tabular}




\section{FIGURE LEGENDS}

FIG. 1. Viral vectors and protocol used to measure HIV-1 recombination rates with markers $1 \mathrm{~kb}$ apart. (A) General structures of the vectors. pro, CMV promoter; hygro, hygromycin phosphotransferase B gene; IR, internal ribosomal entry site; neo, neomycin phosphotransferase gene; asterisk, inactivating frameshift mutation. N, NgoMIV; B, BssHII; S and E with slash, destroyed SacII and EheI sites, respectively. (B) Protocol used to measure recombination rates.

FIG. 2. Characterization of the proviral structures by Southern analyses. (A) Partial restriction enzyme maps of parental and recombinant proviruses. A 1.0-kb DNA fragment (probe) was used for the random-priming reaction to generate a probe for Southern hybridization analysis. E, EheI. (B) A representative Southern analysis of virus-producing cells and the doubly resistant cell clones. $1.0 \mathrm{~B} 2,1.0 \mathrm{C} 3$, and $1.0 \mathrm{C} 4$ were doubly infected cell clones used to produce virus to measure recombination rates. B2B1, B2B2, and B2C1 were hygromycin-plus-G418-resistant target cell clones infected by viruses harvested from 1.0B2; $\mathrm{C} 3 \mathrm{~A} 1$ and $\mathrm{C} 4 \mathrm{~B} 1$ were doubly resistant target cell clones infected by viruses harvested from $1.0 \mathrm{C} 3$ and $1.0 \mathrm{C} 4$, respectively. Molecular size markers are indicated on the right of the Southern blot. All abbreviations are the same as in Fig. 1.

FIG. 3. Southern analyses of the doubly resistant cell clones from the $1.3-\mathrm{kb}$ marker distance study. (A) Partial restriction enzyme maps of proviruses. M, MluI; X, XhoI. (B) A representative Southern analysis of virus-producing cells and the doubly 
resistant target cell clones. $1.3 \mathrm{~A} 4$ and $1.3 \mathrm{C} 2$ were doubly infected cell clones used to produce virus to measure recombination rates. $\mathrm{A} 4 \mathrm{~A} 4, \mathrm{C} 2 \mathrm{C} 3$, and $\mathrm{C} 2 \mathrm{C} 5$ were hygromycin-plus-G418-resistant target cell clones infected by viruses harvested from $1.3 \mathrm{~A} 4$ and $1.3 \mathrm{C} 2$. Molecular size markers are indicated on the left of the Southern blot. Other abbreviations are the same as Fig. 1 and 2.

FIG. 4. Southern analyses of the doubly resistant cell clones from the $1.9-\mathrm{kb}$ marker distance study. (A) Partial restriction enzyme maps of proviruses. Ns, NsiI; Nc, $N c o I$; Nc with slash, destroyed NcoI. (B) A representative Southern analysis of virusproducing cells and the doubly resistant target cell clones. $1.9 \mathrm{~B} 3$ and $1.9 \mathrm{G} 2$ were doubly infected cell clones used to produce virus to measure recombination rates. B3A1, G2A1, G2A2, and G2B1 were hygromycin-plus-G418-resistant cell clones infected by viruses harvested from 1.9B3 and 1.9G2. Molecular size markers are indicated on the left of the Southern blot. All abbreviations are the same as in Fig. 1, 2, and 4. 
A.

pTR-HyIN
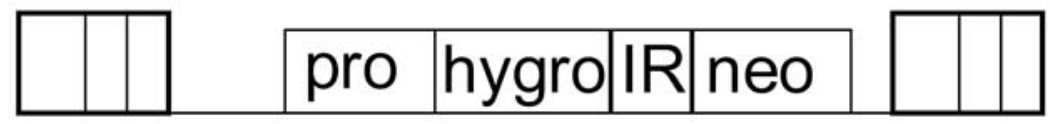

pTR-HyS2NIN

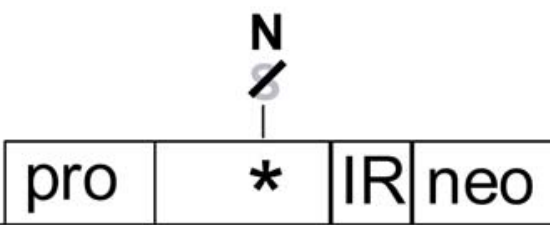

pTR-HyINE2B

$-1 \mathrm{~kb} \dashv \mathrm{B}$

pro hygro|IR *

B.

helper constructs

$\downarrow$ transfect

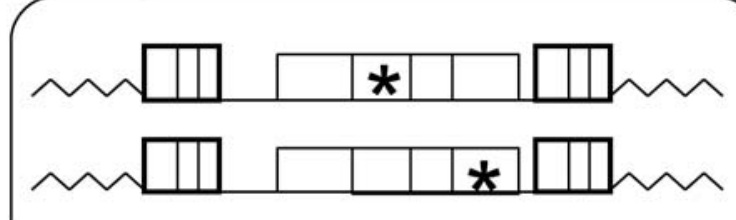

cell

clone

$\downarrow$ harvest virus

$\downarrow$ infect target cells

Selection

hygromycin

$\downarrow$

virus titer

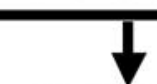

G418 hygromycin + G418

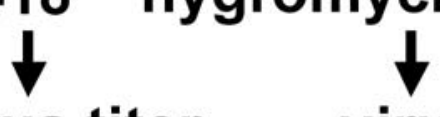

virus titer virus titer

Fig. 1. 
A. Parental proviruses

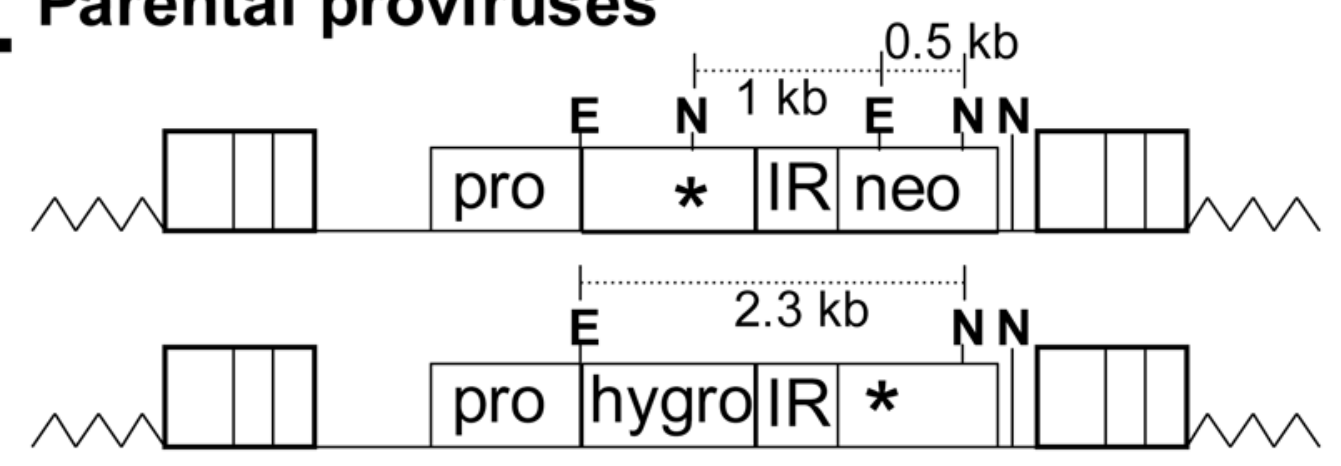

Recombinant provirus

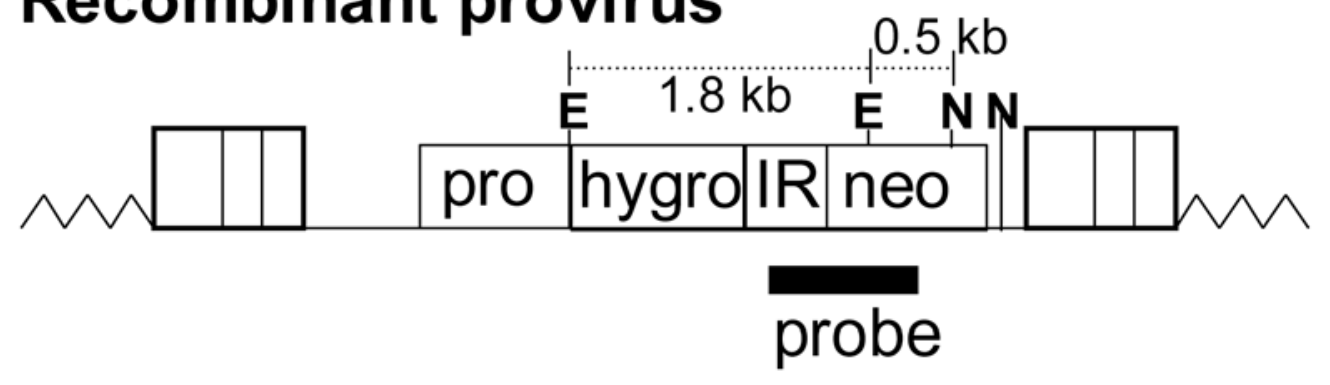

B.

1.0B2

$1.0 \mathrm{C} 3$

$1.0 \mathrm{C} 4$

B2B1 B2B2 B2C1

C3A1

C4B1
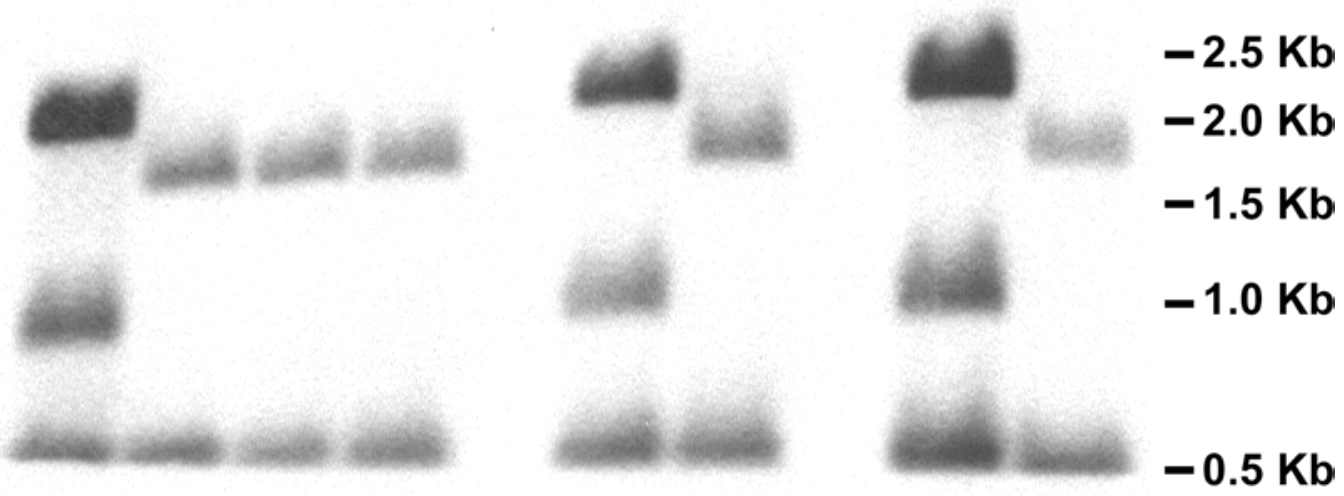

Fig. 2. 
A.

\section{Parental proviruses}
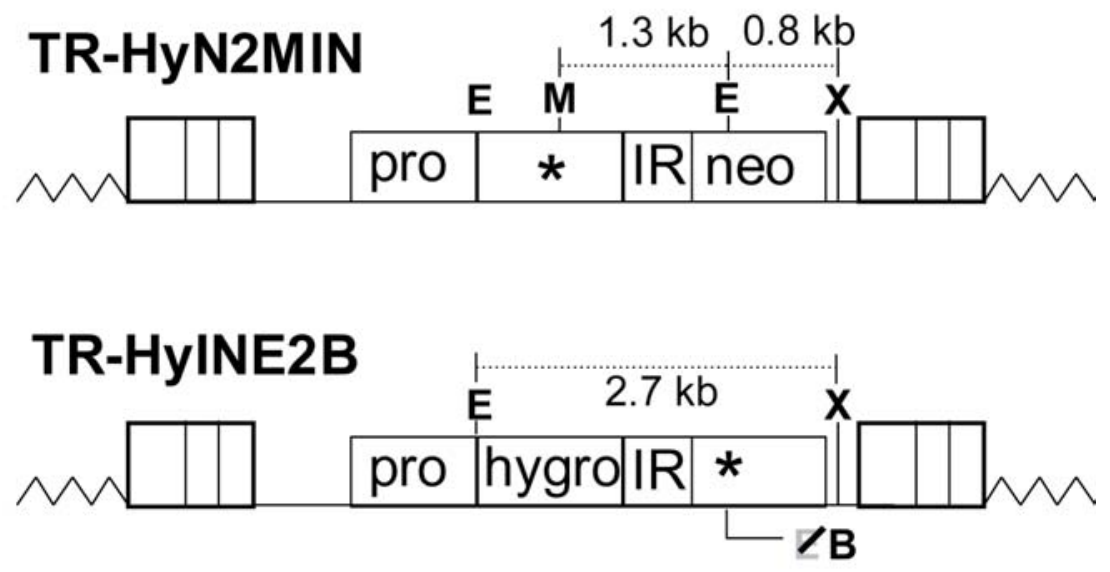

Recombinant provirus $\quad 0.8 \mathrm{~kb}$

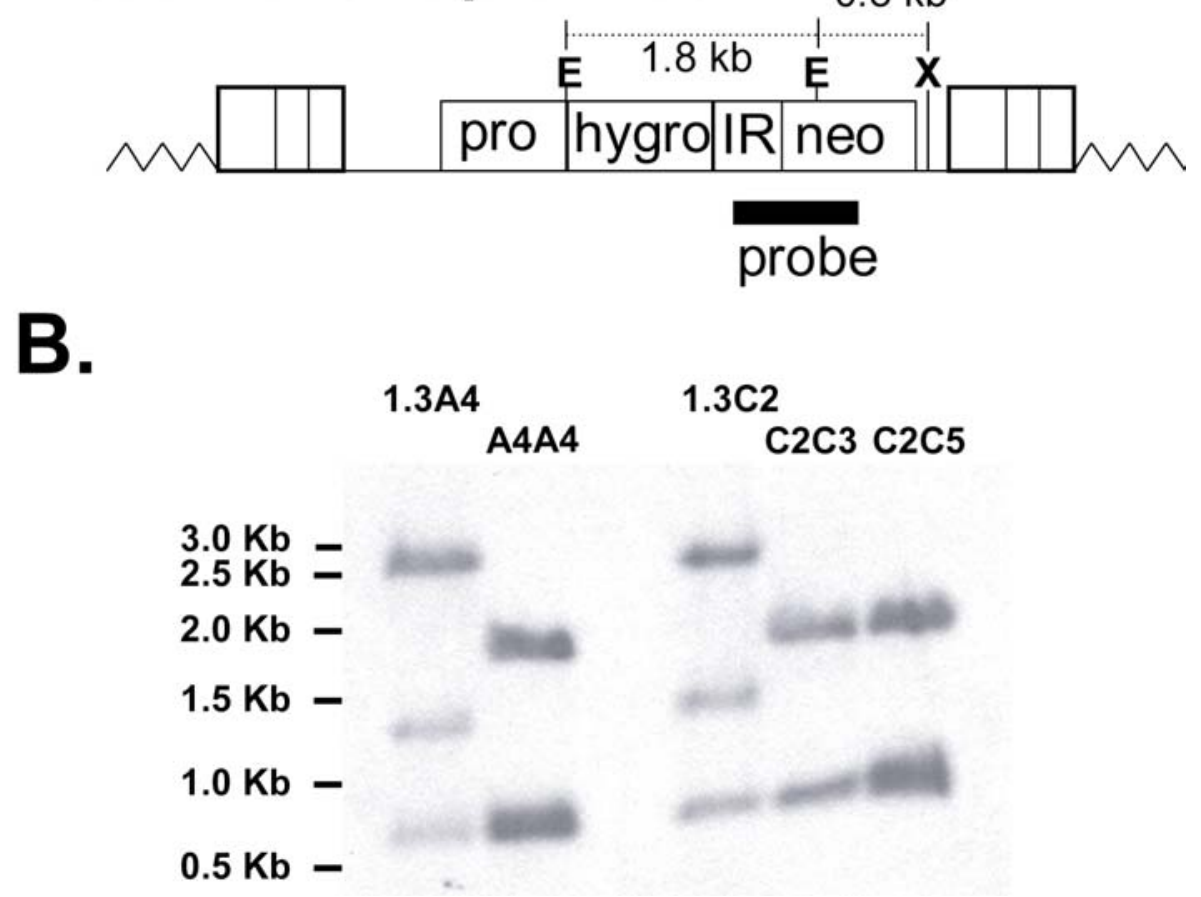

Fig. 3. 
A.

\section{Parental proviruses}

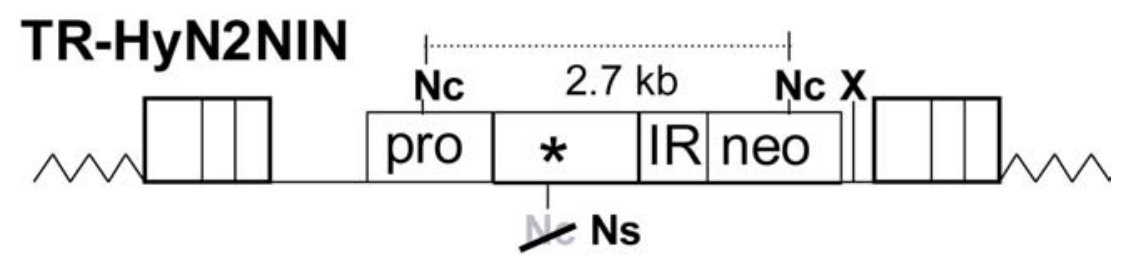

TR-HyINN2N

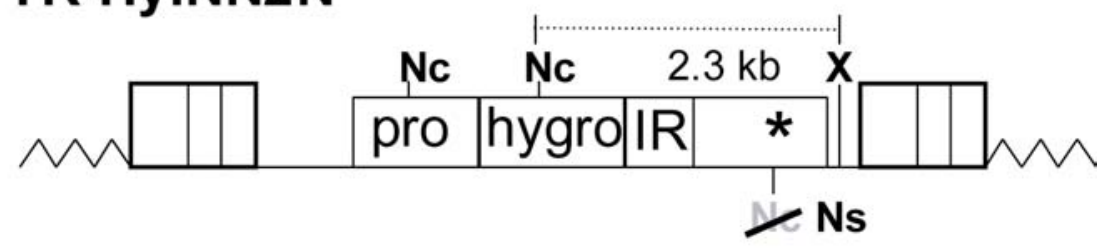

Recombinant provirus

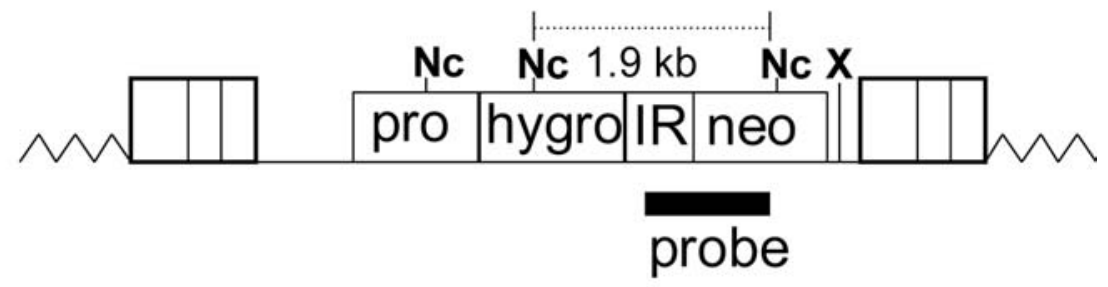

B.

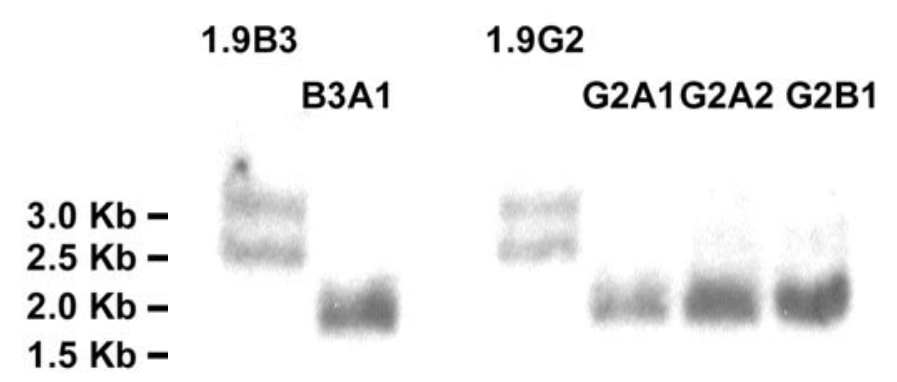

Fig. 4. 


\section{REFERENCES}

1. Anderson, J. A., E. H. Bowman, and W. S. Hu. 1998. Retroviral recombination rates do not increase linearly with marker distance and are limited by the size of the recombining subpopulation. J Virol 72:1195-202.

2. Anderson, J. A., V. K. Pathak, and W. S. Hu. 2000. Effect of the murine leukemia virus extended packaging signal on the rates and locations of retroviral recombination. J Virol 74:6953-63.

3. Balakrishnan, M., B. P. Roques, P. J. Fay, and R. A. Bambara. 2003. Template dimerization promotes an acceptor invasion-induced transfer mechanism during human immunodeficiency virus type 1 minus-strand synthesis. J Virol 77:4710-21.

4. Bobkov, A., E. Kazennova, L. Selimova, M. Bobkova, T. Khanina, N. Ladnaya, A. Kravchenko, V. Pokrovsky, R. Cheingsong-Popov, and J. Weber. 1998. A sudden epidemic of HIV type 1 among injecting drug users in the former Soviet Union: identification of subtype A, subtype B, and novel gagA/envB recombinants. AIDS Res Hum Retroviruses 14:669-76.

5. Bredell, H., G. Hunt, A. Casteling, T. Cilliers, C. Rademeyer, M. Coetzer, S. Miller, D. Johnson, C. T. Tiemessen, D. J. Martin, C. Williamson, and L. Morris. 2002. HIV-1 Subtype A, D, G, AG and unclassified sequences identified in South Africa. AIDS Res Hum Retroviruses 18:681-3.

6. Clavel, F., M. D. Hoggan, R. L. Willey, K. Strebel, M. A. Martin, and R. Repaske. 1989. Genetic recombination of human immunodeficiency virus. J Virol 63:1455-9. 
7. Coffin, J. M. 1979. Structure, replication, and recombination of retrovirus genomes: some unifying hypotheses. J Gen Virol 42:1-26.

8. Condra, J. H., D. J. Holder, W. A. Schleif, O. M. Blahy, R. M. Danovich, L. J. Gabryelski, D. J. Graham, D. Laird, J. C. Quintero, A. Rhodes, H. L. Robbins, E. Roth, M. Shivaprakash, T. Yang, J. A. Chodakewitz, P. J. Deutsch, R. Y. Leavitt, F. E. Massari, J. W. Mellors, K. E. Squires, R. T. Steigbigel, H. Teppler, and E. A. Emini. 1996. Genetic correlates of in vivo viral resistance to indinavir, a human immunodeficiency virus type 1 protease inhibitor. J Virol 70:8270-6.

9. Cornelissen, M., G. Kampinga, F. Zorgdrager, and J. Goudsmit. 1996. Human immunodeficiency virus type 1 subtypes defined by env show high frequency of recombinant gag genes. The UNAIDS Network for HIV Isolation and Characterization. J Virol 70:8209-12.

10. Cornelissen, M., R. van Den Burg, F. Zorgdrager, and J. Goudsmit. 2000. Spread of distinct human immunodeficiency virus type 1 AG recombinant lineages in Africa. J Gen Virol 81:515-23.

11. Delviks, K. A., W. S. Hu, and V. K. Pathak. 1997. Psi- vectors: murine leukemia virus-based self-inactivating and self-activating retroviral vectors. $\mathrm{J}$ Virol 71:6218-24.

12. DeStefano, J. J. 1994. Kinetic analysis of the catalysis of strand transfer from internal regions of heteropolymeric RNA templates by human immunodeficiency virus reverse transcriptase. J Mol Biol 243:558-67. 
13. DeStefano, J. J., L. M. Mallaber, L. Rodriguez-Rodriguez, P. J. Fay, and R. A. Bambara. 1992. Requirements for strand transfer between internal regions of heteropolymer templates by human immunodeficiency virus reverse transcriptase. J Virol 66:6370-8.

14. DeStefano, J. J., B. Roberts, and D. Shriner. 1997. The mechanism of retroviral recombination: the role of sequences proximal to the point of strand transfer. Arch Virol 142:1797-812.

15. Diaz, R. S., E. C. Sabino, A. Mayer, J. W. Mosley, and M. P. Busch. 1995. Dual human immunodeficiency virus type 1 infection and recombination in a dually exposed transfusion recipient. The Transfusion Safety Study Group. J Virol 69:3273-81.

16. Duesberg, P. H. 1968. Physical properties of Rous Sarcoma Virus RNA. Proc Natl Acad Sci U S A 60:1511-8.

17. Feinberg, A. P., and B. Vogelstein. 1983. A technique for radiolabeling DNA restriction endonuclease fragments to high specific activity. Anal Biochem 132:613.

18. Gao, F., D. L. Robertson, S. G. Morrison, H. Hui, S. Craig, J. Decker, P. N. Fultz, M. Girard, G. M. Shaw, B. H. Hahn, and P. M. Sharp. 1996. The heterosexual human immunodeficiency virus type 1 epidemic in Thailand is caused by an intersubtype (A/E) recombinant of African origin. J Virol 70:701329. 
19. Gritz, L., and J. Davies. 1983. Plasmid-encoded hygromycin B resistance: the sequence of hygromycin B phosphotransferase gene and its expression in Escherichia coli and Saccharomyces cerevisiae. Gene 25:179-88.

20. Hu, W. S., E. H. Bowman, K. A. Delviks, and V. K. Pathak. 1997. Homologous recombination occurs in a distinct retroviral subpopulation and exhibits high negative interference. J Virol 71:6028-36.

21. Hu, W. S., and H. M. Temin. 1990. Genetic consequences of packaging two RNA genomes in one retroviral particle: pseudodiploidy and high rate of genetic recombination. Proc Natl Acad Sci U S A 87:1556-60.

22. Iglesias-Sanchez, M. J., and C. Lopez-Galindez. 2002. Analysis, quantification, and evolutionary consequences of HIV-1 in vitro recombination. Virology 304:392-402.

23. Jetzt, A. E., H. Yu, G. J. Klarmann, Y. Ron, B. D. Preston, and J. P. Dougherty. 2000. High rate of recombination throughout the human immunodeficiency virus type 1 genome. J Virol 74:1234-40.

24. Jorgensen, R. A., S. J. Rothstein, and W. S. Reznikoff. 1979. A restriction enzyme cleavage map of Tn5 and location of a region encoding neomycin resistance. Mol Gen Genet 177:65-72.

25. Julias, J. G., D. Hash, and V. K. Pathak. 1995. E- vectors: development of novel self-inactivating and self-activating retroviral vectors for safer gene therapy. J Virol 69:6839-46.

26. Kampinga, G. A., A. Simonon, P. Van de Perre, E. Karita, P. Msellati, and J. Goudsmit. 1997. Primary infections with HIV-1 of women and their offspring in 
Rwanda: findings of heterogeneity at seroconversion, coinfection, and recombinants of HIV-1 subtypes A and C. Virology 227:63-76.

27. Kellam, P., C. A. Boucher, and B. A. Larder. 1992. Fifth mutation in human immunodeficiency virus type 1 reverse transcriptase contributes to the development of high-level resistance to zidovudine. Proc Natl Acad Sci U S A 89:1934-8.

28. Kempf, D. J., J. D. Isaacson, M. S. King, S. C. Brun, Y. Xu, K. Real, B. M. Bernstein, A. J. Japour, E. Sun, and R. A. Rode. 2001. Identification of genotypic changes in human immunodeficiency virus protease that correlate with reduced susceptibility to the protease inhibitor lopinavir among viral isolates from protease inhibitor-experienced patients. J Virol 75:7462-9.

29. Kung, H. J., J. M. Bailey, N. Davidson, M. O. Nicolson, and R. M. McAllister. 1975. Structure, subunit composition, and molecular weight of RD-114 RNA. J Virol 16:397-411.

30. Kuwata, T., Y. Miyazaki, T. Igarashi, J. Takehisa, and M. Hayami. 1997. The rapid spread of recombinants during a natural in vitro infection with two human immunodeficiency virus type 1 strains. J Virol 71:7088-91.

31. Landau, N. R., K. A. Page, and D. R. Littman. 1991. Pseudotyping with human T-cell leukemia virus type I broadens the human immunodeficiency virus host range. J Virol 65:162-9.

32. Larder, B. A., K. E. Coates, and S. D. Kemp. 1991. Zidovudine-resistant human immunodeficiency virus selected by passage in cell culture. J Virol 65:5232-6. 
33. Leitner, T., D. Escanilla, S. Marquina, J. Wahlberg, C. Brostrom, H. B. Hansson, M. Uhlen, and J. Albert. 1995. Biological and molecular characterization of subtype $\mathrm{D}, \mathrm{G}$, and $\mathrm{A} / \mathrm{D}$ recombinant $\mathrm{HIV}-1$ transmissions in Sweden. Virology 209:136-46.

34. Liu, S. L., J. E. Mittler, D. C. Nickle, T. M. Mulvania, D. Shriner, A. G. Rodrigo, B. Kosloff, X. He, L. Corey, and J. I. Mullins. 2002. Selection for human immunodeficiency virus type 1 recombinants in a patient with rapid progression to AIDS. J Virol 76:10674-84.

35. McCutchan, F. E., P. A. Hegerich, T. P. Brennan, P. Phanuphak, P. Singharaj, A. Jugsudee, P. W. Berman, A. M. Gray, A. K. Fowler, and D. S. Burke. 1992. Genetic variants of HIV-1 in Thailand. AIDS Res Hum Retroviruses 8: 1887-95.

36. Naldini, L., U. Blomer, F. H. Gage, D. Trono, and I. M. Verma. 1996. Efficient transfer, integration, and sustained long-term expression of the transgene in adult rat brains injected with a lentiviral vector. Proc Natl Acad Sci U S A 93:11382-8.

37. Naldini, L., U. Blomer, P. Gallay, D. Ory, R. Mulligan, F. H. Gage, I. M. Verma, and D. Trono. 1996. In vivo gene delivery and stable transduction of nondividing cells by a lentiviral vector. Science 272:263-7.

38. Negroni, M., and H. Buc. 2001. Mechanisms of retroviral recombination. Annu Rev Genet 35:275-302.

39. Negroni, M., and H. Buc. 1999. Recombination during reverse transcription: an evaluation of the role of the nucleocapsid protein. J Mol Biol 286:15-31. 
40. Onafuwa, A., W. An, N. D. Robson, and A. Telesnitsky. 2003. Human Immunodeficiency Virus Type 1 Genetic Recombination Is More Frequent Than That of Moloney Murine Leukemia Virus despite Similar Template Switching Rates. J Virol 77:4577-87.

41. Peeters, M., F. Liegeois, N. Torimiro, A. Bourgeois, E. Mpoudi, L. Vergne, E. Saman, E. Delaporte, and S. Saragosti. 1999. Characterization of a highly replicative intergroup $\mathrm{M} / \mathrm{O}$ human immunodeficiency virus type 1 recombinant isolated from a Cameroonian patient. J Virol 73:7368-75.

42. Quinones-Mateu, M. E., Y. Gao, S. C. Ball, A. J. Marozsan, A. Abraha, and E. J. Arts. 2002. In vitro intersubtype recombinants of human immunodeficiency virus type 1: comparison to recent and circulating in vivo recombinant forms. $\mathrm{J}$ Virol 76:9600-13.

43. Ramos, A., A. Tanuri, M. Schechter, M. A. Rayfield, D. J. Hu, M. C. Cabral, C. I. Bandea, J. Baggs, and D. Pieniazek. 1999. Dual and recombinant infections: an integral part of the HIV-1 epidemic in Brazil. Emerg Infect Dis 5:65-74.

44. Robertson, D. L., J. P. Anderson, J. A. Bradac, J. K. Carr, B. Foley, R. K. Funkhouser, F. Gao, B. H. Hahn, M. L. Kalish, C. Kuiken, G. H. Learn, T. Leitner, F. McCutchan, S. Osmanov, M. Peeters, D. Pieniazek, M. Salminen, P. M. Sharp, S. Wolinsky, and B. Korber. 2000. HIV-1 nomenclature proposal. Science 288:55-6.

45. Robertson, D. L., P. M. Sharp, F. E. McCutchan, and B. H. Hahn. 1995. Recombination in HIV-1. Nature 374:124-6. 
46. Rodenburg, C. M., Y. Li, S. A. Trask, Y. Chen, J. Decker, D. L. Robertson, M. L. Kalish, G. M. Shaw, S. Allen, B. H. Hahn, and F. Gao. 2001. Near fulllength clones and reference sequences for subtype $\mathrm{C}$ isolates of HIV type 1 from three different continents. AIDS Res Hum Retroviruses 17:161-8.

47. Saksena, N. K., B. Wang, Y. C. Ge, S. H. Xiang, D. E. Dwyer, and A. L. Cunningham. 1997. Coinfection and genetic recombination between HIV-1 strains: possible biological implications in Australia and South East Asia. Ann Acad Med Singapore 26:121-7.

48. Sambrook, J., E. F. Fritsch, and T. Maniatis. 1989. Molecular cloning: a laboratory manual, 2nd ed. Cold Spring Harbor Laboratory Press, Cold Spring Harbor, N.Y.

49. Snoeck, J., S. Van Dooren, K. Van Laethem, I. Derdelinckx, E. Van Wijngaerden, E. De Clercq, and A. M. Vandamme. 2002. Prevalence and origin of HIV-1 group M subtypes among patients attending a Belgian hospital in 1999. Virus Res 85:95-107.

50. St. Louis, D. C., D. Gotte, E. Sanders-Buell, D. W. Ritchey, M. O. Salminen, J. K. Carr, and F. E. McCutchan. 1998. Infectious molecular clones with the nonhomologous dimer initiation sequences found in different subtypes of human immunodeficiency virus type 1 can recombine and initiate a spreading infection in vitro. J Virol 72:3991-8.

51. Takehisa, J., L. Zekeng, E. Ido, Y. Yamaguchi-Kabata, I. Mboudjeka, Y. Harada, T. Miura, L. Kaptu, and M. Hayami. 1999. Human immunodeficiency virus type 1 intergroup (M/O) recombination in cameroon. J Virol 73:6810-20. 
52. Temin, H. M. 1991. Sex and recombination in retroviruses. Trends Genet 7:71-4.

53. Weiss, R. A., W. S. Mason, and P. K. Vogt. 1973. Genetic recombinants and heterozygotes derived from endogenous and exogenous avian RNA tumor viruses. Virology 52:535-52.

54. Yee, J. K., A. Miyanohara, P. LaPorte, K. Bouic, J. C. Burns, and T. Friedmann. 1994. A general method for the generation of high-titer, pantropic retroviral vectors: highly efficient infection of primary hepatocytes. Proc Natl Acad Sci U S A 91:9564-8.

55. Yirrell, D. L., P. Kaleebu, D. Morgan, C. Watera, B. Magambo, F. Lyagoba, and J. Whitworth. 2002. Inter- and intra-genic intersubtype HIV-1 recombination in rural and semi-urban Uganda. Aids 16:279-86.

56. Zhu, T., N. Wang, A. Carr, S. Wolinsky, and D. D. Ho. 1995. Evidence for coinfection by multiple strains of human immunodeficiency virus type 1 subtype B in an acute seroconvertor. J Virol 69:1324-7.

57. Zhuang, J., A. E. Jetzt, G. Sun, H. Yu, G. Klarmann, Y. Ron, B. D. Preston, and J. P. Dougherty. 2002. Human immunodeficiency virus type 1 recombination: rate, fidelity, and putative hot spots. J Virol 76:11273-82. 


\section{CHAPTER 4}

Genetic Recombination of Human Immunodeficiency Virus Type I in One Round of Viral Replication: The Effects of Genetic Distances, Target Cells, Accessory Genes, and Lack of Interference.

Terence D. Rhodes, ${ }^{1,2}$ Olga Nikolaitchik, ${ }^{1}$ Jianbo Chen, ${ }^{1}$ and Wei-Shau Hu ${ }^{1 *}$

HIV Drug Resistance Program, National Cancer Institute at Frederick, Frederick, Maryland

21702, ${ }^{1}$ and Department of Microbiology, Immunology, and Cell Biology, West Virginia University, Morgantown, West Virginia $26505^{2}$

This manuscript has recently been submitted for publication in the Journal of Virology 


\begin{abstract}
Recombination is a major mechanism that generates variation in populations of the human immunodeficiency virus type 1 (HIV-1). Mutations that confer replication advantages, such as drug resistance, often cluster within regions of the HIV-1 genome. To explore how efficiently HIV-1 can assort markers separated by short distances, we developed a flowcytometry-based system to study recombination. Two HIV-1-based vectors were generated, one encoding the mouse heat-stable antigen gene and green fluorescent protein gene $(G F P)$, and the other encoding the mouse Thy-1 gene and GFP. We generated derivatives of both vectors that contained nonfunctional GFP inactivated by different mutations. Recombination in the region between the two inactivating mutations during reverse transcription could yield a functional $G F P$. Using this system, we determined that the recombination rates of markers separated by $588,300,288$, and $103 \mathrm{bp}$ in one round of viral replication are $56,38,31$, and $12 \%$, respectively, of the theoretical maximum measurable recombination rate. Statistical analyses revealed that at these intervals, recombination rates and marker distances have a near-linear relationship that is part of an overall quadratic fit. Additionally, we examined the segregation of three markers within $600 \mathrm{bp}$ and concluded that HIV-1 recombination does not exhibit high negative interference. We also examined the effects of target cells and viral accessory proteins on recombination rate. Similar recombination rates were observed when human primary $\mathrm{CD} 4^{+} \mathrm{T}$ cells and a human $\mathrm{T}$ cell line were used as target cells. We also found equivalent recombination rates in the presence or absence of accessory genes vif, vpr, vpu, and nef. These results illustrate the power of recombination in generating viral population variation and predict the rapid assortment of mutations in the HIV-1 genome in infected individuals.
\end{abstract}




\section{INTRODUCTION}

Genetic recombination plays an important role in the evolution of human immunodeficiency virus type 1 (HIV-1) (34). Recombination shuffles viral genomes and redistributes the mutations generated from reverse transcription, leading to increased variation within the infected host and, ultimately, the viral populations distributed throughout the world (34). Of the more than 70,000 sequences that are catalogued in the HIV sequence database at the Los Alamos National Laboratory (http://www.hiv.lanl.gov), approximately $8 \%(>5,500)$ are classified as recombinants. Furthermore, recombinant strains of HIV-1 have been observed worldwide $(13,16,25,27,37,45)$. The inherent ability for HIV-1 to recombine poses a constant problem for effective anti-HIV-1 treatment because multidrug resistant variants can be generated by recombining the genome of singly or weakly resistant viruses. The increased variation caused by recombination also hinders the development of effective vaccines: the induced host immune response has to combat not only the variants generated by the rapidly changing virus genome but also all the different subtypes of HIV-1. Therefore, rapid recombination of the HIV-1 genome creates a vast advantage for the evolution of the virus and an enormous difficulty for the host.

The ability of HIV-1 to carry out frequent recombination is the result of a unique feature of the retrovirus family: retroviruses package two copies of viral RNA into each virion $(15,22)$. During reverse transcription, reverse transcriptase (RT) can use portions of the genomes from each RNA as templates to generate a recombinant viral DNA $(7,18)$. Although recombination can occur in all virions, a genetically different progeny can only be generated from virions with two different RNAs (heterozygous virions), not from virions with two identical RNAs (homozygous virions) (17). Heterozygous virions are only generated from cells infected with more than one retrovirus (double infection) (17). We have previously demonstrated that double 
infection occurs frequently in HIV-1 infection of cultured T cells and primary T cells (8), providing the basis for the generation of heterozygous virions that allows the observed frequent recombination.

Frequent HIV-1 recombination has been evident from studies using different approaches. Studies of individuals infected with more than one genetically distinct HIV-1 revealed that these patients often also harbor hybrid viruses in their viral populations $(13,16,25,27,37,45)$. Intersubtype recombinants that cause epidemics in certain geographical areas have multiple break-off points along the genome (34). Additionally, some circulating forms of recombinants have mosaic genomes that were derived from five or more genetically distinct HIV-1 variants, emphasizing the common occurrence of double infection and frequent recombination (42). In addition to the viral populations in infected individuals, recombination events have also been observed in experimental systems. It has been demonstrated that recombination can occur using purified RT and nucleic acid templates $(5,10-12,29)$; these studies have also yielded interesting data on different aspects of recombination, such as the effects of the viral nucleocapsid protein $(9,29,32,35,36)$ and the templates $(5,11,12,32,35,36)$. Using cell-culture-based systems, it has been demonstrated that HIV-1 recombination is frequent and occurs throughout the viral genome with potential localized hot spots $(6,19,21,23,24,46)$. Comparisons between HIV-1 and the simple retrovirus murine leukemia virus (MLV) revealed that HIV-1 recombines more frequently than $\operatorname{MLV}(30,33)$.

In a previous study, we measured HIV-1 recombination rates for three genetic distances $(1.9,1.3$, and $1.0 \mathrm{~kb})(33)$. We observed that HIV-1 recombines at exceedingly high rates, because sequences separated by $1.3 \mathrm{~kb}$ segregated as unlinked alleles in a single round of viral replication. These results also led to questions that could not be easily addressed using the same 
system such as the relationship between recombination rate and marker distances shorter than 1.0 $\mathrm{kb}$. Many of the mutations that cause drug resistance or immune evasion are clustered within 1.0 $\mathrm{kb}$ of the viral genome $(20,40)$. Therefore, it is important to measure how frequently these mutations can be assorted. Furthermore, because drug selection was used in the previous system to measure recombination, we could not easily adapt this strategy to measure recombination in cells that grow in suspension, such as T cells, which are natural target cells for HIV-1.

In this report, we describe the development of a new experimental system that can measure recombination rates when markers are separated by short distances ( $0.6 \mathrm{~kb}$ or less). Furthermore, since this system is based on the detection of green fluorescent protein (GFP) and cell surface proteins that can be labeled with fluorescence antibodies, we can measure the recombination rates in cultured $\mathrm{T}$ cells and primary cells. Using this new system, we have measured the recombination rates at four genetic distances. In addition, we measured the frequency of double recombination to test whether HIV-1 recombination exhibits interference.

\section{MATERIALS AND METHODS}

Nomenclature and plasmid construction. Plasmids were constructed using standard molecular cloning techniques (38). The names of all plasmids used in this study begin with "p", but the names of the viruses derived from these plasmids do not. Plasmid pHIV-HSA-IRESGFP (a kind gift from Derya Unutmaz, Vanderbilt University) is a pNL4-3-based construct that encodes gag, pol, tat, and rev but contains inactivating mutations in vif, vpu, vpr, and env. Additionally, this plasmid has an insertion in the nef reading frame that contains a mouse heatstable antigen gene (HSA) followed by an internal ribosomal entry site (IRES) from encephalomyocarditis virus and the green fluorescent protein gene (GFP). 
Plasmid pON-fHIG is identical to pHIV-HSA-IRES-GFP, except that an NcoI site in the plasmid backbone was eliminated by partial $N c o$ I digestion and fill-in reaction with the Klenow fragment of Escherihia coli DNA polymerase I. Plasmid pON-fTIG was identical to pONfHIG, except that HSA was replaced with the mouse CD90.2 gene, also known as Thy-1. Thy-1 was PCR amplified from pSRalphaLthy (31) (a kind gift from Irvin S.Y. Chen, University of California at Los Angeles) with primers containing SacII and XhoI sites. The PCR product was digested with SacII-plus-XhoI and the resulting DNA fragment was inserted into SacII plus XhoI digested HDV-eGFP (41) to generate pHIV-Thy1. Thy-1 was amplified by PCR from pHIVThy1; the PCR products were digested with NotI plus EcoRI, and inserted into NotI-plus-EcoRIdigested pON-fHIG to generate pfTIG-SL-delta. The sequence between env and the 5' end of Thy-1 in pfTIG-SL-delta was replaced with the sequence from pHIV-Thy1 by substituting the BamHI-BstEII DNA fragment to generate pON-fTIG.

HIV-1 vectors with mutated GFP were constructed by generating PCR products of mutated GFP, then subcloning the PCR DNA fragment into pON-fHIG or pON-fTIG. Mutated GFP was generated by single-round or overlapping PCR using pON-fHIG as the template. The PCR product containing the mutated GFP was digested with $N c o$ I plus $X h o \mathrm{I}$ and cloned into NcoI-plus-XhoI-digested pON-fHIG or pON-fTIG . The names of these plasmids contain a letter indicating the encoded functional marker ( $\mathrm{H}$ for HSA and $\mathrm{T}$ for Thy-1) and a number indicating the position of the mutation in GFP from the translational start codon. Plasmid pON-H0, H5, and $\mathrm{H} 6$ contained mutations 15, 500, 603 bp downstream from the translation start codon, whereas T3 and T6 contained mutations 303 and 603 bp downstream from the GFP start codon, respectively. 
Helper plasmid pCMV-dGag was derived from pCMV $\Delta 8.2$ (28) in two steps: first, a 4-bp frameshift mutation was introduced into the SpeI site in gag to generate pCMV-Spe*. A second mutation in gag, an in-frame stop codon, was introduced 37 bp downstream of the gag AUG by site-directed mutagenesis to generate pCMV-dGag.

All constructs were characterized by restriction digestion and the PCR-amplified regions were verified by DNA sequencing to avoid inadvertent mutations. The phenotypes of the constructs were characterized by flow cytometry analyses of cells transfected with these plasmids and cells infected with viruses derived from these plasmids.

Cells, transfections, and infections. The modified human embryonic kidney cell line 293T (14) was maintained in Dulbecco's modified Eagle's medium. The human T cell line Hut/CCR5, derived from Hut78 to express chemokine receptor CCR5 (43), was maintained in RPMI medium. Media for both cell lines were supplemented with $10 \%$ fetal calf serum, penicillin (50 U/ml), and streptomycin $(50 \mathrm{U} / \mathrm{ml})$. Puromycin $(1 \mu \mathrm{g} / \mathrm{ml})$ and G418 $(500 \mu \mathrm{g} / \mathrm{ml})$ were also added to the medium for Hut/CCR5 cells. All cultured cells were maintained in humidified $37^{\circ} \mathrm{C}$ incubators with $5 \% \mathrm{CO}_{2}$.

Primary blood lymphocytes were isolated from healthy donors through HISTOPAQUE (Sigma) gradients and activated by phytohemagglutinin $(2 \mu \mathrm{g} / \mathrm{ml})$ for 3 days. Activated cells were maintained in RPMI medium supplemented with $10 \%$ fetal calf serum and $200 \mathrm{U} / \mathrm{ml}$ recombinant interleukin-2 for 3-4 days. $\mathrm{CD}^{+} \mathrm{T}$ cells were isolated using the Dynabeads CD4 Positive Isolation Kit, which typically generated $>99 \%$ purity of $\mathrm{CD}^{+} \mathrm{T}$ cells as determined by flow cytometry analyses.

DNA transfections were performed by the calcium phosphate method (38) using an MBS Mammalian Transfection Kit (Stratagene). Cells were plated at a density of $4 \times 10^{6}$ per 100- 
mm-diameter dish and transfected $18 \mathrm{~h}$ later. Viral supernatants were harvested $24 \mathrm{~h}$ later, clarified through a $0.45-\mu \mathrm{m}$-pore size filter to remove cellular debris, and used immediately or stored at $-80^{\circ} \mathrm{C}$ prior to infection.

For infection of $293 \mathrm{~T}$ cells, cells were plated in a 100-mm-diameter dish at a density of 1 $\times 10^{6}$ cells and infected $18 \mathrm{~h}$ later. Serial dilutions were generated from each viral stock and used for infection in the presence of Polybrene at a final concentration of $50 \mu \mathrm{g} / \mathrm{ml}$. Viruses were removed $1 \mathrm{~h}$ later, and fresh medium was added to the cells; $48 \mathrm{~h}$ postinfection, the cells were processed and flow cytometry analyses were performed. For infection of Hut/CCR5 cells, $2.5 \times 10^{5}$ or $1 \times 10^{6}$ cells were plated in a 24 - or 6 -well plate, respectively; infection was performed without Polybrene, and infected cells were analyzed $72 \mathrm{~h}$ postinfection.

Antibody staining and flow cytometry. Cells were stained with phycoerythrin (PE)conjugated $\alpha$-HSA antibody (Becton Dickinson Biosciences) and allophycocyanin (APC)conjugated $\alpha$-Thy 1 antibody (eBioscience). The concentrations of antibodies used to stain 293T cells were $0.8 \mu \mathrm{g} / \mathrm{ml}$ (PE-HSA) and $3.6 \mu \mathrm{g} / \mathrm{ml}$ (APC-Thy 1.2), whereas the concentrations of antibodies used to stain Hut/CCR5 cells were $0.48 \mu \mathrm{g} / \mathrm{ml}$ (PE-HSA) and $3.6 \mu \mathrm{g} / \mathrm{ml}$ (APC-Thy-1). Cells that were used only for flow cytometry analyses were fixed with paraformaldehyde (1\%, final concentration). Flow cytometry analyses were performed on a FACSCalibur (BD Biosciences), whereas cell sorting was performed on a FACSVantage SE System with the FACSDiVa Digital Option (BD Biosciences). Data obtained from flow cytometry analyses were analyzed using FlowJo software (Tree Star).

Calculation of the recombination rate. Multiplicity of infection (MOI) was calculated as follows. Y represents the number of total analyzed live cells during flow cytometry analyses; $\mathrm{Zi}$ and $\mathrm{Zg}$ represent the number of infected cells and the number of $\mathrm{GFP}^{+}$cells, respectively. 
Infection MOI was calculated as $\log (1-\mathrm{Zi} / \mathrm{Y}) / \log ((\mathrm{Y}-1) / \mathrm{Y}) / \mathrm{Y}$, whereas GFP MOI was calculated as $\log (1-\mathrm{Zg} / \mathrm{Y}) / \log ((\mathrm{Y}-1) / \mathrm{Y}) / \mathrm{Y}$. The percent of theoretical maximum measurable recombination rate for measuring markers 588, 300, 288, and 103 bp apart was calculated as $\left(\left(\mathrm{GFP}^{+} \mathrm{MOI} /\right.\right.$ Infection MOI $\left.) / 12.5 \%\right) \times 100 \%$.

\section{RESULTS}

Experimental system used to examine HIV-1 recombination. We developed a flowcytometry-based system to measure the recombination rates at marker distances shorter than 1.0 $\mathrm{kb}$ in a single round of HIV-1 replication. This system uses three markers: HSA, Thy-1, and GFP; HSA and Thy-1 are cell-surface proteins that can be detected with specific fluorochromeconjugated antibodies and flow cytometry, whereas GFP is a fluorescent protein. We constructed two pNL4-3-based HIV-1 vectors, pON-fHIG and pON-fTIG (Fig. 1A). These vectors contained all the cis-acting elements necessary for virus replication and encoded gag, pol, tat, and rev. In addition, each vector contained two marker genes in the nef reading frame: pON-fHIG had HSA and GFP, whereas pON-fTIG had Thy-1 and GFP. HSA and Thy-1 were expressed by spliced mRNAs, whereas the translation of GFP was facilitated by an IRES from encephalomyocarditis virus in both vectors.

Three vectors were derived from pON-fHIG by introducing inactivating mutations in GFP. Plasmid pON-H0 contained 7-nt substitutions between nt 6 and 15 that introduced a stop codon in each reading frame, with the translation start site as nt 1 (Table 1). Plasmids pON-H5 and pON-H6 contained a +1 frameshift between nt 500 and 501, and between nt 603 and 604 of

GFP, respectively (Table 1). Similarly, two vectors were derived from pON-fTIG: pON-T3 and pON-T6 contained a +1 frameshift between nt 303 and 304, and between nt 603 and 604 of GFP, 
respectively (Table 1). None of the five plasmids with mutation in GFP gene could express functional GFP; however, upon recombination, a functional GFP gene could be generated and its gene products could be scored by flow cytometry. By combining different pairs of vectors, we could measure the recombination rates for different marker distances.

\section{Experimental procedure used to generate producer cell lines and measure}

recombination rates. To measure the recombination rates in a single round of HIV-1 replication, we elected to produce the virus for the recombination assay from established cell lines containing HIV-1 vector proviruses instead of transiently cotransfecting the two HIV-1 vectors along with helper plasmids into cells. Although more laborious, our procedure eliminated possible DNA recombination between the two HIV-1 vectors during transfection and avoided overexpression of transfected plasmids, which would not reflect the true expression of the integrated proviruses. Furthermore, our procedure allowed us to measure the recombination events in one complete round of virus replication - from a provirus in the producer cells to a provirus in the target cells.

The experiments were performed in the following manner (Fig. 1B). First, 293T cells were transfected with an HIV-1 vector and pHCMV-G (44), a plasmid that expresses vesicular stomatitis virus G protein that can pseudotype HIV-1. Viral supernatants were harvested, clarified through a filter, serially diluted, and used to infect fresh $293 \mathrm{~T}$ cells. A portion of the infected cells was stained with antibodies and analyzed by flow cytometry. Although this procedure could easily infect more than $80 \%$ of the cells, we selected cell populations that were infected with an MOI of 0.05 to 0.1 for further experiments. This approach allowed us to avoid cell populations in which a large proportion of the cells contained more than one virus; selecting such populations would complicate later analyses (see Discussion). The infected cells were 
enriched by cell sorting (Fig. 1B), and infected by a second virus at an MOI of 0.05 to 0.1 ; the doubly infected cells were then sorted until more than $95 \%$ of the cells expressed both HSA and Thy-1. During the generation of the cell lines, cells were sorted no more than a total of four times. To avoid biases, each cell line consisted of a large number $(20,000$ to 60,000$)$ of independently infected cells.

To measure the recombination rate, cell lines expressing both $H S A$ - and Thy-1-encoding vectors were transfected with helper plasmids, and viruses harvested from these cells were used to infected the human T cell line Hut/CCR5; the infected cells were then analyzed by flow cytometry to determine the numbers of cells expressing HSA, Thy-1, or GFP. Two helper plasmids were used in these experiments: pIIINL(AD8)env, which expressed HIV-1 envelope from the AD8 strain (8), and pCMV-dGag, which expressed HIV-1 accessory genes vif, vpr, $v p u$, tat, rev, and nef. Because 293T cells did not express CD4, virus generated from these cells could not reinfect the producer cells; additionally, once transferred into Hut/CCR5 cells, the HIV-1 vectors did not express Env, and thus could not reinfect target cells. Therefore, these experiments measured recombination events that occurred between the provirus in the producer cells to the provirus in the target cells - one complete cycle of HIV-1 replication.

Experimental controls for the flow cytometry analyses. Before this new system could be used for recombination studies, we performed various control experiments to establish the background of the experimental system and our ability to detect the marker genes. Flow cytometry analyses were performed on uninfected $293 \mathrm{~T}$ cells and the producer cells. Uninfected 293T cells stained with anti-HSA and anti-Thy-1 antibodies had negligible numbers of cells that were positive for any of the three markers (Fig. 2A and B). An example of a producer cell line doubly infected with ON-H0 and ON-T6 is shown in Fig. 2C and D; although more than 95\% of 
the cells were positive for both HSA and Thy-1 expression, none of the cells were positive for GFP expression (0 in 11,698 live events or less than $0.008 \%$ ).

To determine the experimental background, we mock-infected Hut/CCR5 cells, stained these cells with anti-HSA and anti-Thy-1 antibodies, and analyzed them by flow cytometry. An example is shown in Fig. 2E and 2F; very few cells were positive for HSA, Thy-1, or GFP expression. Because recombination events were scored by the reconstitution of a functional GFP gene, we further defined the background of GFP detection. In multiple independent experiments, we scored a total of more than 2.3 million mock-infected cells and observed $18 \mathrm{GFP}^{+}$cells, indicating a background of $\sim 0.0008 \%$. We generated viruses derived from either $\mathrm{pON}-\mathrm{fHIG}$ or pON-fTIG, using transient transfection of $293 \mathrm{~T}$ cells along with helper plasmids, and infected Hut/CCR5 cells. As shown in the representative analyses (Fig. 2G for ON-fHIG virus infection and Fig. $2 \mathrm{H}$ for ON-fTIG virus infection), most of the cells were either double-negative or double-positive, indicating equivalent detection of the two marker genes in both HIV-1 vectors.

It was also important that the GFP mutants used in these experiments were indeed negative for GFP expression; we performed multiple experiments to confirm that all four mutations in GFP inactivated the gene product (Fig. $2 \mathrm{D}$ and data not shown).

Detection of recombination events for markers separated by 588 bp. Three independent cell lines doubly infected with ON-H0 and ON-T6 viruses were generated (shown as cell lines 1,2, and 3 in Table 2); the GFP mutations in ON-H0 and ON-T6 were 15 and 603 bp downstream of the AUG codon, creating a genetic distance of $588 \mathrm{bp}$. Helper plasmids were transfected into producer cell lines, viruses were harvested and used to infect Hut/CCR5 cells, and the infected cells were analyzed by flow cytometry. Representative mock-infected Hut/CCR5 cells are shown in Fig. 3A and 3B, and infected Hut/CCR5 cells are shown in Fig. 3C 
and D. As shown in Fig. 3C and D, cell populations that were negative, single-positive, or double-positive for the markers could be easily detected and scored. Data generated from these analyses are summarized in Table 2. For example, viruses produced from cell line 1 were used to infect Hut/CCR5 cells; of the 302,115 live events scored, 132,787 cells expressed at least one marker (infected cells), and 11,866 cells expressed GFP. To more accurately calculate the recombination events, we converted the cell numbers into MOI (see Materials and Methods for formula for conversion); the MOI for infection and $\mathrm{GFP}^{+}$virus were 0.58 and 0.04 , respectively, indicating that $6.9 \%$ of the infection events generated $\mathrm{GFP}^{+}$phenotypes.

Calculation of theoretical maximum $\mathrm{GFP}^{+}$phenotype. In this experimental system, we could measure the virus titers of the two parental phenotypes and the $\mathrm{GFP}^{+}$recombinant phenotype. Assuming that RNA expression of the two parental vectors was equal in the producer cell and that RNA packaging was random, $50 \%$ of the virion produced would contain a copy of RNA from each parent (heterozygotes), 25\% would contain two copies of RNA from one parent, and $25 \%$ would contain RNAs from the other parent (both homozygotes). The GFP phenotype could only be generated from reverse transcription of the heterozygous virions. With two mutations in GFP, four GFP genotypes could be generated during recombination (Fig. 4); of these, only the GFP without any mutation could express functional proteins. At the maximum recombination rate, the two markers in GFP assorted randomly; of all the virions generated from the producer cells, only $12.5 \%$ of the progeny was expected to reconstitute a functional GFP. Therefore, at most, $12.5 \%$ of the infection events should yield the $\mathrm{GFP}^{+}$phenotype. When we observed that $6.9 \%$ of the infection events had the $\mathrm{GFP}^{+}$phenotype, recombination between these two markers in GFP separated by 588 bp occurred at $55.4 \%$ of the theoretical maximum measurable rate $(6.9 \% / 12.5 \% \times 100 \%)$ (Table 2$)$. 
Recombination rates for markers separated by 300, 288, and 103 bp. We generated cell lines containing both $\mathrm{ON}-\mathrm{H} 0$ and $\mathrm{ON}-\mathrm{T} 3$ proviruses, and cell lines containing both ON-T3 and $\mathrm{ON}-\mathrm{H} 6$ proviruses. The distance between the $\mathrm{H} 0$ and $\mathrm{T} 3$ mutations in GFP was 288 bp, whereas the distance between the T3 and H6 mutations was $300 \mathrm{bp}$. Despite the similar genetic distance between these two sets of mutations, they contained completely different nucleotide sequences: $\mathrm{H} 0$ to $\mathrm{T} 3$ comprised the sequences from the 5' portion of GFP whereas $\mathrm{T} 3$ to $\mathrm{H} 6$ encompassed the $3^{\prime}$ portion of GFP (Fig. 1). We measured the frequencies at which $\mathrm{GFP}^{+}$ phenotypes were generated among infection events in cell lines containing either set of mutations; these results are summarized in Table 3 and 4. The recombination rate between H0 and T3 (288 bp) was $30.7 \% \pm 4.3 \%$ standard deviation (SD) of the theoretical maximum measurable rate; the recombination rate between T3 and H6 (300 bp) was 38.2\% $\pm 5.6 \%$ (SD). There were overlaps among the three sets of measurements of the two distances, indicating that the two measured sequences yielded similar recombination rates.

We also generated cell lines containing ON-H5 and ON-T6 proviruses and measured the recombination rate when the two markers were separated by $103 \mathrm{bp}$. The data generated from three independent experiments indicated that $1.4 \%$ of the infection events were $\mathrm{GFP}^{+}$, or $11.5 \%$ $\pm 2.4 \%$ (SD) of the theoretical maximum measurable recombination rate.

Effect of accessory genes on the recombination rate. The recombination experiments described above were performed in the presence of the accessory gene products. It has been shown that some accessory genes could affect the HIV-1 mutation rate or the process of reverse transcription $(1,26,39)$. To examine the effect of accessory genes on the recombination rate, we also performed parallel experiments without the expression of vif, vpr, vpu, and nef by omitting the helper construct pCMVdGag. Results from these experiments are summarized in Tables 2, 3, 
4, and 5; these results indicated that although the presence of the accessory gene products might have affected the infectivity of the virus as previously described, these gene products did not affect the overall recombination rate significantly (two-way ANOVA, $P=0.435$; analysis of covariance, $P=0.514$ ) (Fig. 5).

HIV-1 recombination in primary $\mathrm{CD4}^{+}$activated $\mathrm{T}$ cells. We also measured the HIV1 recombination rate in activated human primary $\mathrm{CD}^{+} \mathrm{T}$ cells. In order to make direct comparisons between the recombination rates in different target cells, we performed infection of the primary cells with the same virus stocks that were used to generate data for Tables 2,4 , and 5. Only viruses propagated in the presence of all accessory genes were used in these experiments. Three days postinfection, these cells were processed and analyzed by flow cytometry. For each recombination rate, we performed experiments using cells derived from three different donors and viruses generated from three independent cell lines. The ratio of GFP MOI/infection MOI for markers separated by 588, 288, and 103 bp were $7.1 \% \pm 1.1 \%$ (SD), $4.7 \% \pm 0.5 \%$ (SD), and $2.0 \% \pm 0.3 \%$ (SD), respectively. These data correspond to $56.8,37.6$, and $16 \%$ of the theoretical maximum measurable recombination rate, which were similar to those determined in Hut/CCR5 cells (Fig. 5).

Assortment of the HSA, Thy-1, and GFP markers in target cells. The two parental vectors used in this study had different marker genes upstream of GFP. Therefore, we could also analyze the distribution of the $\mathrm{GFP}^{+}$cells in $\mathrm{HSA}^{+}$and Thy- $1^{+}$cells to monitor additional recombination events. The distance between the $3^{\prime}$ end of HSA/Thy-1 to the H0, T3, and H5 mutations in $G F P$ were $0.6,0.9$, and $1.1 \mathrm{~kb}$, respectively. In order for the $\mathrm{GFP}^{+}$provirus in the H0-T6 or H0-T3 experiment to have HSA, RT would have to switch templates between the 0.6 kb separating the $H S A$ and the first 4 nt of GFP on the Thy-1-containing RNA. Similarly, in 
order for the $\mathrm{GFP}^{+}$provirus to have Thy-1 or HSA in the T3-H6 or the H5-T6 experiments, RT would have to switch templates within 0.9 or $1.1 \mathrm{~kb}$, respectively. We also analyzed the distribution of $\mathrm{GFP}^{+}$cells in $\mathrm{HSA}^{+}$and Thy- $1^{+}$cells (Fig. 6). In both the H0-T6 and H0-T3 experiments, the ratios of $\mathrm{GFP}^{+}$in $\mathrm{HSA}^{+}$cells were higher than those of $\mathrm{GFP}^{+}$in Thy- $1^{+}$cells, whereas in T3-H6 and H5-T6 experiments, the ratios of $\mathrm{GFP}^{+}$in $\mathrm{HSA}^{+}$cells were similar to those of $\mathrm{GFP}^{+}$in Thy- $1^{+}$cells. The marker distributions in these experiments were similar to the expected distribution based on the distance. For example, we expected that more $\mathrm{GFP}^{+}$viruses would have Thy-1 markers in the H0-T6 experiment because the recombination rate was under the maximum rate when markers were separated by $0.6 \mathrm{~kb}$. These data suggested that HIV -1 recombination does not have high negative interference, in contrast to the previous proposal by others (46). Although able to provide useful information, the distribution of the markers could be complicated by the doubly infected cell population and the expression of the two parental viruses. We performed further experiment to address whether HIV-1 recombination has high negative interference.

Generating GFP $^{+}$phenotype by double-crossover events. High negative interference is defined by double recombination generated at a frequency far higher than predicted from the rate of the single recombination. To directly test whether HIV-1 recombination exhibits high negative interference, we generated pON-H06 (Fig. 1A), which is identical to pON-H0 except it also has the H6 mutation in GFP. Using the same protocol described in Fig. 1B, we generated two cell lines doubly infected with ON-H06 and ON-T3, and measured the rates at which GFP viruses were generated after one round of HIV-1 replication in the presence or absence of the accessory genes. These results are summarized in Table 6. Based on our data from the H0-T3 and T3-H6 experiments, we could calculate the theoretical frequency at which $\mathrm{GFP}^{+}$viruses 
would be generated if the recombination events were independent. In the H0-T3 and T3-H6 experiments, the ratio of the $\mathrm{GFP}^{+}$phenotype in the total infection events was 3.8 and $5.1 \%$, respectively. Because heterozygous viruses were present in only half of the viruses, and only half of the recombinant genotypes could be scored in this system, the recombination rate between H0-T3 and T3-H6 was $15.2 \%(3.8 \% \times 2 \times 2)$ and $20.4 \%(5.1 \% \times 2 \times 2)$, respectively. Therefore the predicted double recombination rate was $3.1 \%(15.2 \% \times 20.4 \%)$. Given the inability to score one of the double-crossover recombinant genotypes and the presence of the homozygous viruses, the expected ratio of the $\mathrm{GFP}^{+}$phenotype in infected events was $0.77 \%$ $(3.1 \% / 4)$. The predicted numbers based on single recombination rates are very similar to our observed rate: the average ratio of $\mathrm{GFP}^{+}$in infected events was $0.93 \%$. Therefore, our data do not support the hypothesis that HIV-1 recombination exhibits high negative interference.

\section{DISCUSSION}

Development of a versatile system for HIV-1 recombination studies. In this report, we describe the development of a system to examine factors that influence the HIV-1 recombination rate. Detection of the infected cells and recombinants is based on the expression of proteins that can be scored by flow cytometry. The advantages of this system are the ability to detect recombination events in T cells and primary cells, and the ease and speed of collecting data from samples with large numbers of cells. Additionally, our system is versatile; we can directly measure recombination rates at various distances up to $600 \mathrm{bp}$ using the mutants with defined genotypes and phenotypes to generate recombinants. Furthermore, we collected viruses used in recombination studies from infected, sorted producer cells, thereby eliminating background problems such as the detection of DNA recombination events of the transfected 
parental vectors and allowing us to measure events that occur at lower frequencies. Recently, another flow-cytometry-based assay for studying HIV-1 recombination was described, which uses derivatives of GFP that fluoresce at different wavelengths as markers and reconstitution of GFP* as a mean to measure recombination (24). Although based on similar principles, the system is limited to mutations that conferred alteration of the fluorescence wavelength, and could be complicated by the presence of more than one mutation that could affect the protein excitation wavelength and the multiple recombinant genotypes that could have varied phenotypes.

Calculation of HIV-1 recombination rate. Previously, we measured the recombination rates of spleen necrosis virus (SNV), MLV, and HIV-1 $(2,17,33)$. In these studies, we used two parental vectors each encoding a functional and a nonfunctional drug-resistance gene; recombination events were scored by the generation of recombinants with two functional drugresistance genes. In these previous experiments, three drug-selection regimens - two single and one double - were used to measure the titers of the two parents and the recombinant, respectively. The recombination rate was calculated by dividing the double-drug-resistance titer with the lower of the two parental titers; the resulting number was then doubled to account for the recombinant with two nonfunctional genes, which could not be detected.

In our current system, flow cytometry analyses can simultaneously measure the expression of all three markers. Therefore, in addition to measuring the cell population infected by viruses with the parental phenotypes, and by virus with the recombinant phenotype (GFP $\left.{ }^{+}\right)$, we can directly determine the total infected cell population. Based on Poisson distribution, the number of infected cells is not always in linear proportion to the number of infection events, especially at higher MOIs. Additionally, the number of $\mathrm{GFP}^{+}$cells is always lower than the total number of infected cells. Therefore, to estimate the recombination rate more accurately, we 
converted the numbers of infected cells to MOIs prior to calculation. This concern is less of an issue for previous studies because the numbers of drug resistance colonies are always counted on cells infected with virus at low MOIs.

To better appreciate that the true frequency with which markers separated by a given distance segregate in one round of viral replication, we compared the rate at which $\mathrm{GFP}^{+}$was generated during infection to the theoretical maximum measurable recombination rate. We calculated the theoretical maximum measurable recombination rate in this experimental design (Fig. 4) based on the assumption that the two parents had the same level of RNA expression. In all our experiments, the expression of the HSA and Thy-1 indicated that the titers of the two parental viruses were similar, generally within two-fold of each other. Because all the producer cells were pools of infected cells, it was possible that the two parents were expressed at very different levels in each cell, yet generated similar titers when viruses were harvested from a large pool of cells. To reduce this bias, we infected the cells with low MOIs (0.1 to 0.05$)$ during the generation of our cell lines to decrease the probability of the presence of multiple proviruses from the same parent in one cell. Therefore, the $12.5 \%$ of $\mathrm{GFP}^{+}$cells estimated (Fig. 4) is likely to reflect the maximum that can be observed in our experimental condition. On the other hand, if we convert the two fold difference in the parental titer in some experiments to differences of RNA expression in the producer cells, the theoretical maximum measurable recombination rate would be $11.1 \%$, similar to the $12.5 \%$ we estimated in Fig. 4.

Near-linear relationship between recombination rate and marker distance at the range of 0.1 to $0.6 \mathrm{~kb}$ that is part of an overall quadratic fit. The recombination rates measured in this study are shown in Fig. 7A. We performed statistical analyses on the recombination rates measured at the aforementioned four distances. We found that distance is a 
significant factor that affects recombination rates (two-way ANOVA, $P<0.001$; analysis of covariance, $P<0.001)$. Further analyses indicated that at this range, the relationship between recombination rate and marker distance is near-linear and fits a regression model involving both a linear component (first power of distance) and a quadratic component (second power of distance), with both components being significant $(P<0.001$ for the linear and $P=0.015$ for the quadratic component) and an $\mathrm{R}^{2}$ value of 0.985 .

To gain insight into the overall relationship between recombination rate and marker distance, we also converted our previous measurements of recombination rates at 1.0,1.3, and $1.9 \mathrm{~kb}$ into theoretical maximum measurable recombination rates. We then added these rates to the rates determined in this report and generated a model to fit these data (with the caveat that the data came from two different studies). The resulting model illustrates that the relationship between recombination rate and marker distance has a quadratic fit with the linear and quadratic components being the first and second powers, respectively (Fig. 7B). This model has an outstanding fit to the data, with a $\mathrm{R}^{2}$ value of 0.984 ; of the 41 data points from the experiments, only one point was outside the $95 \%$ confidence level of the model.

We also generated a simple simulation to predict the relationship between marker distance and recombination rate. This simulation has the following assumptions: the frequency of crossover between two markers is directly proportion to the distance, and the crossover events are independent, occur randomly throughout the distance, and have a Poisson distribution. Furthermore, we took into the account that between the two markers, only odd numbers of crossover events will generate a recombinant genotype whereas even numbers of crossovers will not. The stimulation is shown in Fig. 7C and resembles the graph shown in Fig. 7B. Therefore, 
our data are consistent with the hypothesis that the frequency of crossover events are proportional to the distance between the markers and are independent from one another.

Lack of interference in HIV-1 recombination. Adding to the evidence in our proposal that crossover events in HIV-1 are independent is our observed lack of interference in the generation of a double recombinant. Previously, it was hypothesized that HIV-1 recombination exhibits high negative interference (46). This hypothesis was based on the mapping data of the crossover events in the HIV-1 genomes, in which some had multiple crossovers while others did not have any crossovers. It is possible that in the previous study, the viral genomes that did not have crossovers came from homozygous viruses. Alternatively, although unlikely, we cannot exclude the possibility that recombination does not exhibit high negative interference in GFP but exhibit interference in the HIV-1 genome sequences. Our previous studies indicated that recombination in SNV and MLV exhibit high negative interference $(3,4)$. We are currently dissecting the mechanisms that cause high negative interference in SNV and MLV but not in HIV-1.

Implications of the high recombination frequency. One of the major hindrances in the treatment of HIV-1 infection is viral variation. The high rate of HIV-1 recombination contributes to viral variation, which hinders effective treatments. Through recombination, multidrug-resistant variants can be generated quickly in a host; for example, sequences separated by $100 \mathrm{bp}$ can be assorted at a frequency of $11 \%$ per replication cycle, and double-crossover events occur frequently without interference. With the high rates of HIV-1 replication in infected individuals, recombination can assort the genome in a short period of time. The ability of HIV-1 to evolve presents a daunting challenge for HIV-1 treatment and vaccine development. However, if we can further define and understand the pathways that HIV-1 uses to generate 
variation, we can better estimate the evolutionary potential and limitations of HIV-1. This understanding can help us design better therapeutic strategies for the treatment of HIV-1 infection. To continue building the scaffold needed to understand the evolution potential of HIV-1, we are currently performing further studies to elucidate the mechanisms and factors important for recombination.

\section{ACKNOWLEDGMENTS}

We sincerely thank Dr. Douglas Powell for performing all of the statistical analyses and also for stimulating discussions; Anne Arthur for expert editorial help; Vinay K. Pathak for intellectual input and encouragement throughout the project; John Coffin for helpful discussions; Vinay K. Pathak, Jeffrey Strathern, Frank Maldarelli and Mario Chin for critical reading and comments on the manuscript; and Derya Unutmaz, Irvin S.Y. Chen, and Eric Freed for their gifts of plasmids.

TDR, a medical scientist trainee in West Virginia University, dedicates this manuscript to Mary, Mercy, and Madelyn Rhodes, whose love and sacrifices have helped him further his graduate career.

This work is supported by the HIV Drug Resistance Program, National Cancer Institute. 


\section{REFERENCES}

1. Aiken, C., and D. Trono. 1995. Nef stimulates human immunodeficiency virus type 1 proviral DNA synthesis. J Virol 69:5048-56.

2. Anderson, J. A., E. H. Bowman, and W. S. Hu. 1998. Retroviral recombination rates do not increase linearly with marker distance and are limited by the size of the recombining subpopulation. J Virol 72:1195-202.

3. Anderson, J. A., V. K. Pathak, and W. S. Hu. 2000. Effect of the murine leukemia virus extended packaging signal on the rates and locations of retroviral recombination. $\mathrm{J}$ Virol 74:6953-63.

4. Anderson, J. A., R. J. Teufel, 2nd, P. D. Yin, and W. S. Hu. 1998. Correlated template-switching events during minus-strand DNA synthesis: a mechanism for high negative interference during retroviral recombination. J Virol 72:1186-94.

5. Balakrishnan, M., B. P. Roques, P. J. Fay, and R. A. Bambara. 2003. Template dimerization promotes an acceptor invasion-induced transfer mechanism during human immunodeficiency virus type 1 minus-strand synthesis. J Virol 77:4710-21.

6. Clavel, F., M. D. Hoggan, R. L. Willey, K. Strebel, M. A. Martin, and R. Repaske. 1989. Genetic recombination of human immunodeficiency virus. J Virol 63:1455-9.

7. Coffin, J. M. 1979. Structure, replication, and recombination of retrovirus genomes: some unifying hypotheses. J Gen Virol 42:1-26.

8. Dang, Q., J. Chen, D. Unutmaz, J. M. Coffin, V. K. Pathak, D. Powell, V. N. KewalRamani, F. Maldarelli, and W. S. Hu. 2004. Nonrandom HIV-1 infection and double infection via direct and cell-mediated pathways. Proc Natl Acad Sci U S A 101:632-7. 
9. Derebail, S. S., M. J. Heath, and J. J. DeStefano. 2003. Evidence for the differential effects of nucleocapsid protein on strand transfer in various regions of the HIV genome. $\mathrm{J}$ Biol Chem 278: 15702-12.

10. DeStefano, J. J. 1994. Kinetic analysis of the catalysis of strand transfer from internal regions of heteropolymeric RNA templates by human immunodeficiency virus reverse transcriptase. J Mol Biol 243:558-67.

11. DeStefano, J. J., L. M. Mallaber, L. Rodriguez-Rodriguez, P. J. Fay, and R. A. Bambara. 1992. Requirements for strand transfer between internal regions of heteropolymer templates by human immunodeficiency virus reverse transcriptase. J Virol 66:6370-8.

12. DeStefano, J. J., B. Roberts, and D. Shriner. 1997. The mechanism of retroviral recombination: the role of sequences proximal to the point of strand transfer. Arch Virol 142:1797-812.

13. Diaz, R. S., E. C. Sabino, A. Mayer, J. W. Mosley, and M. P. Busch. 1995. Dual human immunodeficiency virus type 1 infection and recombination in a dually exposed transfusion recipient. The Transfusion Safety Study Group. J Virol 69:3273-81.

14. DuBridge, R. B., P. Tang, H. C. Hsia, P. M. Leong, J. H. Miller, and M. P. Calos. 1987. Analysis of mutation in human cells by using an Epstein-Barr virus shuttle system. Mol Cell Biol 7:379-87.

15. Duesberg, P. H. 1968. Physical properties of Rous Sarcoma Virus RNA. Proc Natl Acad Sci U S A 60:1511-8.

16. Gao, F., D. L. Robertson, S. G. Morrison, H. Hui, S. Craig, J. Decker, P. N. Fultz, M. Girard, G. M. Shaw, B. H. Hahn, and P. M. Sharp. 1996. The heterosexual human 
immunodeficiency virus type 1 epidemic in Thailand is caused by an intersubtype (A/E) recombinant of African origin. J Virol 70:7013-29.

17. Hu, W. S., and H. M. Temin. 1990. Genetic consequences of packaging two RNA genomes in one retroviral particle: pseudodiploidy and high rate of genetic recombination. Proc Natl Acad Sci U S A 87:1556-60.

18. Hwang, C. K., E. S. Svarovskaia, and V. K. Pathak. 2001. Dynamic copy choice: steady state between murine leukemia virus polymerase and polymerase-dependent RNase $\mathrm{H}$ activity determines frequency of in vivo template switching. Proc Natl Acad Sci U S A 98:12209-14.

19. Iglesias-Sanchez, M. J., and C. Lopez-Galindez. 2002. Analysis, quantification, and evolutionary consequences of HIV-1 in vitro recombination. Virology 304:392-402.

20. Iversen, A. K., R. W. Shafer, K. Wehrly, M. A. Winters, J. I. Mullins, B. Chesebro, and T. C. Merigan. 1996. Multidrug-resistant human immunodeficiency virus type 1 strains resulting from combination antiretroviral therapy. J Virol 70:1086-90.

21. Jetzt, A. E., H. Yu, G. J. Klarmann, Y. Ron, B. D. Preston, and J. P. Dougherty. 2000. High rate of recombination throughout the human immunodeficiency virus type 1 genome. J Virol 74:1234-40.

22. Kung, H. J., J. M. Bailey, N. Davidson, M. O. Nicolson, and R. M. McAllister. 1975. Structure, subunit composition, and molecular weight of RD-114 RNA. J Virol 16:397411.

23. Kuwata, T., Y. Miyazaki, T. Igarashi, J. Takehisa, and M. Hayami. 1997. The rapid spread of recombinants during a natural in vitro infection with two human immunodeficiency virus type 1 strains. J Virol 71:7088-91. 
24. Levy, D. N., G. M. Aldrovandi, O. Kutsch, and G. M. Shaw. 2004. Dynamics of HIV1 recombination in its natural target cells. Proc Natl Acad Sci U S A.

25. Liu, S. L., J. E. Mittler, D. C. Nickle, T. M. Mulvania, D. Shriner, A. G. Rodrigo, B. Kosloff, X. He, L. Corey, and J. I. Mullins. 2002. Selection for human immunodeficiency virus type 1 recombinants in a patient with rapid progression to AIDS. J Virol 76:10674-84.

26. Mansky, L. M. 1996. The mutation rate of human immunodeficiency virus type 1 is influenced by the vpr gene. Virology 222:391-400.

27. McCutchan, F. E., P. A. Hegerich, T. P. Brennan, P. Phanuphak, P. Singharaj, A. Jugsudee, P. W. Berman, A. M. Gray, A. K. Fowler, and D. S. Burke. 1992. Genetic variants of HIV-1 in Thailand. AIDS Res Hum Retroviruses 8:1887-95.

28. Naldini, L., U. Blomer, P. Gallay, D. Ory, R. Mulligan, F. H. Gage, I. M. Verma, and D. Trono. 1996. In vivo gene delivery and stable transduction of nondividing cells by a lentiviral vector. Science 272:263-7.

29. Negroni, M., and H. Buc. 1999. Recombination during reverse transcription: an evaluation of the role of the nucleocapsid protein. J Mol Biol 286:15-31.

30. Onafuwa, A., W. An, N. D. Robson, and A. Telesnitsky. 2003. Human Immunodeficiency Virus Type 1 Genetic Recombination Is More Frequent Than That of Moloney Murine Leukemia Virus despite Similar Template Switching Rates. J Virol $77: 4577-87$.

31. Planelles, V., A. Haislip, E. S. Withers-Ward, S. A. Stewart, Y. Xie, N. P. Shah, and I. S. Chen. 1995. A new reporter system for detection of retroviral infection. Gene Ther 2:369-76. 
32. Raja, A., and J. J. DeStefano. 2003. Interaction of HIV reverse transcriptase with structures mimicking recombination intermediates. J Biol Chem 278:10102-11.

33. Rhodes, T., H. Wargo, and W. S. Hu. 2003. High rates of human immunodeficiency virus type 1 recombination: near-random segregation of markers one kilobase apart in one round of viral replication. J Virol 77:11193-200.

34. Robertson, D. L., P. M. Sharp, F. E. McCutchan, and B. H. Hahn. 1995. Recombination in HIV-1. Nature 374:124-6.

35. Roda, R. H., M. Balakrishnan, M. N. Hanson, B. M. Wohrl, S. F. Le Grice, B. P. Roques, R. J. Gorelick, and R. A. Bambara. 2003. Role of the Reverse Transcriptase, Nucleocapsid Protein, and Template Structure in the Two-step Transfer Mechanism in Retroviral Recombination. J Biol Chem 278:31536-46.

36. Roda, R. H., M. Balakrishnan, J. K. Kim, B. P. Roques, P. J. Fay, and R. A. Bambara. 2002. Strand transfer occurs in retroviruses by a pause-initiated two-step mechanism. J Biol Chem 277:46900-11.

37. Saksena, N. K., B. Wang, Y. C. Ge, S. H. Xiang, D. E. Dwyer, and A. L. Cunningham. 1997. Coinfection and genetic recombination between HIV-1 strains: possible biological implications in Australia and South East Asia. Ann Acad Med Singapore 26:121-7.

38. Sambrook, J., E. F. Fritsch, and T. Maniatis. 1989. Molecular cloning: a laboratory manual, 2nd ed. Cold Spring Harbor Laboratory Press, Cold Spring Harbor, N.Y.

39. Schwartz, O., V. Marechal, O. Danos, and J. M. Heard. 1995. Human immunodeficiency virus type 1 Nef increases the efficiency of reverse transcription in the infected cell. J Virol 69:4053-9. 
40. Shirasaka, T., M. F. Kavlick, T. Ueno, W. Y. Gao, E. Kojima, M. L. Alcaide, S. Chokekijchai, B. M. Roy, E. Arnold, R. Yarchoan, and et al. 1995. Emergence of human immunodeficiency virus type 1 variants with resistance to multiple dideoxynucleosides in patients receiving therapy with dideoxynucleosides. Proc Natl Acad Sci U S A 92:2398-402.

41. Unutmaz, D., V. N. KewalRamani, S. Marmon, and D. R. Littman. 1999. Cytokine signals are sufficient for HIV-1 infection of resting human T lymphocytes. J Exp Med 189:1735-46.

42. Vidal, N., C. Mulanga-Kabeya, N. Nzilambi, E. Delaporte, and M. Peeters. 2000. Identification of a complex env subtype E HIV type 1 virus from the democratic republic of congo, recombinant with A, G, H, J, K, and unknown subtypes. AIDS Res Hum Retroviruses 16:2059-64.

43. Wu, L., T. D. Martin, R. Vazeux, D. Unutmaz, and V. N. KewalRamani. 2002. Functional evaluation of DC-SIGN monoclonal antibodies reveals DC-SIGN interactions with ICAM-3 do not promote human immunodeficiency virus type 1 transmission. $\mathrm{J}$ Virol 76:5905-14.

44. Yee, J. K., A. Miyanohara, P. LaPorte, K. Bouic, J. C. Burns, and T. Friedmann. 1994. A general method for the generation of high-titer, pantropic retroviral vectors: highly efficient infection of primary hepatocytes. Proc Natl Acad Sci U S A 91:9564-8.

45. Zhu, T., N. Wang, A. Carr, S. Wolinsky, and D. D. Ho. 1995. Evidence for coinfection by multiple strains of human immunodeficiency virus type 1 subtype $B$ in an acute seroconvertor. J Virol 69:1324-7. 
46. Zhuang, J., A. E. Jetzt, G. Sun, H. Yu, G. Klarmann, Y. Ron, B. D. Preston, and J. P. Dougherty. 2002. Human immunodeficiency virus type 1 recombination: rate, fidelity, and putative hot spots. J Virol 76:11273-82. 
TABLE 1. Sequence comparison between wild-type and mutant GFP

Mutation DNA sequence in GFP*

$\mathrm{HO}$

$$
\begin{array}{ll}
\text { Wild-type } & \text { AtGGTGAGCAAGGGCGAG } \\
\text { Mutant } & \text { ATGGTAGTTAACTGAGAG }
\end{array}
$$

T3

$$
\begin{array}{ll}
\text { Wild-type } & \text { CATCTTCTTC-AAGGACGACG } \\
\text { Mutant } & \text { CATCTTCTTCGAAGGACGACG }
\end{array}
$$

H5

$$
\begin{array}{ll}
\text { Wild-type } & \text { TGAACTTCAA-GATCCGCCAC } \\
\text { Mutant } & \text { TGAACTTCAAGGATCCGCCAC }
\end{array}
$$

$\mathrm{H} 6 / \mathrm{T} 6$

$$
\begin{array}{ll}
\text { Wild-type } & \text { ACAACCACTAC-CTGAGCACC } \\
\text { Mutant } & \text { ACAACCACTAGTCTGAGCACC }
\end{array}
$$

\footnotetext{
* Bold letters denote substituted and inserted nucleotides.
} 
TABLE 2. Recombination between two markers separated by $588 \mathrm{bp}$.

\begin{tabular}{|c|c|c|c|c|c|c|c|}
\hline & $\begin{array}{c}\text { Total } \\
\text { live events }\end{array}$ & $\begin{array}{c}\text { Infected } \\
\text { cells }\end{array}$ & $\begin{array}{l}\mathbf{G F P}^{+} \\
\text {cells }\end{array}$ & $\begin{array}{c}\text { Infection } \\
\text { MOI }\end{array}$ & $\begin{array}{l}\text { GFP } \\
\text { MOI }\end{array}$ & $\begin{array}{c}\text { GFP MOI / } \\
\text { Infection MOI }\end{array}$ & $\begin{array}{c}\text { \% of } \\
\text { TMMRR* }\end{array}$ \\
\hline \multicolumn{8}{|c|}{ With all accessory gene products } \\
\hline Cell line 1 & 302,115 & 132,787 & 11,866 & 0.58 & 0.040 & 0.069 & $55.4 \%$ \\
\hline Cell line 2 & 311,294 & 108,238 & 7,896 & 0.43 & 0.026 & 0.060 & $48.1 \%$ \\
\hline Cell line 3 & 134,998 & 53,493 & 5,366 & 0.50 & 0.041 & 0.080 & $64.3 \%$ \\
\hline Mean \pm SD & & & & & & & $55.9 \% \pm 8.1 \%$ \\
\hline \multicolumn{8}{|c|}{ Without Vif, Vpr, Vpu, and Nef } \\
\hline Cell line 1 & 244,153 & 92,266 & 7,543 & 0.47 & 0.031 & 0.066 & $52.9 \%$ \\
\hline Cell line 2 & 323,309 & 102,981 & 7,682 & 0.38 & 0.024 & 0.063 & $50.2 \%$ \\
\hline Cell line 3 & 153,351 & 44,530 & 3,800 & 0.34 & 0.025 & 0.073 & $58.5 \%$ \\
\hline Mean \pm SD & & & & & & & $53.9 \% \pm 4.3 \%$ \\
\hline
\end{tabular}

* TMMRR: Theoretical maximum measurable recombination rate. 
TABLE 3. Recombination between two markers separated by $300 \mathrm{bp}$.

\begin{tabular}{|c|c|c|c|c|c|c|c|}
\hline & $\begin{array}{c}\text { Total } \\
\text { live events }\end{array}$ & $\begin{array}{c}\text { Infected } \\
\text { cells }\end{array}$ & $\begin{array}{l}\mathbf{G F P}^{+} \\
\text {cells }\end{array}$ & $\begin{array}{c}\text { Infection } \\
\text { MOI }\end{array}$ & $\begin{array}{l}\text { GFP } \\
\text { MOI }\end{array}$ & $\begin{array}{c}\text { GFP MOI / } \\
\text { Infection MOI }\end{array}$ & $\begin{array}{c}\text { \% of } \\
\text { TMMRR* }\end{array}$ \\
\hline \multicolumn{8}{|c|}{ With all accessory gene products } \\
\hline Cell line 1 & 169,742 & 68,118 & 4,751 & 0.51 & 0.028 & 0.055 & $44.3 \%$ \\
\hline Cell line 2 & 457,070 & 125,496 & 6,071 & 0.32 & 0.013 & 0.042 & $33.3 \%$ \\
\hline Cell line 3 & 377,710 & 142,939 & 8,228 & 0.48 & 0.022 & 0.046 & $37.1 \%$ \\
\hline Mean \pm SD & & & & & & & $38.2 \% \pm 5.6 \%$ \\
\hline \multicolumn{8}{|c|}{ Without Vif, Vpr, Vpu, and Nef } \\
\hline Cell line 1 & 177,088 & 43,332 & 2,513 & 0.28 & 0.014 & 0.051 & $40.7 \%$ \\
\hline Cell line 2 & 543,741 & 133,692 & 6,768 & 0.28 & 0.013 & 0.044 & $35.5 \%$ \\
\hline Cell line 3 & 710,696 & 157,916 & 7,463 & 0.25 & 0.011 & 0.042 & $33.6 \%$ \\
\hline Mean \pm SD & & & & & & & $36.6 \% \pm 3.7 \%$ \\
\hline
\end{tabular}

* TMMRR: Theoretical maximum measurable recombination rate. 
TABLE 4. Recombination between two markers separated by $288 \mathrm{bp}$.

\begin{tabular}{|c|c|c|c|c|c|c|c|}
\hline & $\begin{array}{c}\text { Total } \\
\text { live events }\end{array}$ & $\begin{array}{c}\text { Infected } \\
\text { cells }\end{array}$ & $\begin{array}{l}\mathbf{G F P}^{+} \\
\text {cells }\end{array}$ & $\begin{array}{c}\text { Infection } \\
\text { MOI }\end{array}$ & $\begin{array}{l}\text { GFP } \\
\text { MOI }\end{array}$ & $\begin{array}{c}\text { GFP MOI / } \\
\text { Infection MOI }\end{array}$ & $\begin{array}{c}\text { \% of } \\
\text { TMMRR }\end{array}$ \\
\hline \multicolumn{8}{|c|}{ With all accessory gene products } \\
\hline Cell line 1 & 174,404 & 72,866 & 4,140 & 0.54 & 0.024 & 0.044 & $35.5 \%$ \\
\hline Cell line 2 & 540,508 & 195,323 & 8,225 & 0.45 & 0.015 & 0.034 & $27.4 \%$ \\
\hline Cell line 3 & 271,641 & 127,694 & 6,218 & 0.64 & 0.023 & 0.036 & $29.2 \%$ \\
\hline Mean \pm SD & & & & & & & $30.7 \% \pm 4.3 \%$ \\
\hline \multicolumn{8}{|c|}{ Without Vif, Vpr, Vpu, and Nef } \\
\hline Cell line 1 & 176,526 & 41,014 & 1,777 & 0.26 & 0.010 & 0.038 & $30.6 \%$ \\
\hline Cell line 2 & 469,566 & 144,843 & 6,371 & 0.37 & 0.014 & 0.037 & $29.6 \%$ \\
\hline Cell line 3 & 585,638 & 203,767 & 8,356 & 0.43 & 0.014 & 0.034 & $26.9 \%$ \\
\hline Mean \pm SD & & & & & & & $29.0 \% \pm 1.9 \%$ \\
\hline
\end{tabular}


TABLE 5. Recombination between two markers separated by $103 \mathrm{bp}$.

\begin{tabular}{|c|c|c|c|c|c|c|c|}
\hline & $\begin{array}{c}\text { Total } \\
\text { live events }\end{array}$ & $\begin{array}{c}\text { Infected } \\
\text { cells }\end{array}$ & $\begin{array}{l}\mathbf{G F P}^{+} \\
\text {cells }\end{array}$ & $\begin{array}{c}\text { Infection } \\
\text { MOI }\end{array}$ & $\begin{array}{l}\text { GFP } \\
\text { MOI }\end{array}$ & $\begin{array}{c}\text { GFP MOI / } \\
\text { Infection MOI }\end{array}$ & $\begin{array}{c}\text { \% of } \\
\text { TMMRR }\end{array}$ \\
\hline \multicolumn{8}{|c|}{ With all accessory gene products } \\
\hline Cell line 1 & 155,972 & 63,480 & 1455 & 0.52 & 0.009 & 0.018 & $14.3 \%$ \\
\hline Cell line 2 & $1,067,637$ & 405,475 & 6,241 & 0.48 & 0.006 & 0.012 & $9.8 \%$ \\
\hline Cell line 3 & $1,049,218$ & 321,544 & 5,021 & 0.37 & 0.005 & 0.013 & $10.5 \%$ \\
\hline Mean \pm SD & & & & & & & $11.6 \% \pm 2.4 \%$ \\
\hline \multicolumn{8}{|c|}{ Without Vif, Vpr, Vpu, and Nef } \\
\hline Cell line 1 & 171,884 & 44,695 & 841 & 0.30 & 0.005 & 0.016 & $13.0 \%$ \\
\hline Cell line 2 & $1,094,731$ & 387,098 & 5,960 & 0.44 & 0.005 & 0.013 & $10.0 \%$ \\
\hline Cell line 3 & $1,319,480$ & 372,408 & 5,565 & 0.33 & 0.004 & 0.013 & $10.2 \%$ \\
\hline Mean \pm SD & & & & & & & $11.1 \% \pm 1.7 \%$ \\
\hline
\end{tabular}

* TMMRR: Theoretical maximum measurable recombination rate. 
TABLE 6. Recombination between three markers using ON-H06 and ON-T3 viruses.

\begin{tabular}{|c|c|c|c|c|c|c|}
\hline & $\begin{array}{c}\text { Total } \\
\text { live events }\end{array}$ & $\begin{array}{c}\text { Infected } \\
\text { cells }\end{array}$ & $\begin{array}{l}\mathbf{G F P}^{+} \\
\text {cells }\end{array}$ & $\begin{array}{c}\text { Infection } \\
\text { MOI }\end{array}$ & $\begin{array}{l}\text { GFP } \\
\text { MOI }\end{array}$ & $\begin{array}{c}\text { GFP MOI / } \\
\text { Infection MOI }\end{array}$ \\
\hline \multicolumn{7}{|c|}{ With all accessory gene products } \\
\hline Cell line 1 & 919,357 & 223,561 & 2,379 & 0.28 & 0.003 & 0.0093 \\
\hline Cell line 2 & $1,034,680$ & 343,027 & 3,868 & 0.40 & 0.004 & 0.0093 \\
\hline \multicolumn{7}{|c|}{ Without Vif, Vpr, Vpu, and Nef } \\
\hline Cell line 1 & 930,100 & 262,201 & 2,946 & 0.33 & 0.003 & 0.0096 \\
\hline Cell line 2 & 813,916 & 326,331 & 3,955 & 0.51 & 0.005 & 0.0095 \\
\hline
\end{tabular}




\section{FIGURE LEGENDS}

FIG. 1. Viral vectors and protocol used to measure HIV-1 recombination rates. (A) General structures of the vectors. All listed vectors have similar structures but differ in the encoded marker genes. Asterisk, inactivating mutation in GFP. (B) Protocol used to measure the recombination rates of HIV-1.

FIG. 2. Representative flow cytometry analyses of mock-infected cells, producer cells, and cells infected with control plasmids. (A and B) Analyses of mock-infected 293T cells stained with anti-HSA and anti-Thy-1 antibodies. (C and D) Analyses of a producer cell line used for virus production. This cell line was sequentially infected with $\mathrm{ON}-\mathrm{H} 0$ and $\mathrm{ON}-\mathrm{T} 3$ at low MOIs; $\mathrm{HSA}^{+}$and Thy $-1^{+}$cells were enriched by sorting, stained with antibodies, and analyzed. (E and F) Analyses of uninfected Hut/CCR5 target cells stained with anti-HSA and anti-Thy-1 antibodies. (G) Analysis of Hut/CCR5 target cells infected with ON-fHIG virus and stained with anti-HSA antibody. (H) Analysis of Hut/CCR5 cells infected with ON-fTIG virus and stained with anti-Thy-1 antibody. In all panels, the $\mathrm{x}$ - and $\mathrm{y}$-axes denote the expression of a particular marker as indicated.

FIG. 3. Representative flow cytometry analyses of mock-infected and infected target cells. (A and B) Analyses of mock-infected Hut/CCR5 target cells stained with anti-HSA and anti-Thy-1 antibodies. (C and D) Analyses of Hut/CCR5 target cells infected with virus harvested from a producer cell line harboring both $\mathrm{ON}-\mathrm{H} 0$ and ON-T6. 
FIG. 4. Distribution of GFP genotypes and phenotypes in the progeny generated from doubly infected cells after one round of viral replication. Vectors ON-H0 and ON-T6 were used as examples (shown as $\mathrm{H} 0$ and $\mathrm{T} 6$, respectively). Several assumptions were made in the calculated frequency. First, the 25\%:50\%: 25\% distribution of the virion content was based on the assumptions that $\mathrm{H} 0$ and $\mathrm{T} 6$ were expressed at similar levels in the producer cells and virion RNAs were packaged randomly. Second, the $12.5 \%$ distribution of each genotype was based on the assumption that $\mathrm{H} 0$ and $\mathrm{T} 6$ markers segregated as unlinked markers. $\mathrm{GFP}^{-}$, cells that did not express functional GFP; $\mathrm{GFP}^{+}$, cells expressing functional GFP.

FIG. 5. Effects of accessory proteins and target cells on HIV-1 recombination. The yaxis represents the percentage of the theoretical maximum measurable recombination rate (TMMRR); x-axis, distances between markers. White and gray bars represent the average recombination rates measured in the presence or absence, respectively, of accessory genes vif, $v p r, v p u$, and $n e f$ in the experimental system using Hut/CCR5 as target cells. Black bars represent the recombination rate in the presence of accessory genes using activated primary $\mathrm{T}$ cells as the target cells. All of the histograms show the average of three independent experiments; standard deviations are shown as error bars.

FIG. 6. Distribution of the $\mathrm{GFP}^{+}$phenotype in $\mathrm{HSA}^{+}$and Thy $-1^{+}$cells. The y-axis denotes the percentage of $\mathrm{GFP}^{+}$cells; $\mathrm{x}$-axis, vector pairs used. White bars represent $\mathrm{GFP}^{+}$cells within the $\mathrm{HSA}^{+}$populations; black bars, $\mathrm{GFP}^{+}$cells within the Thy- $1^{+}$populations. 
FIG. 7. Relationship between HIV-1 recombination rate and marker distance. (A) Nearlinear relationship between recombination rate and marker distance in the 0.1 to $0.6 \mathrm{~kb}$ range. (B) The relationship between HIV-1 recombination rate and marker distances has a quadratic fit. All data points are shown as triangles, the quadratic fit is shown as a black line, and the $95 \%$ confidence level is shown as dotted lines. (C) Simulation of observed recombination rate. This simulation is based on the assumptions that the frequency of crossover event is proportional to the marker distance, crossover occurs randomly throughout the genome, and crossovers are independent events. The x-axis, marker distance; $y$-axis, percentage of theoretical maximum measurable recombination rate (TMMRR). 
A.

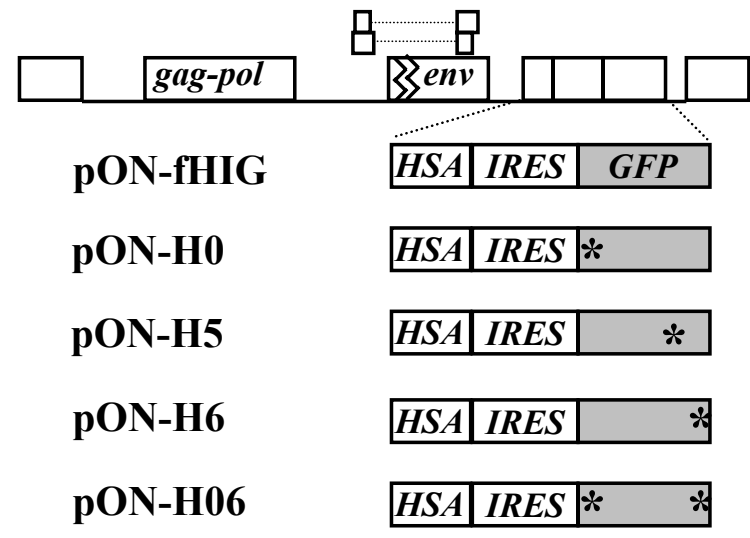

\begin{tabular}{lll|l|l|} 
pON-fTIG $\quad$ Thy-1 & IRES & GFP \\
\hline
\end{tabular}

\begin{tabular}{ll|l|l|} 
pON-T3 & Thy-1 & IRES & $*$ \\
\hline
\end{tabular}

\begin{tabular}{ll|l|l|}
\hline pON-T6 & Thy-1 & IRES & * \\
\hline
\end{tabular}

B.

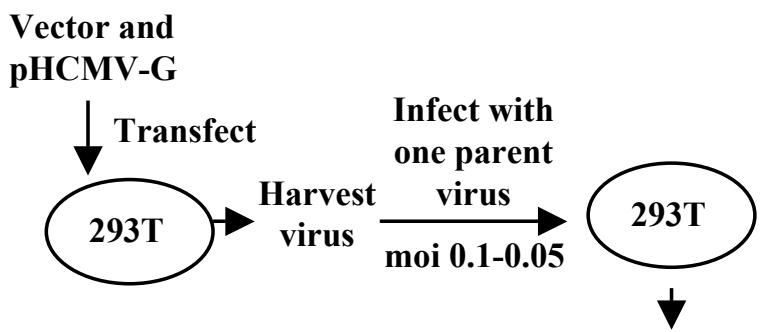

Sort positive cells

Fig. 1

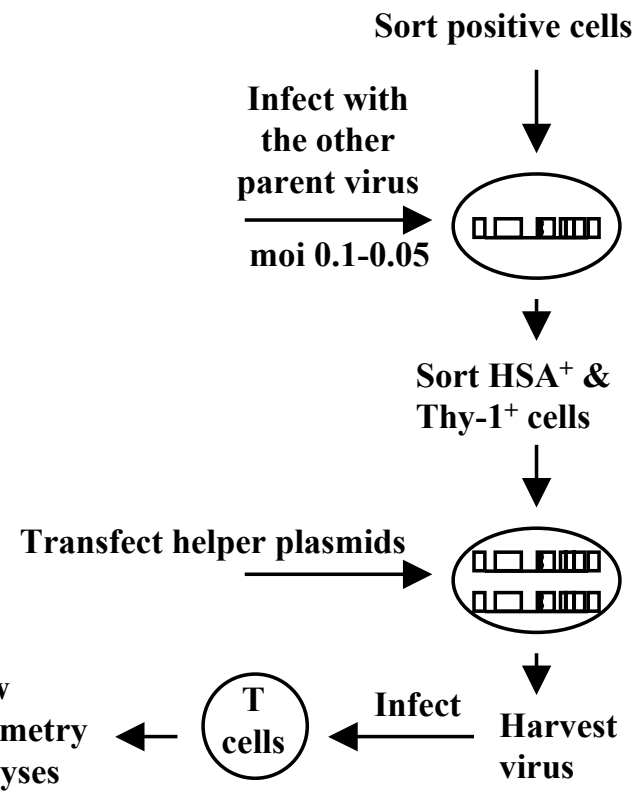



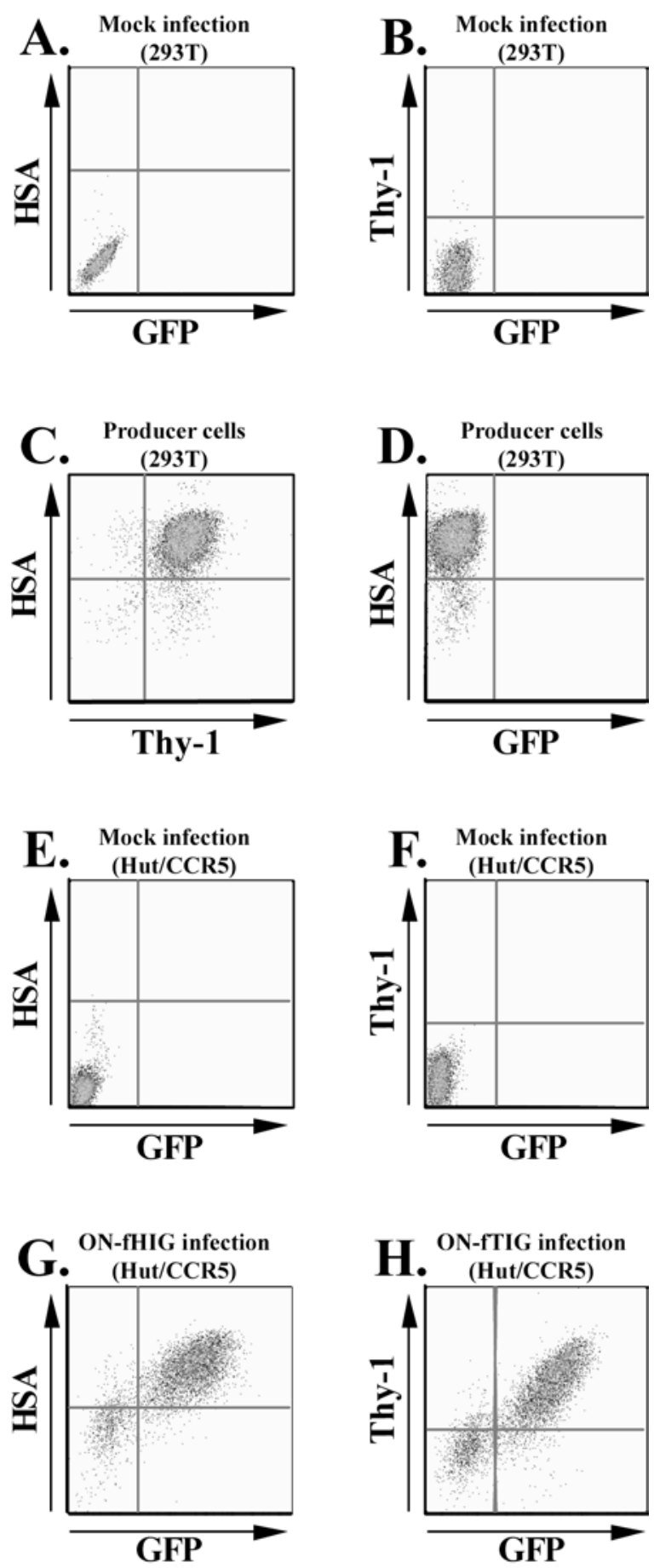

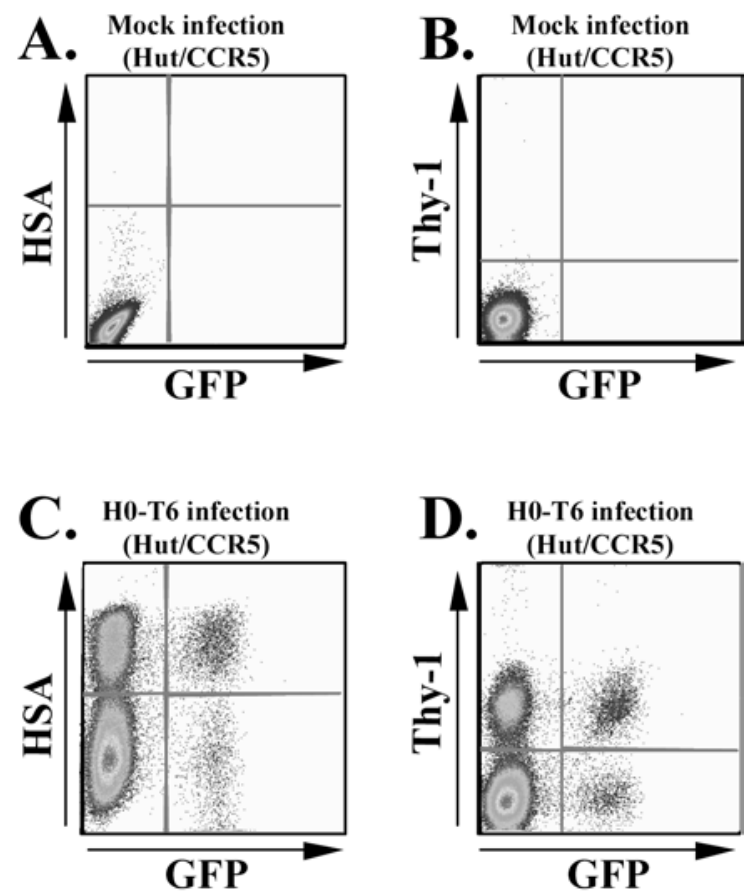


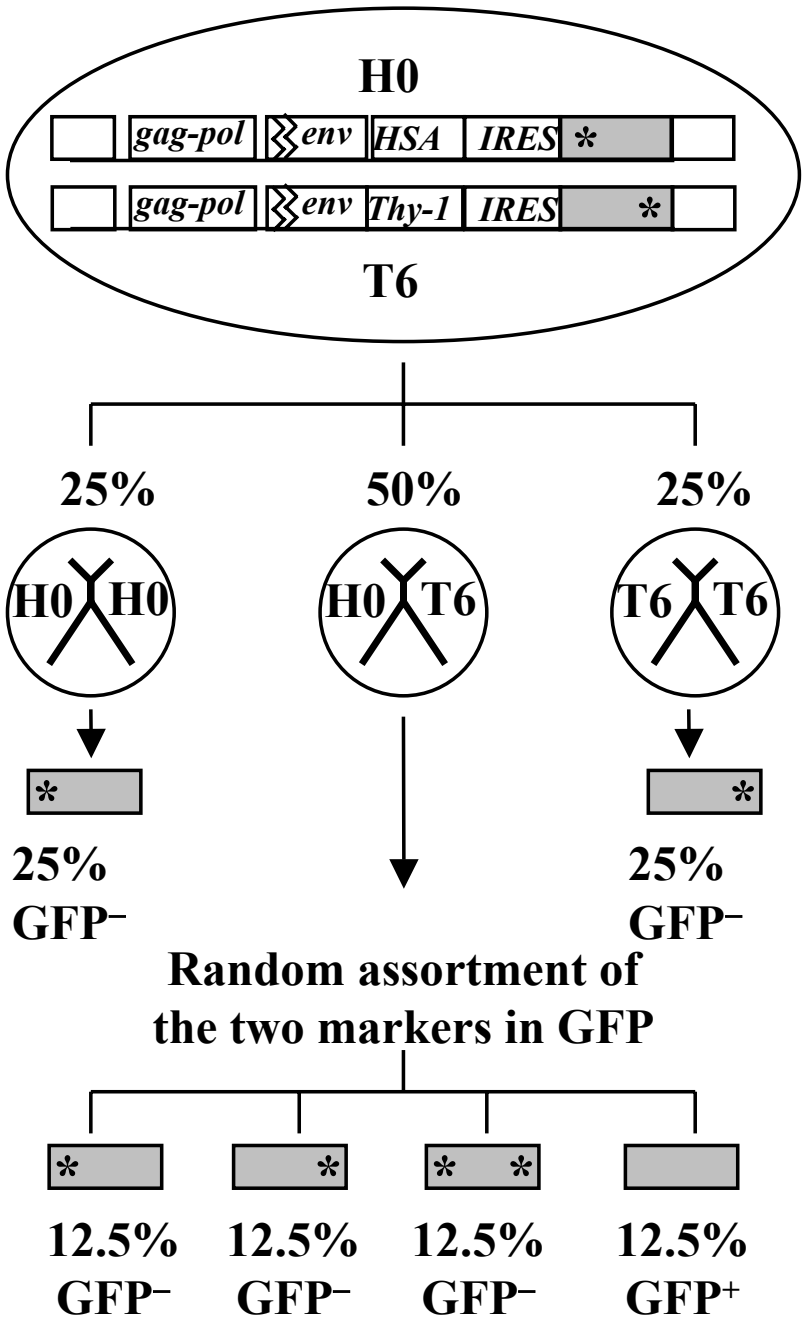

Fig. 4 


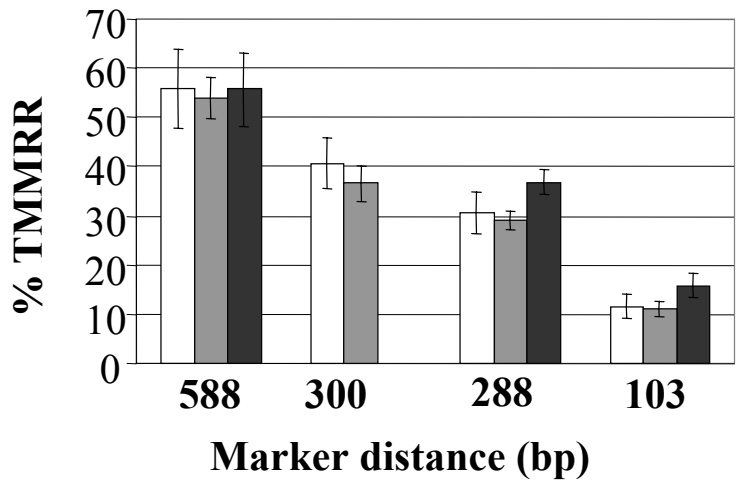

Fig. 5 


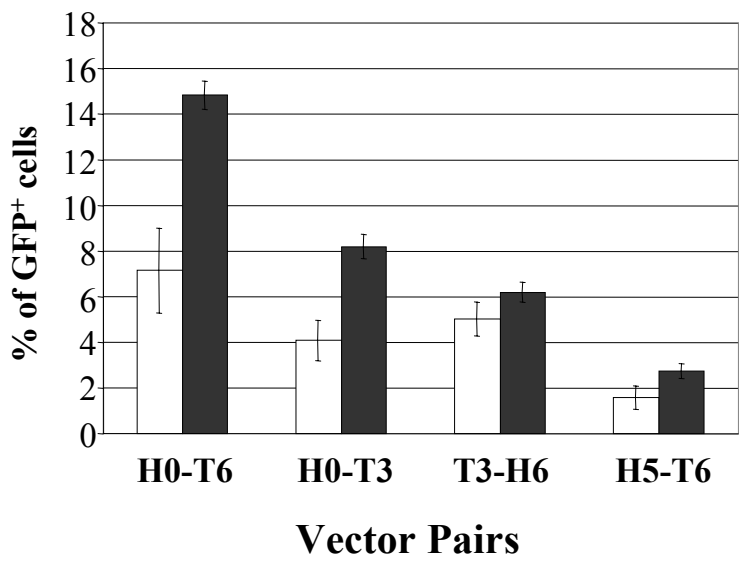

Fig. 6 
A.

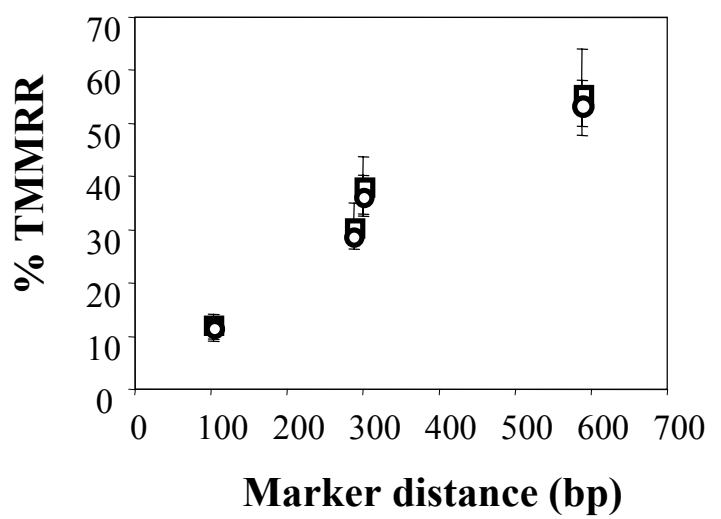

B.

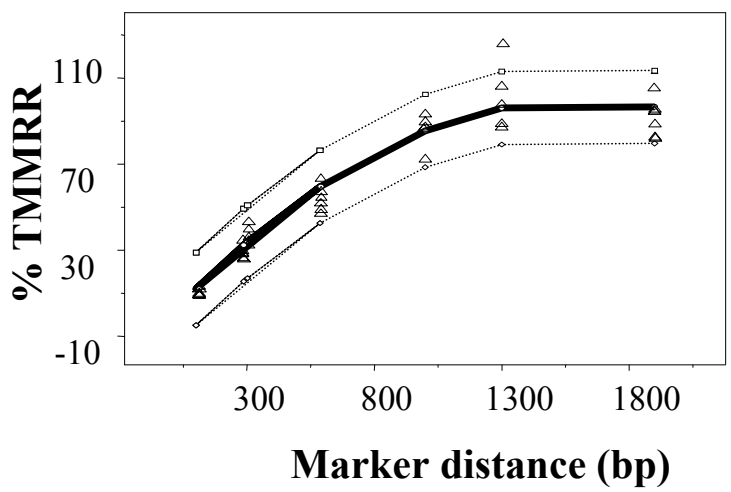

C.

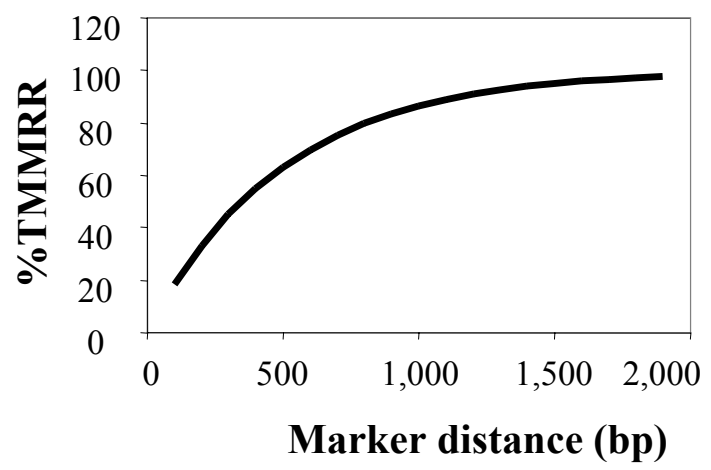

Fig. 7 
CHAPTER 5

DISCUSSION 


\section{Discussion}

The general theme of this dissertation is retroviral evolution. The ability of HIV1 to evolve poses the greatest threat to developing an effective therapy to fighting the AIDS pandemic. The ability to generate variation and the relative plasticity of the viral genome to tolerate variation allows HIV-1 to quickly develop drug resistance mutations and hinder the development of vaccines. The high mutation rate of HIV-1 and high viral loads found in patients contribute greatly to the evolution of HIV-1. Because of these phenomena, experiments were set forth in this thesis to study retroviral evolution, albeit through a simple retrovirus. Another major mechanism for retroviruses to generate variation is recombination. Through work in this thesis, I discovered that HIV-1 exhibits a extremely high recombinogenic nature, which underscores the need to develop therapies that fight recombination.

The first chapter introduced the significance of studying retroviruses, the retroviral lifecycle, and selected literature known concerning evolution and retroviral recombination. This chapter provided the necessary background information to understand the experiments and concepts set forth in the work presented in this thesis. In the second chapter, I described a project that was designed to study the evolution of a defective simple retrovirus. The goal of this project was to gain a greater understanding of evolution dynamics and identify important sequences and/or residues important to the replicating retrovirus. In the third chapter, I discussed HIV-1 recombination and described the project that measures the recombination rate of HIV-1 at three genetic marker distances. Within the fourth chapter, I presented the project that resulted in the 
development of a novel system to measure HIV-1 recombination and measured the recombination rate at exceedingly short genetic marker distances.

Allowing defective viruses to evolve in tissue culture has proven to be a fruitful strategy in some instances $(3,11,23)$. However, a defective hybrid simple retrovirus that replicated at a 100-fold reduction over wild type evidently had too much deficiency to evolve in a timely manner in our experiment. Following the initial burst of virus after transient transfection, replication was not detected in the 239T cell line. Using two different approaches, we could not detect virus replication, even after fifty-six days in tissue culture. Since viral replication provides the opportunity for a virus population to mutate and adapt, the lack of replication hinders the further development of the project. A cell line that encourages greater viral replication should provide the material needed to move this project forward.

Because of two conflicting reports $(7,12)$, it was unknown whether SNV could replicate in human cells. We demonstrated that $293 \mathrm{~T}$ cells could be infected by and could produce SNV virus. This knowledge could be valuable to the field of gene therapy. Retroviral vectors are one tool used for those scientists pursuing gene therapy as a strategy to fight disease. SNV can replicate in human cells, although with less efficiency than other viruses, such as MLV. Although we discovered that SNV could replicate within human cells in 2000, recently published papers have confirmed these results (18, 19).

From the first report (4), there have been several studies focusing on HIV-1 recombination $(9,10,13,14,17,25)$. Most of these experiments gave valuable information about the subject, but none of them provided a quantitative measurement of 
the recombination rate and related it to genetic marker distances in one round of replication. In the third chapter, I described our experiments that measured recombination rates when markers are separated by a distance of $1.0 \mathrm{~kb}$ and greater. The recombination rate reached the maximum rate at $1.3 \mathrm{~kb}$; therefore, markers that are separated by $1.3 \mathrm{~kb}$ or more segregate as unlinked alleles. This is an astonishingly high recombination rate considering that $\mathrm{MLV}$ and $\mathrm{SNV}$ recombine at rates of 6- to 10-fold less at the same distances $(1,2,8)$. When the recombination rate for HIV-1 was measured with markers $1.0 \mathrm{~kb}$ apart, it was $84 \%$ of the theoretical maximum measurable recombination rate. These results suggest that where markers are separated at distances $1.3 \mathrm{~kb}$ apart and above illustrate a definite plateau, the distance of $1.0 \mathrm{~kb}$ might prove to be the point of transition where the recombination rate becomes proportional to genetic marker distance. Based on the marker distances versus recombination rate profile of MLV (1), it is logical to assume that a linear relationship exist for HIV-1. However, it could not be determined by the experiments performed in chapter three.

Several conclusions are reached from this work. First, full-length RNA transcripts from two proviruses in a dually infected cell can be assorted in a random manner; that is, heterozygotic virion can be generated at the maximum rate, which is $50 \%$ of the total virion population. Second, template-switching events occur at a high frequency. Based on the measured rates, most, if not all, DNA molecules generated through HIV-1 reverse transcription contain genetic information from portions of two copackaged RNAs. Third, two drug resistance mutations located at different positions in the viral genes of two different proviruses in dually infected cells will produce progeny containing both mutations. This work, along with other recombination studies $(9,10,13$, 
$14,17,25)$, indicates that HIV-1 recombination is a major mechanism for generating variation within the viral genome.

In the fourth chapter, I described further studies on HIV-1 recombination. We determined the recombination rate for HIV-1 when markers were separated by less than $0.6 \mathrm{~kb}$. To perform this study, we developed a new flow cytometry-based system to study HIV-1 recombination. The system used for recombination studies described in chapter 3 was based on reconstitution of two functional drug resistance genes separated by IRES, which is $0.6 \mathrm{~kb}$ in length. This system yielded several disadvantages. First, we could not easily adapt the system to measure recombination rates when markers were separated by less than $1.0 \mathrm{~kb}$. Second, because drug selection and the number of double drug resistant colonies were used to calculate recombination, this system could not be adapted to measure the recombination rate in cells that grow in suspension, such as $\mathrm{T}$ cells, the natural host cells for HIV-1. Third, the previous assay proved to be very time consuming. A new, flow cytometry-based assay can bypass these disadvantages.

Using the new system, we have measured the recombination rate of HIV-1 when markers were between 0.1 and $0.6 \mathrm{~kb}$ apart. We observed a near linear relationship between marker distance and the recombination rate. The recombination rate for 0.10 , $0.29,0.30,0.59 \mathrm{~kb}$ was $11.6,30.7,38.2$, and $55.9 \%$ of the theoretical maximum measurable recombination rate. We have also examined whether the presence or absence of accessory proteins vif, vpr, vpu, and nef had an effect on the recombination rate.

Recombination rates for the aforementioned distances do not change significantly with or without vif, vpr, vpu, and nef. The effect of target cells also did not alter the recombination rate. The above experiments were performed with the Hut/CCR5 cell line 
as target cells. When we used primary $\mathrm{CD}^{+} \mathrm{T}$ lymphocytes, as target cells, the recombination rates were not significant different compared with Hut/CCR5 cells.

Recombination in some retroviruses, such as MLV and SNV, exhibit high negative interference $(2,8)$, which is defined by multiple cross-over events occurring more frequently than expected when calculated from single recombination events. This means that once a recombination event occurs, the chances are greater for a second event. Experiments described in chapter four determined that HIV-1 recombination does not exhibit high negative interference. HIV-1 recombination differs from MLV in at least two aspects: one, HIV-1 recombines at a rate substantially higher than MLV, and two, HIV-1 recombination does not exhibit high negative interference.

The development of a novel flow cytometry-based system based on to study HIV1 recombination increases the speed at which new studies can be performed. Our previous system using drug resistance genes as markers took considerable time to perform. For example, once the required vectors were generated, it would take more than 3 months to acquire the cell lines and obtain the recombination rate. With the flow cytometry method, the time required for each experiment can be reduced significantly. In addition, testing multiple hypotheses in parallel is more rapid and feasible.

Several conclusions can be made from the work described in chapter three and chapter four. As stated previously, recombination is a major determinant of variation in HIV-1. Since, during HIV-1 replication, the vast majority of the heterozygotic virions can be generated efficiently and recombination can occur frequently. Therefore, any dually infected cell with similar proviruses should produce recombinant progeny. This is consistent with sequence analyses on circulating recombinant forms from infected 
patients (20). Several of these circulating recombinant forms are hybrid virus, some of which contain sequences from up to five different genetically distinct ancestries (22). Sequence analyses of HIV-1 variants from dually infected individuals frequently recover recombinants $(5,6,15,16,21,24)$. We demonstrated that even at a short genetic distance, such as $100 \mathrm{bp}$, frequent recombination can occur. Among the three cell types that were used, namely $293 \mathrm{~T}$ cells in chapter three and Hut/CCR5 and primary $\mathrm{T}$ lymphocytes in chapter four, there did not seem to be an appreciable difference in recombination. Although this does not rule out the possibility that recombination could be more frequent in other untested cell types, it shows that an established immortalized cell line such as Hut/CCR5 can give biological relevant data.

In summary, this thesis focused on retroviral evolution and recombination. First, the evolution of a defective simple retrovirus was studied. Although this project failed to yield better-fit viruses, it demonstrated the importance of viral replication capacity on viral evolution and adaptation. Second, HIV-1 recombination projects focused on determining the frequencies of HIV-1 recombination in one round of viral replication at multiple marker distances and factors that affect the recombination rate. Furthermore, these studies defined the relationship between the recombination rate and marker distances. The results and conclusions in this thesis provide the scientific community a more comprehensive understanding on the role HIV-1 recombination plays in variation and how recombination must be considered in order to develop effective drugs and/or vaccines. 


\section{References}

1. Anderson, J. A., E. H. Bowman, and W. S. Hu. 1998. Retroviral recombination rates do not increase linearly with marker distance and are limited by the size of the recombining subpopulation. J Virol 72:1195-1202.

2. Anderson, J. A., R. J. Teufel, 2nd, P. D. Yin, and W. S. Hu. 1998. Correlated template-switching events during minus-strand DNA synthesis: a mechanism for high negative interference during retroviral recombination. J Virol 72:1186-1194.

3. Chakrabarti, L., M. Emerman, P. Tiollais, and P. Sonigo. 1989. The cytoplasmic domain of simian immunodeficiency virus transmembrane protein modulates infectivity. J Virol 63:4395-4403.

4. Clavel, F., M. D. Hoggan, R. L. Willey, K. Strebel, M. A. Martin, and R. Repaske. 1989. Genetic recombination of human immunodeficiency virus. J Virol 63:1455-1459.

5. Diaz, R. S., E. C. Sabino, A. Mayer, J. W. Mosley, and M. P. Busch. 1995. Dual human immunodeficiency virus type 1 infection and recombination in a dually exposed transfusion recipient. The Transfusion Safety Study Group. J Virol 69:3273-3281.

6. Gao, F., D. L. Robertson, S. G. Morrison, H. Hui, S. Craig, J. Decker, P. N. Fultz, M. Girard, G. M. Shaw, B. H. Hahn, and P. M. Sharp. 1996. The heterosexual human immunodeficiency virus type 1 epidemic in Thailand is caused by an intersubtype (A/E) recombinant of African origin. J Virol 70:70137029. 
7. Gautier, R., A. Jiang, V. Rousseau, R. Dornburg, and T. Jaffredo. 2000. Avian reticuloendotheliosis virus strain A and spleen necrosis virus do not infect human cells. J Virol 74:518-522.

8. Hu, W. S., and H. M. Temin. 1990. Genetic consequences of packaging two RNA genomes in one retroviral particle: pseudodiploidy and high rate of genetic recombination. Proc Natl Acad Sci U S A 87:1556-1560.

9. Iglesias-Sanchez, M. J., and C. Lopez-Galindez. 2002. Analysis, quantification, and evolutionary consequences of HIV-1 in vitro recombination. Virology 304:392-402.

10. Jetzt, A. E., H. Yu, G. J. Klarmann, Y. Ron, B. D. Preston, and J. P. Dougherty. 2000. High rate of recombination throughout the human immunodeficiency virus type 1 genome. J Virol 74:1234-1240.

11. Kashanchi, F., R. Shibata, E. K. Ross, J. N. Brady, and M. A. Martin. 1994. Second-site long terminal repeat (LTR) revertants of replication-defective human immunodeficiency virus: effects of revertant TATA box motifs on virus infectivity, LTR-directed expression, in vitro RNA synthesis, and binding of basal transcription factors TFIID and TFIIA. J Virol 68:3298-3307.

12. Koo, H. M., A. M. Brown, Y. Ron, and J. P. Dougherty. 1991. Spleen necrosis virus, an avian retrovirus, can infect primate cells. J Virol 65:4769-4776.

13. Kuwata, T., Y. Miyazaki, T. Igarashi, J. Takehisa, and M. Hayami. 1997. The rapid spread of recombinants during a natural in vitro infection with two human immunodeficiency virus type 1 strains. J Virol 71:7088-7091. 
14. Levy, D. N., G. M. Aldrovandi, O. Kutsch, and G. M. Shaw. 2004. Dynamics of HIV-1 recombination in its natural target cells. Proc Natl Acad Sci U S A.

15. Liu, S. L., J. E. Mittler, D. C. Nickle, T. M. Mulvania, D. Shriner, A. G. Rodrigo, B. Kosloff, X. He, L. Corey, and J. I. Mullins. 2002. Selection for human immunodeficiency virus type 1 recombinants in a patient with rapid progression to AIDS. J Virol 76:10674-10684.

16. McCutchan, F. E., P. A. Hegerich, T. P. Brennan, P. Phanuphak, P. Singharaj, A. Jugsudee, P. W. Berman, A. M. Gray, A. K. Fowler, and D. S. Burke. 1992. Genetic variants of HIV-1 in Thailand. AIDS Res Hum Retroviruses 8:1887-1895.

17. Onafuwa, A., W. An, N. D. Robson, and A. Telesnitsky. 2003. Human Immunodeficiency Virus Type 1 Genetic Recombination Is More Frequent Than That of Moloney Murine Leukemia Virus despite Similar Template Switching Rates. J Virol 77:4577-4587.

18. Parveen, Z., M. Mukhtar, A. Goodrich, E. Acheampong, R. Dornburg, and R. J. Pomerantz. 2004. Cross-Packaging of Human Immunodeficiency Virus Type 1 Vector RNA by Spleen Necrosis Virus Proteins: Construction of a New Generation of Spleen Necrosis Virus-Derived Retroviral Vectors. J Virol 78:6480-6488.

19. Parveen, Z., M. Mukhtar, M. Rafi, D. A. Wenger, K. M. Siddiqui, C. A. Siler, B. Dietzschold, R. J. Pomerantz, M. J. Schnell, and R. Dornburg. 2003. Celltype-specific gene delivery into neuronal cells in vitro and in vivo. Virology 314:74-83. 
20. Robertson, D. L., P. M. Sharp, F. E. McCutchan, and B. H. Hahn. 1995. Recombination in HIV-1. Nature 374:124-126.

21. Saksena, N. K., B. Wang, Y. C. Ge, S. H. Xiang, D. E. Dwyer, and A. L. Cunningham. 1997. Coinfection and genetic recombination between HIV-1 strains: possible biological implications in Australia and South East Asia. Ann Acad Med Singapore 26:121-127.

22. Vidal, N., C. Mulanga-Kabeya, N. Nzilambi, E. Delaporte, and M. Peeters. 2000. Identification of a complex env subtype E HIV type 1 virus from the democratic republic of congo, recombinant with $A, G, H, J, K$, and unknown subtypes. AIDS Res Hum Retroviruses 16:2059-2064.

23. Willey, R. L., D. H. Smith, L. A. Lasky, T. S. Theodore, P. L. Earl, B. Moss, D. J. Capon, and M. A. Martin. 1988. In vitro mutagenesis identifies a region within the envelope gene of the human immunodeficiency virus that is critical for infectivity. J Virol 62:139-147.

24. Zhu, T., N. Wang, A. Carr, S. Wolinsky, and D. D. Ho. 1995. Evidence for coinfection by multiple strains of human immunodeficiency virus type 1 subtype B in an acute seroconvertor. J Virol 69:1324-1327.

25. Zhuang, J., A. E. Jetzt, G. Sun, H. Yu, G. Klarmann, Y. Ron, B. D. Preston, and J. P. Dougherty. 2002. Human immunodeficiency virus type 1 recombination: rate, fidelity, and putative hot spots. J Virol 76:11273-11282. 


\title{
Curriculum Vitae
}

\author{
Terence Rhodes
}

Charleston, WV

trhodes1@mix.wvu.edu

\section{Education}

\author{
Aug. 1997 - present: M.D./Ph.D. program at West Virginia University School of Medicine, \\ Morgantown/Charleston, WV. \\ June 2004 - Ph.D. dissertation defense. \\ Aug. 1994 - May 1997: Marshall University, Huntington, WV. Bachelor of Science in \\ Chemistry, Magna Cum Laude. \\ June 1992 - July 1992: West Virginia University-Parkersburg, Ripley, WV. \\ Aug. 1991 - May 1992: West Virginia State College, Institute, WV.
}

\section{$\underline{\text { Research Experience }}$}

Aug. 1999 - June 2004: Doctoral Candidate under Dr. Wei-Shau Hu at HIV Drug Resistance Program, National Cancer Institute, Frederick, MD.

May 1998 - Aug. 1998: Student Internship under Dr. Wei-Shau Hu at Microbiology and Immunology Department, WVU Health Sciences Center, Morgantown, WV.

May 1997 - June 1997: Student Internship under Dr. Jeanine Strobel at WVU Health Sciences Center in the Pharmacology Department, Morgantown, WV.

Jan. 1997 - May 1997: Student Research Assistant under Dr. Gary Anderson at Marshall University in the Chemistry Department, Huntington, WV

May 1996 - Aug. 1996: Student Internship under Dr. Beverly Delidow at Marshall University School of Medicine in the Biochemistry Department, Huntington, WV.

June 1995 - Aug. 1995: Student Externship with Dr. Chaffin at Charleston Area Medical Center in the Obstetrics and Gynecology Department, Charleston, WV.

\section{$\underline{\text { Special Training and Skills }}$}

- Certified Operator of the BD FACSVantage SE which allows for multicolor analysis and sorting of samples based on the principles of flow cytometry. 
- Self-taught and proficient operator of the BD FACSVantage SE FACSDiva Digital Option which allows full digital acquisition of data and four-color flow cytometry sorting.

- Competent and skilled in standard laboratory techniques, including gel electrophoresis, plasmid design and construction, DNA isolation, tissue culture, viral isolation, RT assays, DNA transfection, immunostaining, Southern blot, etc.

- Instructed junior graduate students and undergraduate students in standard laboratory techniques and informally taught basic science including cell and molecular biology, immunology, and retrovirology.

\section{$\underline{\text { Oral Presentations }}$}

International meetings

1) Frequencies of Recombination of HIV-1 in One Round of Viral Replication. Cold Spring Harbor Retroviruses Meeting 2004: May 18 -23, 2004. Cold Spring Harbor, New York.

2) HIV-1 Recombination. 2004 Think Tank Meeting. April 6, 2004 NCIFrederick Conference Center, Frederick, MD.

\section{$\underline{\text { Posters }}$}

1) Identification of a major restriction in HIV-1 intersubtype recombination. Mario P. S. Chin, Terence D. Rhodes, Jianbo Chen, William Fu, and WeiShau Hu. XIV International HIV Drug Resistance Workshop June 7-11, 2005. Quebec City, Canada.

2) Identification of a major restriction in HIV-1 intersubtype recombination. Mario P. S. Chin, Terence D. Rhodes, Jianbo Chen, William Fu, and WeiShau Hu. Cold Spring Harbor Retroviruses Meeting 2005: May 24 -29, 2005. Cold Spring Harbor, New York.

3) Comparison of the Genetic Recombination Rates of Human Immunodeficiency Virus Type 1 in Macrophages and T Cells. Jianbo Chen, Terence D. Rhodes, and Wei-Shau Hu. Cold Spring Harbor Retroviruses Meeting 2005: May $24-$ 29, 2005. Cold Spring Harbor, New York.

4) HIV-1 Recombination: Rates, Restrictions, and Implications. Terence D. Rhodes, Mario P.-S. Chin, Jianbo Chen, Olga Nikolaitchik, William Fu, and Wei-shau Hu. The 2005 Palm Springs Symposium on HIV/AIDS: Pathogen versus Host in HIV disease. March 3-5, 2005. Palm Springs, California.

5) Sequence Differences in the dimerization initiation signal OF HIV1 restrict $B / C$ intersubtype recombination. Mario P.-S. Chin, Terence D. Rhodes, Jianbo Chen, and Wei-Shau Hu. Fifth HIV DRP symposium: Antiviral Drug Resistance. November 14-17, 2004. Chantilly, Virginia.

6) High Rates Of Human Immunodeficiency Virus Type 1 Recombination: NearRandom Segregation Of Markers 1 Kilobase Apart In One Round Of Viral Replication. Terence D. Rhodes, Heather Wargo, and Wei-Shau Hu. Fourth 
HIV DRP Symposium: Antiviral Drug Resistance. Dec. 7-10, 2002. Chantilly, Virginia.

7) Electric Wire Motif In Murine Leukemia Virus Capsid: An Important Region For Virus Assembly And Particle Size Determination. Dexter T.K. Poon, Sara K. Cheslock, William Fu, Terence D. Rhodes, Louis E. Henderson, Kunio Nagashima, Connor F. McGrath, and Wei-Shau Hu. Third HIV DRP Symposium: Antiviral Drug Resistance. Dec. 8-11, 2002. Chantilly, Virginia.

\section{$\underline{\text { Publications }}$}

1) Chen J, Rhodes TD, Hu WS. Comparison of the genetic recombination rates of human immunodeficiency virus type 1 in macrophages and T cells. Journal of Virology. 2005 Jul;79(14):9337-40.

2) Chin MP, Rhodes TD, Chen J, Fu W, Hu WS. Identification of a major restriction in HIV-1 intersubtype recombination. Proc Natl Acad Sci U S A. 2005 Jun 21;102(25):9002-7.

3) Rhodes TD, Nikolaitchik O, Chen J, Powell D, Hu WS. Genetic recombination of human immunodeficiency virus type 1 in one round of viral replication: effects of genetic distance, target cells, accessory genes, and lack of high negative interference in crossover events. Journal of Virology. 2005 Feb;79(3):1666-77.

4) Hu, WS, T Rhodes, Q Dang, and V Pathak. 2003. Retroviral recombination: review of genetic analyses. Frontiers in Bioscience. 2003 Jan 1;8:d143-55.

5) Rhodes T, H Wargo, and WS Hu. 2003. High rates of human immunodeficiency virus type 1 recombination: near-random segregation of markers one kilobase apart in one round of viral replication. Journal of Virology. 2003 Oct; 77(20): 11193-200.

6) Cheslock, SR, DT Poon, W Fu, TD Rhodes, LE Henderson, K Nagashima, CF McGrath, and WS Hu. Charged assembly helix motif in murine leukemia virus capsid: an important region for virus assemble and particle size determination. Journal of Virology. 2003 Jun; 77(12): 7058-66. 